\title{
Design, Mechanism of Action, Bioavailability and Therapeutic Effects of Mn Porphyrin-Based Redox Modulators
}

\author{
Artak Tovmasyan $^{a}$ Huaxin Sheng ${ }^{b, e}$ Tin Weitner ${ }^{a}$ Amanda Arulpragasam ${ }^{d}$ \\ Miaomiao Lu ${ }^{b, e, f}$ David S. Warner ${ }^{b, e}$ Zeljko Vujaskovic $^{a}$ Ivan Spasojevic $^{c}$ \\ Ines Batinic-Haberle ${ }^{a}$
}

Departments of ${ }^{\mathrm{a}}$ Radiation Oncology, ${ }^{\mathrm{b}}$ Anesthesiology and ${ }^{\mathrm{c}}$ Medicine, ${ }^{\mathrm{d}}$ Duke University Neuroscience Undergraduate

Program, and ${ }^{\mathrm{e}}$ Multidisciplinary Neuroprotection Laboratories, Duke University Medical Center, Durham, N.C., USA;

fDepartment of Anesthesiology, Second Affiliated Hospital, Zhengzhou University, Zhengzhou, China

\section{Key Words}

Cationic Mn porphyrins - Mechanism of action •

Bioavailability · Central nervous system injuries · Cancer •

Radioprotection

\begin{abstract}
Based on aqueous redox chemistry and simple in vivo models of oxidative stress, Escherichia coli and Saccharomyces cerevisiae, the cationic $\mathrm{Mn}(\mathrm{III}) \mathrm{N}$-substituted pyridylporphyrins (MnPs) have been identified as the most potent cellular redox modulators within the porphyrin class of drugs; their efficacy in animal models of diseases that have oxidative stress in common is based on their high ability to catalytically remove superoxide, peroxynitrite, carbonate anion radical, hypochlorite, nitric oxide, lipid peroxyl and alkoxyl radicals, thus suppressing the primary oxidative event. While doing so MnPs could couple with cellular reductants and redox-active proteins. Reactive species are widely accepted as regulators of cellular transcriptional activity: minute, nanomolar levels are essential for normal cell function, while submicromolar or micromolar levels impose oxidative stress, which is evidenced in increased inflammatory and immune responses. By removing reactive species, $\mathrm{MnPs}$ affect redox-based cellular transcriptional activity and consequently secondary oxidative stress, and in turn inflammatory
\end{abstract}

\section{KARGER}

E-Mail karger@karger.ch www.karger.com/mpp
(C) 2012 S. Karger AG, Basel 1011-7571/13/0222-0103\$38.00/0

Karger

Open access

This is an Open Access article licensed under the terms of the Creative Commons Attribution- NonCommercial-NoDerivs 3.0 License (www.karger.com/OA-license), applicable to the online version of the article only. Distribution for non-commercial purposes only. processes. The equal ability to reduce and oxidize superoxide during the dismutation process and recently accumulated results suggest that pro-oxidative actions of MnPs may also contribute to their therapeutic effects. All our data identify the superoxide dismutase-like activity, estimated by $\log \mathrm{k}_{\text {cat }}\left(\mathrm{O}_{\overline{2}}\right)$, as a good measure for the therapeutic efficacy of MnPs. Their accumulation in mitochondria and their ability to cross the bloodbrain barrier contribute to their remarkable efficacy. We summarize herein the therapeutic effects of MnPs in cancer, central nervous system injuries, diabetes, their radioprotective action and potential for imaging. Few of the most potent modulators of cellular redox-based pathways, MnTE2-PyP ${ }^{5+}$, MnTDE-2$\mathrm{ImP}^{5+}, \mathrm{MnTnHex}-2-\mathrm{PyP}^{5+}$ and MnTnBuOE-2-PyP ${ }^{5+}$, are under preclinical and clinical development.

Copyright $\odot 2012$ S. Karger AG, Basel

\section{Introduction}

The increasing awareness of the role of superoxide dismutase (SOD), and in particular the mitochondrial isoform MnSOD under physiological and pathological conditions, resulted in the increased search for their mimics. Few compounds are true SOD mimics, i.e. able to catalytically remove superoxide $\left(\mathrm{O}_{2} ;\right.$ oxidize and reduce it in a two-step dismutation
Ines Batinic-Haberle, $\mathrm{PhD}$

Department of Radiation Oncology

Duke University Medical Center

Durham, NC 27710 (USA)

Tel. +1 919684 2101, E-Mail ibatinic@ duke.edu 


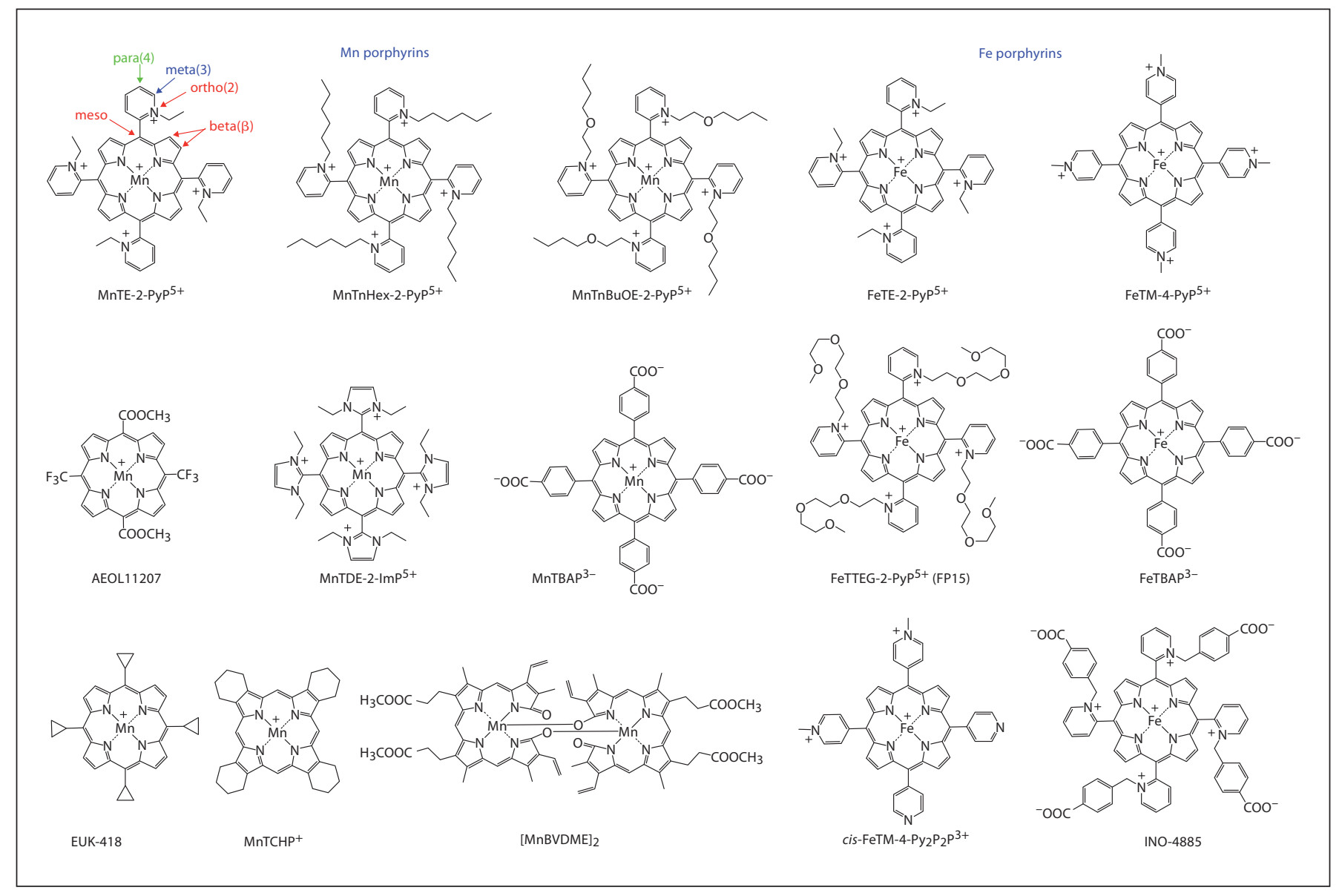

Fig. 1. Structures of redox-active metalloporphyrinoid compounds. Compounds that have anionic or no charge on the periphery lack kinetic and thermodynamic facilitation for the catalysis of $\mathrm{O}_{2}^{\overline{2}}$ dismutation essential for mimicking SOD enzyme. By analogy with MnPs, FP15 [34, 40, 199], though not reported, likely possesses SOD-like activity in addition to $\mathrm{ONOO}^{-}$scavenging ability.

process). Thus far, no compound has been reported to be a specific $\mathrm{O}_{2}^{\overline{2}}$ scavenger. Most of the redox-active compounds explored as potential therapeutics are able to scavenge a wide range of reactive species (though with different rate constants) and thus affect the cellular redox status, oxidative damage of biological molecules, signaling processes and in turn suppress the oxidative stress injuries. Both natural and synthetic compounds have been explored. Most natural compounds are polyphenol based and are able to redox cycle with reactive species between phenol/semiquinone (phenoxyl radical)/quinone forms, thus suppressing oxidative stress injuries [for reviews, see 1-5]; some of these natural compounds possess modest SOD-like activity. Our studies have shown that the ability of compounds to mimic SOD parallels their ability to scavenge other species and impact redox-based cellular transcriptional activity. Most synthetic compounds contain a redox-active metal center and are therefore able to easily exchange electrons with targets of interests such as reactive oxygen, nitrogen and sulfur species as well as with redox units (cysteines) of cellular signaling proteins involved in transcription. Such compounds are shown in figure 1 ( $\mathrm{Mn}$ and Fe porphyrins) and in figure 2 (metallocorroles, metallotexaphyrins, Mn salen derivatives and Mn cyclic polyamines) [for details, see also 6-10]. In addition, simple metal salts and oxides, such as manganese salts, cerium dioxide $\left(\mathrm{CeO}_{2}\right)$, osmium tetroxide $\left(\mathrm{OsO}_{4}\right)$ and $\mathrm{Pt}$ nanoparticles are potent SOD mimics and have been explored for efficacy in in vivo studies (fig. 2) [8,11-13]. Few compounds are redox active but do not bear metals, such as nitroxides, nitrones, mitochondria-targeted ubiquinone and its derivatives $[8,9,14-16]$.

We have recently reviewed different classes of SOD mimics $[8,9]$ and Mn porphyrins in particular $[6,7,10]$. Herein we address the design of Mn pyridylporphyrins (MnPs) and our most recent thoughts on their in vivo mechanisms of action, bioavailability and therapeutic effects. 


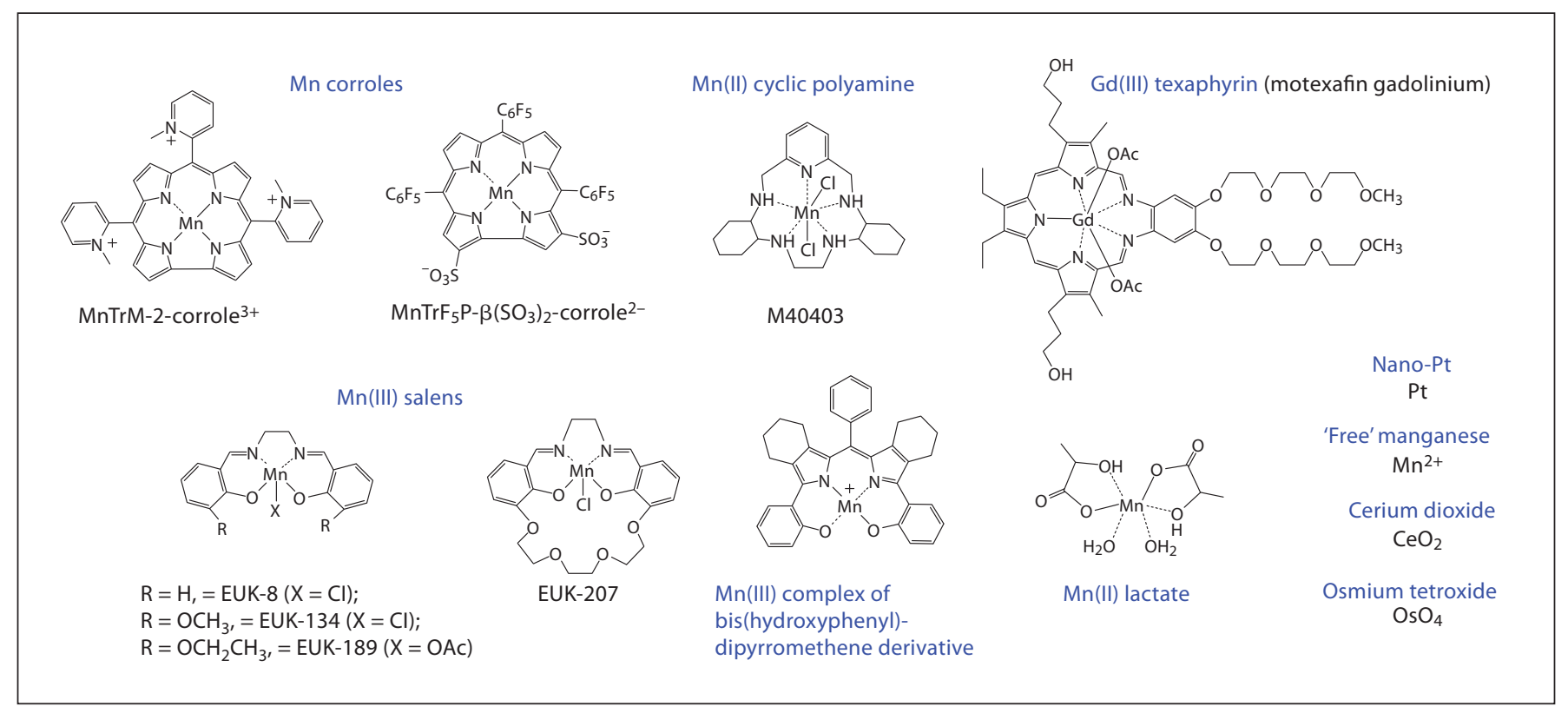

Fig. 2. Structures of other metal-based redox-active compounds [11-13, 18, 20, 41, 45, 46, 200-202].

\section{Design of Mn Porphyrin-Based Redox Regulators}

Redox-active Mn porphyrins have been initially developed as mimics of SOD enzymes. Yet, later it became obvious that SOD-like activity relates closely to their ability to undergo diverse interactions with biological targets, which is the molecular basis for their remarkable therapeutic efficacy. Thus, we will summarize here the principles of their development as SOD mimics.

There are 3 mammalian isoforms within the family of SOD enzymes: extracellular $\mathrm{Cu}, \mathrm{ZnSOD}$, cytosolic/mitochondrial intermembrane $\mathrm{Cu}, \mathrm{ZnSOD}$ and mitochondrial matrix $\mathrm{Mn}$ SOD. SOD enzyme is a high-molecular-weight protein, and thus cannot cross the cellular membrane [17]; further, its use could cause an unfavorable antigenic response. The strategy adopted by Fridovich's group was to mimic the properties of the SOD enzyme as closely as possible by employing lowmolecular-weight compounds, which would cross biological membranes and not exert antigenicity. Archibald and Fridovich [18] showed that low-molecular-weight Mn compounds possess SOD-like activity; the most potent is Mn lactate - only 60 -fold less potent than the SOD enzyme (fig. 3). Some organisms, such as Lactobacillus plantarum, accumulate manganese in millimolar quantities and use it instead of SOD enzyme [18]. Compared to cationic $\mathrm{Mn}$ (III)-ortho-N-substituted pyridylporphyrins, $\mathrm{Mn}^{2+}$ was of much lower efficacy in protecting SOD-deficient Escherichia coli when growing aerobically [19, 20]. Thus, stable complexes based on porphyrin core have been developed where $\mathrm{Mn}$ is coordinated to the porphyrin ligand.
The porphyrin ligand has been modified to finely tune the properties of the Mn trapped within the macrocyclic cavity so that it can be as efficient as the SOD enzyme [7, 8, 21]. Both, Fe and Mn can be used as redox-active metals. When scavenging $\mathrm{O}_{\overline{2}}$, the metal center of those complexes redox cycles between +3 (more stable complex) and +2 (less stable complex) oxidation states. During this process, the less stable complex may release some of its metal. If the metal is $\mathrm{Fe}$, a highly toxic species, hydroxyl radical $(\cdot \mathrm{OH})$, would be formed by the interaction of the free $\mathrm{Fe}^{2+}$ with hydrogen peroxide (Fenton chemistry). Due to the higher $\mathrm{Mn}^{\mathrm{III}} / \mathrm{Mn}^{\mathrm{II}}$ reduction potential of $+1.51 \mathrm{~V}$ versus a normal hydrogen electrode (NHE; relative to $+0.77 \mathrm{~V}$ vs. $\mathrm{NHE}$ for $\mathrm{Fe}^{\mathrm{III}} / \mathrm{Fe}^{\mathrm{II}}$ redox couple), the $\mathrm{Mn}$ reaction with $\mathrm{H}_{2} \mathrm{O}_{2}$ is unfavorable, and thus $\mathrm{Mn}$ does not undergo Fenton chemistry-based $\cdot \mathrm{OH}$ production. Consequently, we explored Fe porphyrins less, and considered them inferior to Mn porphyrins. Recently, though, the potential of Fe porphyrins has been reconsidered either for therapeutic or mechanistic purposes [22].

The first notion that a cationic, water-soluble porphyrin ligand bound to metal presents a strategy to mimic SOD was introduced by Pasternack and Halliwell [23] in 1979 on FeTM$4-\mathrm{PyP}^{5+}$. The rationale behind such a strategy was obvious: to utilize the same advantage of the porphyrin cyclic structure that nature uses as a building block of numerous proteins and enzymes - hemoglobin, myoglobin, the cytochrome P450 enzyme family, nitric oxide (NO) synthases, etc., in order to conduct redox-based biological reactions such as transport of oxygen, synthesis of NO, oxidation (breakdown) of toxins, etc. The 


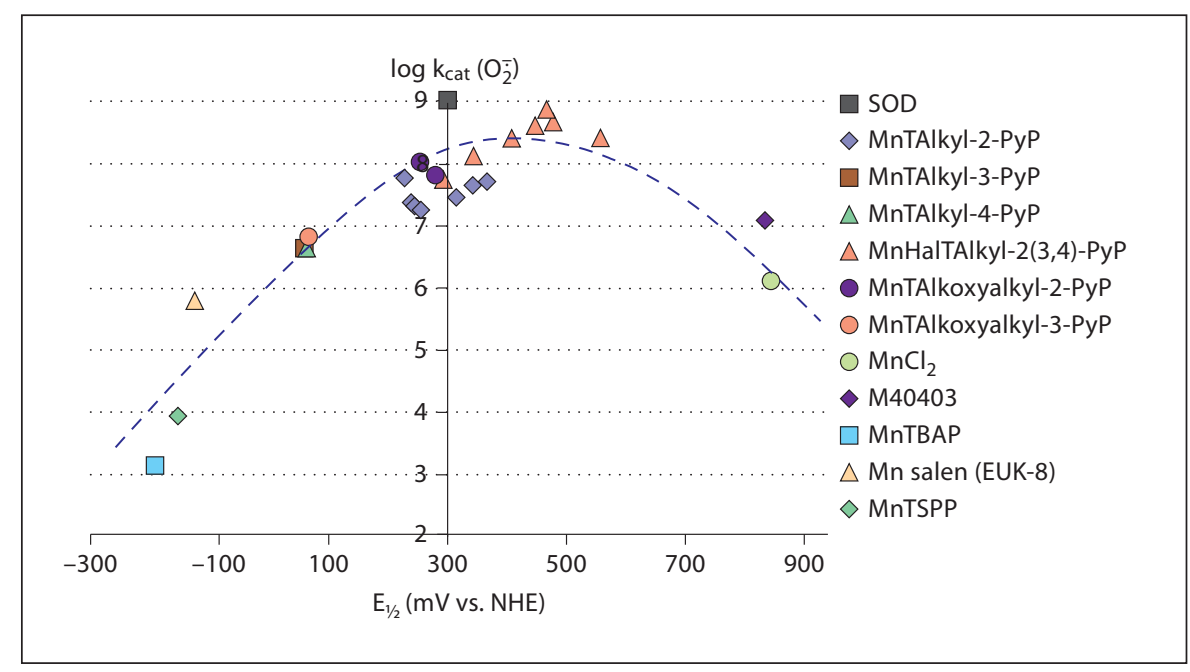

Fig. 3. Structure-activity relationship between the SOD-like activity of compounds (expressed in terms of the log of the catalytic rate constant $\mathrm{k}_{\mathrm{cat}}$ for $\mathrm{O}_{\dot{2}}^{\bar{x}}$ dismutation) and redox ability of $\mathrm{Mn}$ center [expressed as the metal-centered reduction potential $\mathrm{E}_{1 / 2}$ for the $\mathrm{Mn}(\mathrm{III}) /$ $\mathrm{Mn}$ (II) redox couple given in $\mathrm{mV}$ vs. NHE] [7, 8, 21]. At negative potentials, $\mathrm{Mn}(\mathrm{III})$ cannot be reduced with $\mathrm{O}_{\overline{2}}^{\bar{i}}$ in the first step of the dismutation process; thus, this step is rate-limiting in an $\mathrm{O}_{2}^{-}$disproportionation process. Hence, electron-withdrawing groups (positively charged quarternized nitrogens, or halogens) were placed on the molecule to make the metal center electron deficient and thus ready to accept electrons from $\mathrm{O}_{2}^{-}$. As the electron deficiency of the metal site increases, so increases the $\mathrm{k}_{\mathrm{cat}}$ as indicated by the left leg of the bell-shaped curve. At $\mathrm{E}_{1 / 2}$ of approximately $+300 \mathrm{mV}$ versus NHE, the $\mathrm{Mn}$ porphyrin is able to equally easily accept and donate electrons to $\mathrm{O}_{2}^{\bar{*}}$, and thus the rate constants for both steps of dismutation are nearly identical [75]; in turn $\mathrm{Mn}$ porphyrin operates at very high $\mathrm{k}_{\mathrm{cat}}$; for some $\mathrm{Mn}$ porphyrins $\mathrm{k}_{\text {cat }}$ is nearly identical to that of SOD enzyme.

cyclic structure of a porphyrin ligand binds some metals (e.g. $\mathrm{Mn}^{3+}, \mathrm{Fe}^{3+}$ ) so strongly that strong acids like hydrochloric and sulfuric acids cannot cause the loss of the metal $[7,8,24]$. Consequently, the integrity of the metal site, where all actions of interest occur, is preserved. One biologically relevant reagent that can destroy a porphyrin ring is hydrogen peroxide $\left(\mathrm{H}_{2} \mathrm{O}_{2}\right)$ [25-27]. This points to the crucial role of peroxide in vivo, and the reason why so many systems are developed by nature to keep $\mathrm{H}_{2} \mathrm{O}_{2}$ at low physiological nanomolar levels (catalases, glutathione peroxidases, glutathione transferases, glutathione reductases, peroxiredoxins, thioredoxins, etc.) [28].

The report by Pasternack and Halliwell [23] on FeTM-4$\mathrm{Py}^{5+}$ was followed by studies of different investigators on the reactions of $\mathrm{Fe}$ and $\mathrm{Mn}$ porphyrins with small molecules, such as oxygen, NO, carbon monoxide, cyanide, etc. [29-31]. In the 1990s, Irwin Fridovich's group started exploring Mn porphyrins as SOD mimics [32]. The work has been continued in the Batinic-Haberle Laboratory. Several other laboratories are now involved in the development of metalloporphyrins and in the
As $\mathrm{E}^{1 / 2}$ increases further, the Mn center becomes so electron deficient that it is stabilized in the +2 oxidation state, and its oxidation becomes the rate-limiting step of the catalysis; consequently the $\mathrm{k}_{\mathrm{cat}}$ decreases as shown by the right leg of the bell-shaped curve. Compounds with $\mathrm{E}_{1 / 2}$ approximately $+500 \mathrm{mV}$, while of high $\mathrm{k}_{\mathrm{cat}}$, are not stable and lose metal readily, and in turn their function. MnTAlkyl-2-PyP $=\mathrm{Mn}$ (III) meso-tetrakis(N-alkylpyridinium-2-yl)porphyrins; MnTAlkyl-3$\mathrm{PyP}=\mathrm{Mn}(\mathrm{III})$ meso-tetrakis $(\mathrm{N}$-alkylpyridinium-3-yl)porphyrins; MnTAlkyl-4-PyP = Mn(III) meso-tetrakis(N-alkylpyridinium-4-yl) porphyrins; MnHalTAlkyl-2(3,4)-PyP $=\mathrm{Mn}$ (III) $\beta$-halogenat-ed meso-tetrakis(N-alkylpyridinium-2(3,4)-yl)porphyrins; MnTAlkoxyalkyl-2-PyP $=\mathrm{Mn}(\mathrm{III})$ meso-tetrakis $(\mathrm{N}$-alkoxyalkylpyridinium-2-yl) porphyrins; MnTAlkoxyalkyl-3-PyP $=\mathrm{Mn}$ (III) meso-tetrakis(N-alkoxyalkylpyridinium-3-yl)porphyrins; M40403 = cyclic polyamine; MnTBAP $^{3-}=\mathrm{Mn}(\mathrm{III})$ meso-tetrakis(4-carboxyphenyl)porphyrin; MnTSPP $^{3-}=\mathrm{Mn}(\mathrm{III})$ meso-tetrakis(4-sulfonatophenyl)porphyrin. Adapted from Batinic-Haberle et al. [7]. exploration of the mechanistic aspects of their mode(s) of action(s) [33-45]. The modification of the porphyrin core by enlargement (texaphyrins) and shrinkage (corroles) has been explored by Sessler's and Gross's groups, respectively (fig. 2) [46-54]. Mahammed and Gross [51] have shown that metal complexes of 'shrinked' porphyrins - metallocorroles - due to their enhanced stability in a higher +4 oxidation state than that of porphyrins possess a fair catalase-like in addition to SODlike activity [46].

\section{Cationic Mn Porphyrins}

The design of an optimized Mn porphyrin structure was conducted in three phases. In phase I we aimed to synthesize Mn porphyrins that have a rate constant for the dismutation of $\mathrm{O}_{2}^{\overline{2}}$ as high as the SOD enzyme, with $\log \mathrm{k}_{\text {cat }}\left(\mathrm{O}_{2}^{\overline{1}}\right)=8.84-9.30$. To achieve such a value of $k_{\text {cat }}$, we aimed to: (1) adjust the halfwave reduction potential $\left(\mathrm{E}_{1 / 2}\right)$ of Mn porphyrins for the redox couple $\mathrm{Mn}^{\mathrm{III}} \mathrm{P} / \mathrm{Mn}^{\mathrm{II}} \mathrm{P}$, to be around $+300 \mathrm{mV}$ versus NHE, similar to that of SOD enzyme, and (2) provide the electrostatic 
facilitation that would guide the anionic superoxide to the redox-active Mn site. For that reason, the cationic porphyrins were the compounds of choice as they bear 5 positive charges which guide $\mathrm{O}_{2}^{\overline{2}}$ to the $\mathrm{Mn}$ site (fig. 1) $[55,56]$. When cationic nitrogens are in ortho positions, the pyridyl substituents are stuck in vertical positions relative to the porphyrin core and thus form a cavity which additionally guides $\mathrm{O}_{2}^{\overline{2}}$ towards $\mathrm{Mn}$ [57]. Such a situation is reminiscent of the highly preserved electrostatic 'funnel' lined with positively charged amino acid residues that is believed to guide negatively charged superoxide towards the active metal site of the SOD enzyme [56, 58-60]. Moreover, such cationic porphyrins, bearing 4 positively charged nitrogens in the vicinity of the Mn site (ortho positions) withdraw electron density from the Mn center at an appropriate magnitude, which in turn results in nearly identical thermodynamic properties of the Mn site of the porphyrin, as found with all isoforms of SOD proteins, regardless of the type of metal site ( $\mathrm{Fe}, \mathrm{Cu}, \mathrm{Mn}$ or $\mathrm{Ni}$ ). The resulting $\mathrm{E}_{1 / 2}$ allows $\mathrm{Mn}$ porphyrins and enzymes to oxidize (accept electrons, equation 1) and reduce $\mathrm{O}_{2}^{\bar{\alpha}}$ (donate electrons, equation 2 ) similarly fast in a 2-step dismutation process described with equations 1 and 2:

$$
\begin{aligned}
& \mathrm{Mn}^{\mathrm{III}} \mathrm{P}^{5+}+\mathrm{O}_{2}^{\overline{2}} \leftrightarrow \mathrm{Mn}^{\mathrm{II}} \mathrm{P}^{4+}+\mathrm{O}_{2} \\
& \mathrm{Mn}^{\mathrm{II}} \mathrm{P}^{4+}+2 \mathrm{H}^{+}+\mathrm{O}_{2}^{\overline{2}} \leftrightarrow \mathrm{Mn}^{\mathrm{III}} \mathrm{P}^{5+}+\mathrm{H}_{2} \mathrm{O}_{2}
\end{aligned}
$$

Based on the analysis of numerous Mn porphyrins that we have synthesized and some commercial compounds, the structure-activity relationship between the ability of the compound to mimic the enzyme $\left[\log \mathrm{k}_{\mathrm{cat}}\left(\mathrm{O}_{\overline{2}}\right)\right]$ and its redox property $\left(\mathrm{E}_{1 / 2}\right.$, $\mathrm{mV}$ vs. NHE) for $\mathrm{Mn}^{\mathrm{III}} \mathrm{P} / \mathrm{Mn}^{\mathrm{II}} \mathrm{P}$ redox couple (fig. 3) was established. The more positive $\mathrm{E}_{1 / 2}$, the easier $\mathrm{Mn}^{\mathrm{III}} \mathrm{P}$ is reduced to

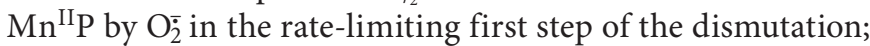
consequently, the higher the $\mathrm{k}_{\mathrm{cat}}$ is of a given $\mathrm{MnP}$ (for details, see also legend of fig. 3).

Based on the critical role played by cationic substituents at the meso positions on the SOD-like activity of the Mn(III) Nalkylpyridylporphyrins and their imidazolyl analogs, N, N'dialkylimidazolylporphyrins of comparable SOD-like potency (table 1, fig. 1) were synthesized. The diethyl analog MnTDE-2-ImP ${ }^{5+}$ (AEOL10150) has been successfully explored for in vivo efficacy in diseases associated with oxidative stress [61-64]. The most potent among those compounds have $\mathrm{E}_{1 / 2}$ close to that of the SOD enzyme (fig. 3; table 1). With two ortho and meta isomeric $\mathrm{Mn}$ porphyrins $\left[\mathrm{MnBr}_{8} \mathrm{TM}-3\right.$ (and 4)- $\left.\mathrm{PyP}^{4+}\right]$, the potency of the SOD enzyme was reached [65, 66]. With $\mathrm{MnCl}_{5} \mathrm{TE}-2-\mathrm{PyP}^{4+}$, an only slightly lower $\mathrm{k}_{\text {cat }}$ than that of SOD was achieved [67]. Those compounds with the highest $\mathrm{k}_{\mathrm{cat}}$ are derivatized in both meso (substituted pyridyl groups) and beta positions (bromines or chlorines) with electron-withdrawing groups [65-67]. Due to excessive electronwithdrawing effects, these porphyrin ligands are so electron deficient that they do not have enough electron density to stabilize +3 oxidation state of $\mathrm{Mn}$, and thus are isolated as $\mathrm{Mn}$ (II) complexes. However, these complexes with Mn bearing a 2+ charge (instead of 3+) are not stable from a metal/ligand structural point of view and lose metal readily $[55,65,66]$. While they are of no practical importance, their existence clearly shows that the same catalytic potency as that of SOD protein could be achieved even with a small porphyrin ligand.

In phase II we aimed to enhance the lipophilicity and in turn bioavailability of such compounds via increasing the length of alkyl chains from methyl to octyl (table 1) $[6-8,68]$. The lipophilicity has been assessed by the thin-layer chromatographic retention factor $\mathrm{R}_{\mathrm{f}}$, and a more commonly used partition between n-octanol and water, $\log \mathrm{P}_{\mathrm{OW}}[68,69]$. Data are shown in table 1: the increase in alkyl chain from ethyl $\left(\mathrm{MnTE}-2-\mathrm{PyP}^{5+}\right)$ to octyl $\left(\mathrm{MnTnOct}-2-\mathrm{PyP}^{5+}\right)$ results in an approximately 5 orders of magnitude increase in lipophilicity, which translates into an approximately 3 orders of magnitude increased efficacy of lipophilic compounds in suppressing oxidative stress injuries in several animal and cellular models [6-8]. To find out how structural modifications of MnPs affect their in vivo availability, we developed high-performance liquid chromatography/fluorescence and tandem liquid chromatogra-phy mass spectrometry methods to determine $\mathrm{MnP}$ levels in plasma, tissues and subcellular compartments [7072]. MnPs bearing long alkyl substituents (e.g. MnTnHex-2$\mathrm{PyP}^{5+}$, MnTnHep-2-PyP ${ }^{5+}$ and MnTnOct-2-PyP ${ }^{5+}$ ) have a polar amphiphilic nature with cationic nitrogens and hydrophobic long alkyl chains - which determines their micellar character. Due to the increased lipophilicity, they accumulate in cells at higher levels. For both reasons, surfactancy and high bioavailability, they are more toxic at high concentrations than the more hydrophilic MnTE-2-PyP ${ }^{5+}[69,73,74]$.

In an ongoing phase III we aimed to reduce the general toxicity via disrupting the micellar property of these compounds by introducing oxygen atoms into hydrophobic long alkyl chains. Our very first analogs of that type were MnTMOE-2$\mathrm{PyP}^{5+}[75]$ and MnTMOHex-3-PyP $\mathrm{P}^{5+}$ [74]. In these compounds, oxygen atoms located at the end of alkyl chains are exposed to solvent, which makes the compounds fairly hydrophilic. We have recently synthesized a superior oxygen derivative, MnTnBuOE-2-PyP ${ }^{5+}$ (fig. 1). This compound has oxygen buried deeper in the alkyl chains, which prevents its excessive solvation [24]. When compared to MnTnHex-2-PyP $\mathrm{P}^{5+}$ and MnTnHep-2-PyP $\mathrm{P}^{5+}$, it has significantly reduced toxicity but preserved lipophilicity and high SOD-like activity [24]. The exploration of its in vivo efficacy and biodistribution is in progress.

\section{Anionic Mn Porphyrins}

We have also listed in figure 2 the anionic Mn porphyrin MnTBAP $^{3-}$ that has been often used by researchers, presumably due to its commercial availability. With its $\mathrm{E}_{1 / 2}$ of $-194 \mathrm{mV}$ versus $\mathrm{NHE}$, it is a fairly redox-inactive compound and is not able to catalyze $\mathrm{O}_{2}^{\overline{2}}$ dismutation; thus it is not a SOD mimic [76]. It cannot be reduced with cellular reductants, ascorbate and 
Table 1. Metal-centered reduction potential $\mathrm{E}_{1 / 2}$ versus NHE (for MnIIIP/MnIIP redox couple), $\log$ kcat $\left(\mathrm{O}_{2}^{\overline{ }}\right)$ for the catalysis of $\mathrm{O}_{2}^{\overline{2}}$ dismutation, $\log \mathrm{k}_{\mathrm{red}}\left(\mathrm{ONOO}^{-}\right)$for the 1-electron reduction of $\mathrm{ONOO}^{-}$to $\cdot \mathrm{NO}_{2}$ and the lipophilicity of $\mathrm{Mn}$ porphyrin-based SOD mimics expressed in terms of partition between $n$-octanol and water, $\log \mathrm{P}_{\mathrm{OW}}$

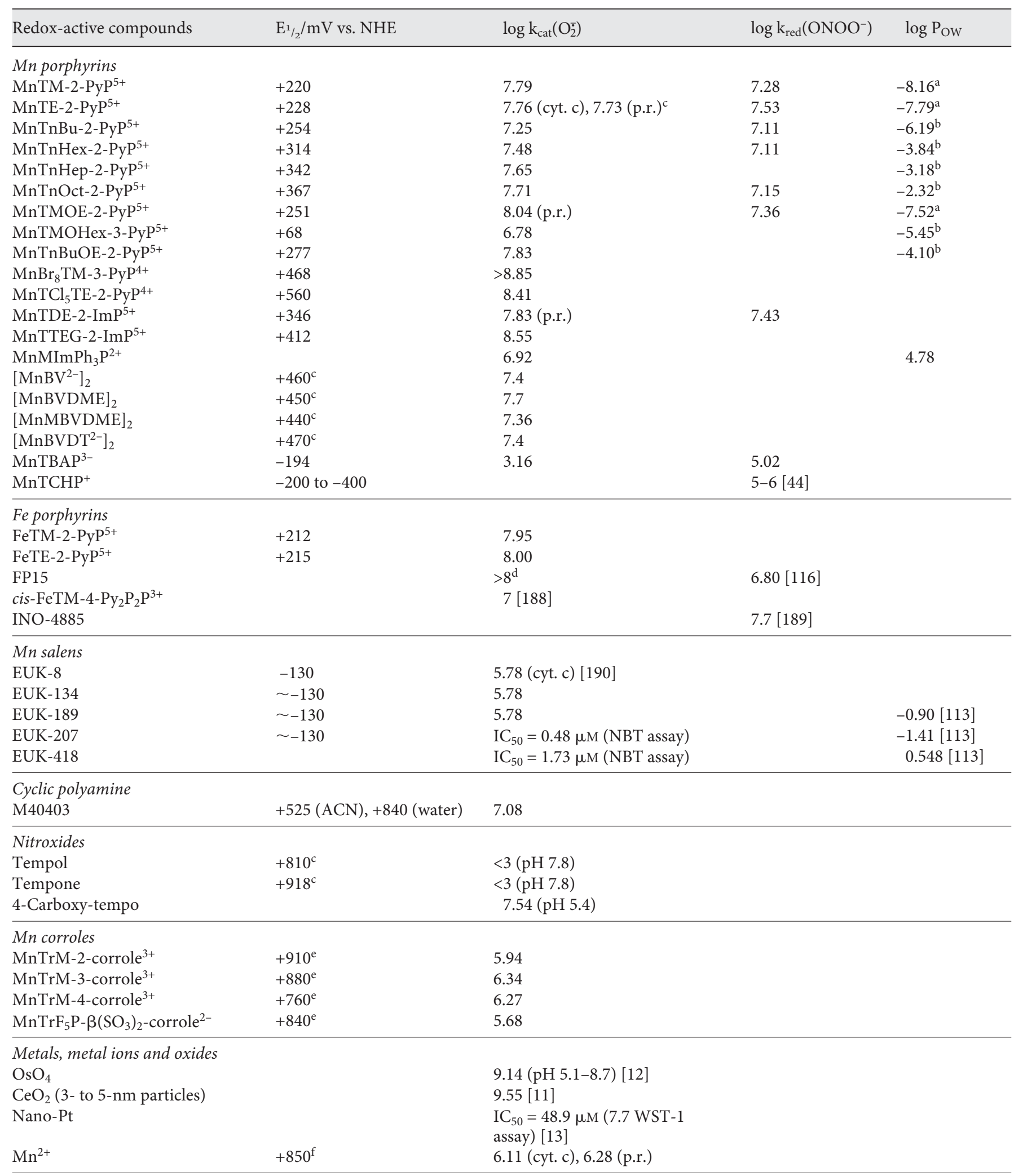


Table 1 (continued)

\begin{tabular}{|c|c|c|c|c|}
\hline Redox-active compounds & $\mathrm{E}_{1 / 2} / \mathrm{mV}$ vs. $\mathrm{NHE}$ & $\log \mathrm{k}_{\mathrm{cat}}\left(\mathrm{O}_{2}^{\bar{z}}\right)$ & $\log \mathrm{k}_{\mathrm{red}}\left(\mathrm{ONOO}^{-}\right)$ & $\log \mathrm{P}_{\mathrm{OW}}$ \\
\hline \multicolumn{5}{|l|}{ Natural compounds (polyphenols) } \\
\hline $\begin{array}{l}\text { Curcumin } \\
\text { Honokiol }\end{array}$ & & $\begin{array}{l}\mathrm{IC}_{50}=115 \mu \mathrm{M}(\mathrm{NBT} \text { assay) [191] } \\
5.5[192]\end{array}$ & & \\
\hline SOD enzymes & $\sim+300$ & $8.84-9.30$ & 3.97 & \\
\hline
\end{tabular}

For comparison, the values for some other compounds listed in figures 1 and 2 are given also. In the absence of SOD enzyme, $\mathrm{O}_{2}^{\overline{1}}$ selfdismutes at $\mathrm{pH} 7.8$ with a rate constant of $\mathrm{k}^{\mathrm{S}}\left(\mathrm{O}_{2}^{\overline{2}}\right.$ self-dismutation $)$ approximately $5 \times 10^{5} \mathrm{M}^{-1} \mathrm{~s}^{-1}$. Therefore, the compounds cannot be SOD mimics, if they disproportionate $\mathrm{O}_{2}^{\overline{2}}$ with a rate constant equal to or lower than $5 \times 10^{5} \mathrm{M}^{-1} \mathrm{~s}^{-1}\left[\log \mathrm{k}\left(\mathrm{O}_{2}^{\overline{5}}\right) \leq 5.7\right]$. cyt. = Cytochrome; p.r. $=$ pulse radiolysis; $\mathrm{IC}_{50}=50 \%$ inhibitory concentration; $\mathrm{NBT}=$ nitroblue tetrazolium; $\mathrm{ACN}=$ acetonitrile; $\mathrm{MitoQ}=$ mitochondriatargeted ubiquinone; $\mathrm{UQH} \cdot=$ ubisemiquinone; $\mathrm{PBS}=$ phosphatebuffered saline. $\mathrm{E}_{1 / 2}$ is determined in $0.05 \mathrm{M}$ phosphate buffer $(\mathrm{pH} 7.8$, $0.1 \mathrm{M} \mathrm{NaCl}$ ); $\mathrm{k}_{\text {cat }}$ was determined by cytochrome $\mathrm{c}$ assay in $0.05 \mathrm{M}$ potassium phosphate buffer ( $\mathrm{pH} 7.8$, at $25 \pm 1^{\circ} \mathrm{C}$ ); for detailed comparison of validity of cytochrome $\mathrm{c}$ vs. NBT assay for $\mathrm{k}_{\mathrm{cat}}$ determination, see Batinic-Haberle et al. [193]. a Data obtained from the relationship
Rf vs. $\log \mathrm{P}_{\mathrm{OW}}\left(\log \mathrm{P}_{\mathrm{OW}}=12.207 \times \mathrm{Rf}-8.521\right)[9,68]$, and direct determinations of $\log \mathrm{P}_{\mathrm{OW}}$ for $\mathrm{Mn}$ (III) $\mathrm{N}$-alkoxyalkylpyridylporphyrins; an error was made in the calculation of $\log \mathrm{P}_{\mathrm{OW}}$ values and is corrected herein. ${ }^{b}$ Determined experimentally using n-butanol and water biphasic system and converted to $\log \mathrm{P}_{\mathrm{OW}}$ according to the equation $\log \mathrm{P}_{\mathrm{OW}}=1.55 \times \mathrm{P}_{\mathrm{BW}}-0.54 ; \mathrm{P}_{\mathrm{BW}}$ is the partition between $\mathrm{n}$ butanol and water $[68,194] .{ }^{\mathrm{c}}$ The 1 -electron reduction potential refers to the $\mathrm{RNO}^{+} / \mathrm{RNO}^{-}$redox couple. ${ }^{\mathrm{d}}$ Estimated based on the determined $\mathrm{k}_{\text {cat }}\left(\mathrm{O}_{2}^{\bar{*}}\right)$ for MnTTEG-2-PyP ${ }^{5+}[7,8]$ and the relationship between the $\mathrm{k}_{\mathrm{cat}}\left(\mathrm{O}_{2}^{\overline{2}}\right)$ for FePs and MnPs [25]. ${ }^{\mathrm{e}} \mathrm{E}_{1 / 2}$ data associated with the $\mathrm{Mn}^{\mathrm{IV}} / \mathrm{Mn}^{\mathrm{III}}$ reduction potential in $\mathrm{mV}$ vs. $\mathrm{Ag} / \mathrm{AgCl}[46] .{ }^{\mathrm{f}}$ Oxidation potential only, $\mathrm{Mn}^{\mathrm{II}} / \mathrm{Mn}^{\mathrm{II}}$ redox couple is irreversible. ${ }^{\mathrm{g}}$ Reduction potential only, in N,N-dimethylformamide. When references are not indicated, the data are taken from Batinic-Haberle et al. [6-8]. glutathione, but it can be oxidized with strong oxidants such as peroxynitrite $\left(\mathrm{ONOO}^{-}\right)$, carbonate radical $\left(\mathrm{CO}_{\overline{3}}^{\overline{3}}\right)$ and likely hypochlorite $\left(\mathrm{ClO}^{-}\right)$. Since the reactivity towards $\mathrm{O}_{2}^{-}$parallels the reactivity of $\mathrm{MnPs}$ towards $\mathrm{ONOO}^{-}$, the ability of $\mathrm{MnT}$ $\mathrm{BAP}^{3-}$ to reduce $\mathrm{ONOO}^{-}$is modest, but if administered at high concentrations, it may account for the reported beneficial in vivo effects $[38,77]$. In addition, the electrostatic interactions disfavor reactions between the anionic $\mathrm{MnTBAP}^{3-}$ and anionic reactive species $\mathrm{ONOO}^{-}, \mathrm{CO}_{3}^{-}$and $\mathrm{ClO}^{-}$, and thus limit the magnitude of the related rate constants. Such a structure-activity relationship is applicable to other anionic $\mathrm{Mn}$ porphyrins as well, such as $\mathrm{MnTSPP}^{3-}, \mathrm{MnBr}_{8} \mathrm{TSPP}^{3-}$ and $\mathrm{MnBr}_{8} \mathrm{TCPP}^{3-}$. Despite having a favorable reduction potential of approximately $+200 \mathrm{mV}$ versus NHE due to the strong electron-withdrawing bromines at $\beta$-positions, $\mathrm{MnBr}_{8} \mathrm{TSPP}^{3-}$ and $\mathrm{MnBr}_{8} \mathrm{TCPP}^{3-}$ lack electrostatic guidance for superoxide, thus demonstrate only fair SOD-mimicking potency.

\section{Other Metal Complexes}

In addition to Mn porphyrins, a few other compounds possess fair-to-high SOD-like activity and are listed in table 1 and figures 1 and 2: $\mathrm{Mn}$ (III) corroles, $\mathrm{Mn}$ (III) biliverdins, $\mathrm{Mn}$ (III) salen derivatives, $\mathrm{Mn}$ (II) polyamines (M40403), as well as $\mathrm{Fe}(\mathrm{III}) \mathrm{N}$-substituted pyridylporphyrins. FP15 and INO-4885 are ortho $\mathrm{Fe}(\mathrm{III}) \mathrm{N}$-substituted pyridylporphyrins with triethyleneglycolated and 4-carboxylatobenzyl substituents.
Their design was governed by the same principles (cationic charges at ortho-nitrogens) which provide $\mathrm{Fe}$ (III) and $\mathrm{Mn}$ (III) $\mathrm{N}$-alkylpyridylporphyrins with high SOD-like activity and high ability to reduce $\mathrm{ONOO}^{-}[22,25]$. While not reported as SOD mimics, and routinely viewed as peroxynitrite scavengers only, cationic Fe porphyrins are potent catalysts of $\mathrm{O}_{\overline{2}}$ dismutation as well, and react with other reactive species in a manner similar to Mn porphyrins (see under 'Mechanism of action of Mn porphyrins') [6, 9]. Indeed, the SOD-like activity of the Mn analog of FP15 MnTTEG-2-PyP ${ }^{5+}$ was reported to be $\log \mathrm{k}_{\mathrm{cat}}\left(\mathrm{O}_{\overline{2}}^{\overline{2}}\right)=8.11$ [78].

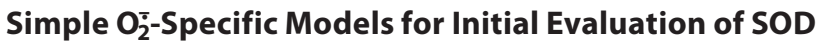 Mimics}

SOD-deficient E. coli mutants lacking cytosolic SOD enzymes (FeSOD and MnSOD) cannot grow aerobically as well as the wild type $[79,80]$. Such mutants appeared as an excellent tool, and an $\mathrm{O}_{2}^{-}$-specific model to evaluate the potential of $\mathrm{Mn}$ porphyrin-based drug candidates $[24,69,74,81]$. Any MnP that has reduction potential $>+50 \mathrm{mV}$ versus NHE has been tested in this SOD-deficient $E$. coli model; any $\mathrm{MnP}$ which supported the aerobic growth of the SOD-deficient $E$. coli was shown later to be efficacious in animal models of oxidative stress injuries. Figure 4a illustrates identical effects of isomer- 
ic Mn ortho- and meta-N-alkylpyridylporphyrins in allowing SOD-deficient JI132 E. coli to grow as well as its SOD-proficient counterpart AB1157. The somewhat inferior SOD efficacy of the meta analogs compared to the ortho species was compensated by their better bioavailability (determined mainly by their higher lipophilicity) $[68,69]$. The prokaryotic E. coli is much more sensitive to the toxicity of long alkyl chain analogs, such as MnTnHex-2-PyP $\mathrm{P}^{5+}$, than are the eukaryotic yeast and mammalian cells [27, 82].

We have therefore recently employed the SOD-deficient Saccharomyces cerevisiae aerobic growth as an additional tool to better evaluate the therapeutic potential of lipophilic analogs [24, 83]; a representative plot of SOD-deficient yeast growth in the presence of $\mathrm{Mn}$ porphyrins is shown in figure $4 \mathrm{~b}$. The oxygen-derivatized $\mathrm{MnTnBuOE}-2-\mathrm{PyP}^{5+}$ was efficacious but less toxic than its alkyl analogs of similar lipophilicities, MnTnHex-2-Py $\mathrm{P}^{5+}$ and MnTnHep-2-PyP $\mathrm{P}^{5+}$. These data parallel the toxicity data obtained in a mouse study [24].

\section{Bioavailability of Mn Porphyrins}

\section{Accumulation of Mn Porphyrins in Mitochondria and}

Nucleus

Despite their high positive charge, originally speculated to serve as a barrier, these compounds accumulate to levels high enough at targeted sites (mitochondria and nucleus) to afford protection from the damage due to oxidative stress. The cationic charge, driven by the negative mitochondrial membrane potential and attracted by anionic phosphate groups of cellular membranes, is the predominant reason for accumulation of Mn porphyrins in the mitochondria.

In an in vivo study, where porphyrin accumulation was investigated in heart mitochondria of mice receiving single intraperitoneal drug injection at $2 \mathrm{mg} / \mathrm{kg}$, lipophilic compounds such as MnTnHex-2-PyP ${ }^{5+}$ accumulated severalfold more in mitochondria than in cytosol compared to the hydrophilic analog MnTE-2-PyP ${ }^{5+}$ (fig. 5) [9]. A similar distribution of porphyrin was registered with the yeast $S$. cerevisiae [72]. One of the evolutionary hypotheses claims that mitochondria arose from symbiotic bacteria. Therefore we can compare data obtained on mouse mitochondria to data obtained on the accumulation of Mn porphyrins in E. coli. Lipophilic MnTnHex-2$\mathrm{Py}^{5+}$ accumulates much more in both cytosol and cell wall/ membranes of E. coli than MnTE-2-PyP ${ }^{5+}$ [9]. To some extent, cationic $\mathrm{Mn}(\mathrm{III}) \mathrm{N}$-alkylpyridylporphyrins may mimic both cytosolic and mitochondrial intermembrane space $\mathrm{Cu}, \mathrm{Zn}$ SOD and matrix MnSOD. Our data on macrophages and lipopolysaccharide-stimulated bone marrow-derived macrophages showed approximately 3 -fold higher levels of MnTE$2-\mathrm{Py}^{5+}$ in the nucleus than in the cytosol, driven there by negatively charged phosphates of nucleic acids [10].
Accumulation of Mn Porphyrins in the Brain

Initial efficacy studies of central nervous system injuries indicated that cationic $\mathrm{Mn}$ porphyrins are able to cross the blood-brain barrier $[9,72,84]$. Even the excessively charged and hydrophilic MnTE-2-PyP ${ }^{5+}$ accumulates over a 7-day period in the brain while its levels in other organs after initial build-up decrease in the same period of time $[9,72,84]$. The brain is rich in phospholipids and thus in anionic phosphates; this appears to be a driving force for the brain accumulation of pentacationic MnPs. After a single injection of $2 \mathrm{mg} / \mathrm{kg}$, the lipophilic MnTnHex-2-PyP ${ }^{5+}$ accumulates at $24 \mathrm{~h}$ to an approximately 9 -fold higher level in the mouse brain than does MnTE-2-PyP ${ }^{5+}$ at $10 \mathrm{mg} / \mathrm{kg}$ [85]. In a pharmacokinetic rat study, we reported for the first time the brain levels of $\mathrm{MnTn}$ Hex-2-PyP ${ }^{5}$, which correspond to its remarkable efficacy in a stroke model (see under 'Stroke') [85].

\section{Oral Availability of Mn Porphyrins}

Comprehensive pharmacokinetic studies via intravenous, intraperitoneal and oral routes of administration were performed for cationic MnTE-2-PyP ${ }^{5+}(10 \mathrm{mg} / \mathrm{kg})$ and MnTnHex$2-\mathrm{PyP}^{5+}(0.5$ or $2 \mathrm{mg} / \mathrm{kg})[70,86]$. Though highly charged and fairly hydrophilic, both compounds are orally available. The plasma oral availability (expressed as $\mathrm{AUC}_{\mathrm{ORAL}} / \mathrm{AUC}_{\mathrm{IV}}$ ) was found to be 23 and 20\% for MnTE-2-PyP $\mathrm{P}^{5+}$ and MnTnHex-2$\mathrm{Py}^{5+}$, respectively. The plasma $\mathrm{AUC}_{\mathrm{IP}}$ was found to be $83 \%$ of $\mathrm{AUC}_{\mathrm{IV}}$ for MnTE-2-PyP ${ }^{5+}$ at $10 \mathrm{mg} / \mathrm{kg}$ and $84 \%$ for MnTnHex$2-\mathrm{PyP}^{5+}$ at $0.5 \mathrm{mg} / \mathrm{kg}$. The organ oral availability (based on the combined AUC of plasma and AUC of vital organs: liver, kidney, spleen, heart, lung, brain) expressed as $\mathrm{AUC}_{\mathrm{ORGAN}(\text { oral }} /$ AUC $_{\text {ORGAN(ip) }}$ was found to be 13 and 33\% for MnTE-2-PyP ${ }^{5+}$ and MnTnHex-2- $\mathrm{Py}^{5+}$, respectively. The less hydrophilic MnTnHex-2-PyP $\mathrm{P}^{5+}$ is approximately 2.5 -fold superior relative to MnTE-2-PyP ${ }^{5+}$ with regard to organ distribution. The data demonstrate the impact of lipophilicity and pentacationic charge on MnP biodistribution and oral availability [86].

\section{Mechanism of Action of Mn Porphyrins}

Cationic Mn(III) pyridyl and imidazolyl porphyrins are among the most potent synthetic SOD mimics available. However, the reactivity of MnPs towards $\mathrm{O}_{2}^{\overline{2}}$ is not specific. $\mathrm{MnPs}$ are also highly reactive towards $\mathrm{ONOO}^{-}$and $\mathrm{CO}_{3}^{-}$(the degradation product of $\mathrm{ONOO}^{-}$and $\mathrm{CO}_{2}$ adduct; fig. 6). The $\mathrm{k}_{\text {red }}\left(\mathrm{ONOO}^{-}\right)$parallels the $\mathrm{k}_{\mathrm{cat}}\left(\mathrm{O}_{2}^{-}\right)$for $\mathrm{Mn}(\mathrm{III}) \mathrm{N}$-alkylpyridylporphyrins [77]. Such a relationship is due to the same thermodynamic and electrostatic factors that favor the reaction of the cationic, electron-deficient metal complex with anionic species $[6-8,10]$. Therefore, the cationic MnPs with the highest $\mathrm{kcat}\left(\mathrm{O}_{2}^{\overline{ }}\right)$ are the most potent scavengers of $\mathrm{ONOO}^{-}$ while anionic porphyrins $\left[\mathrm{MnTBAP}^{3-}\right.$, FeTBAP $^{3-}$, FeTSPP ${ }^{3-}$, $\left.\mathrm{FeT}\left(2,4,6-\mathrm{Me}_{2-} 3,5-\left[\mathrm{SO}_{3}\right]_{2}-\mathrm{P}\right) \mathrm{P}^{7-}\right]$ and metal complexes that 
Fig. 4. The efficacy of $\mathrm{Mn}$ porphyrins in protecting SOD-deficient organisms when grown aerobically: prokaryotic E. coli and eukaryotic S. cerevisiae. a SOD-deficient $E$. coli (JI132) grew in M9CA medium. The wild type AB1157 and SOD-deficient strain JI132 were used. Growth was followed turbidimetrically by measuring the absorbance at 600 $\mathrm{nm}$ as described in details elsewhere [69, 74]. b The wild-type yeast $S$. cerevisiae strain used was EG103, which has a complete genotype of $M A T \alpha$, leu2, his3, $\operatorname{trp} 1$ and $u r a 3$. The sod1s mutant $S$. cerevisiae strain, lacking $\mathrm{Cu}, \mathrm{ZnSOD}$, was EG118, which has a complete genotype of MAT $\alpha$, leu2, his3, trp1, ura3 and sod $1 \triangle:: U R A 3$ [83]. Yeast grew in medium that contained peptone agar supplemented with $2 \%$ dextrose and yeast extract. Growth was followed turbidimetrically by measuring the absorbance at $600 \mathrm{~nm}$. Modified from Rajic et al. [24].

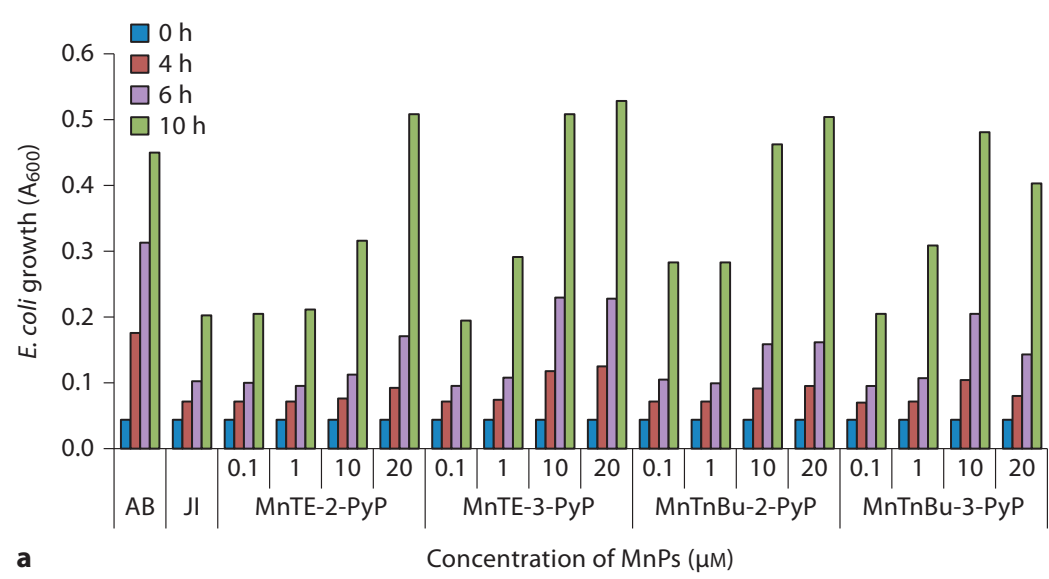

a

Concentration of MnPs ( $\mu \mathrm{M})$

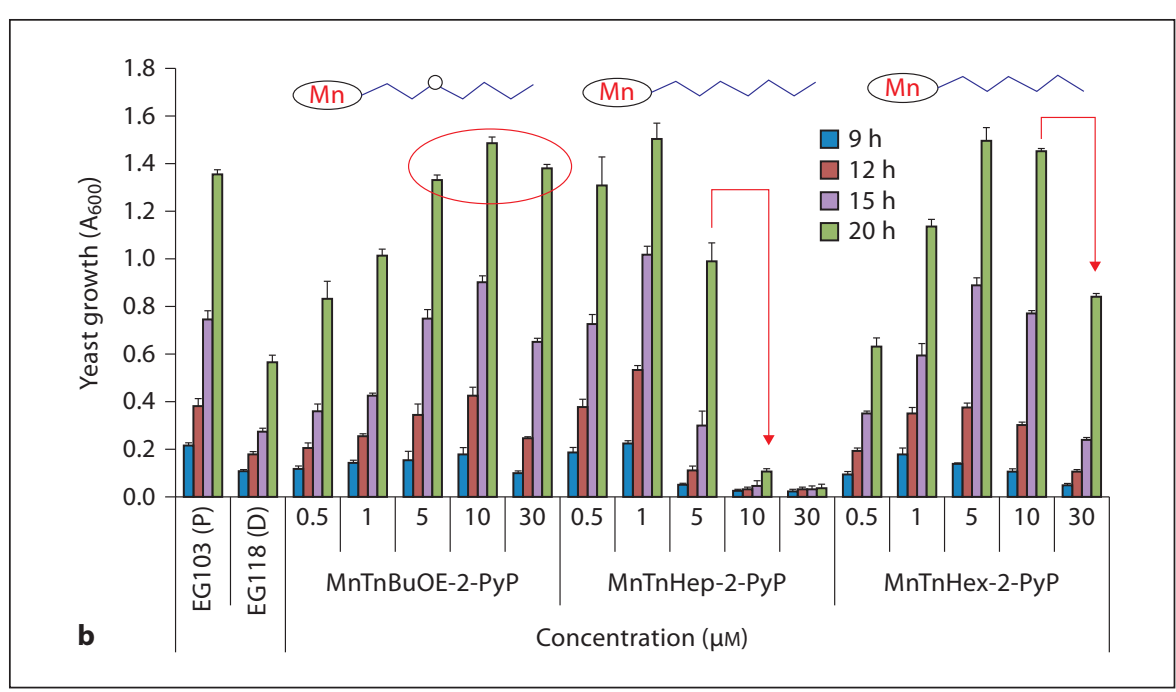

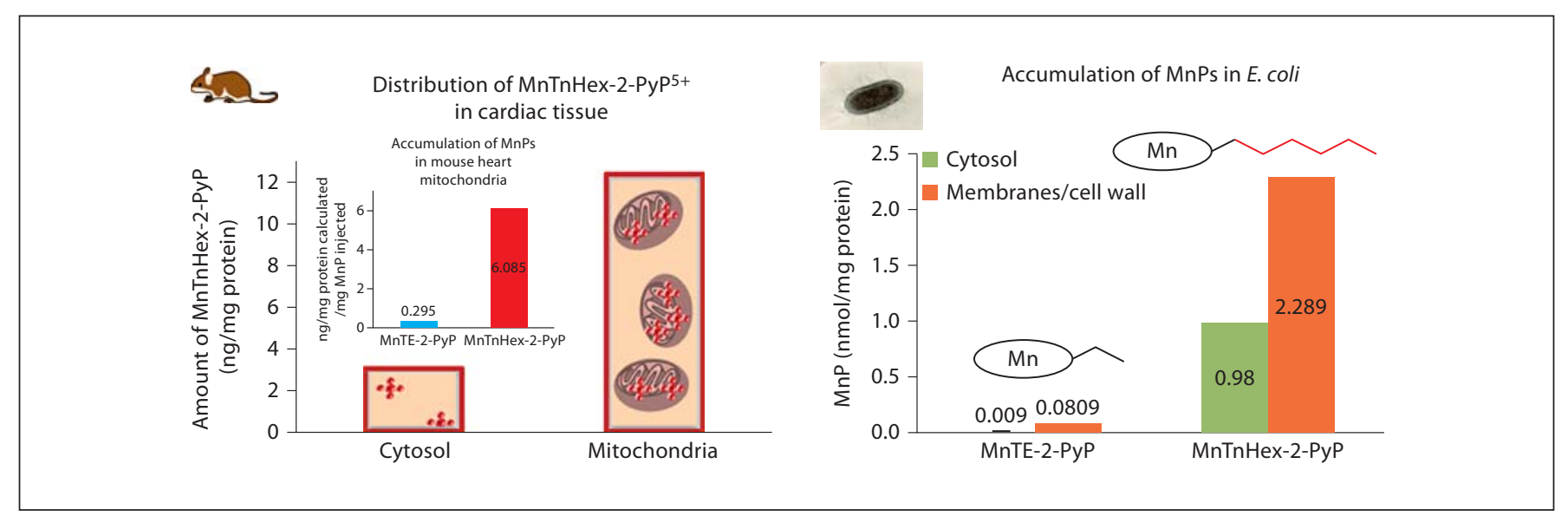

Fig. 5. Distribution of Mn porphyrins in mouse heart and prokaryotic E. coli. In both systems, the more lipophilic MnTnHex-2-PyP $\mathrm{P}^{5+}$ accumulated at severalfold higher levels in mitochondria and cytosol of mouse heart and in cytosol and membranes (resembling mitochondria with inner and outer membranes) than the hydrophilic MnTE-2-PyP $\mathrm{P}^{5+}$. Single injection of MnTE-2-PyP ${ }^{5+} \mathrm{was}_{10} \mathrm{mg} / \mathrm{kg}$ and $2 \mathrm{mg} / \mathrm{kg}$ of MnTnHex-2-PyP $\mathrm{P}^{5+}[9,24]$. E. coli grew for $1 \mathrm{~h}$ in M9CA medium supplied with $5 \mu \mathrm{M}$ MnPs. Adapted from Miriyala et al. [9]. 
Fig. 6. The reactivity of MnPs towards reactive species is related to the electron deficiency of the metal site characterized by $\mathrm{E}_{1 / 2}$ (see fig. 3). The most potent Mn porphyrins have a very electron-deficient metal site and thus favor binding of electron-donating anionic species such as $\mathrm{O}_{2}^{-}, \mathrm{ONOO}^{-}, \mathrm{CO}_{3}^{-}, \mathrm{ClO}^{-}$, etc. Further due to the same fact they favor accepting electrons and being readily reduced with cellular reductants; in a subsequent step (while being oxidized from $\mathrm{Mn}^{\mathrm{II}} \mathrm{P}$ to $\mathrm{Mn}^{\mathrm{III}} \mathrm{P}$ ) $\mathrm{Mn}^{\mathrm{II}} \mathrm{P}$ can reduce the reactive species. The cationic character allows them to approach the anionic deprotonated cysteines of signaling proteins and oxidize those while undergoing reduction. When oxidized to $\mathrm{O}=$ $\mathrm{Mn}^{\mathrm{IV}} \mathrm{P}^{4+}$ (with $\mathrm{ONOO}^{-}, \mathrm{H}_{2} \mathrm{O}_{2}, \mathrm{ClO}^{-}$or $\mathrm{CO}_{3}^{-}$), in a subsequent step they readily oxidize glutathione, ascorbate or uric acid and undergo reduction to $\mathrm{Mn}^{\mathrm{III}} \mathrm{P}$ whereby closing the catalytic cycle. Adapted from Batinic-Haberle et al. [7].

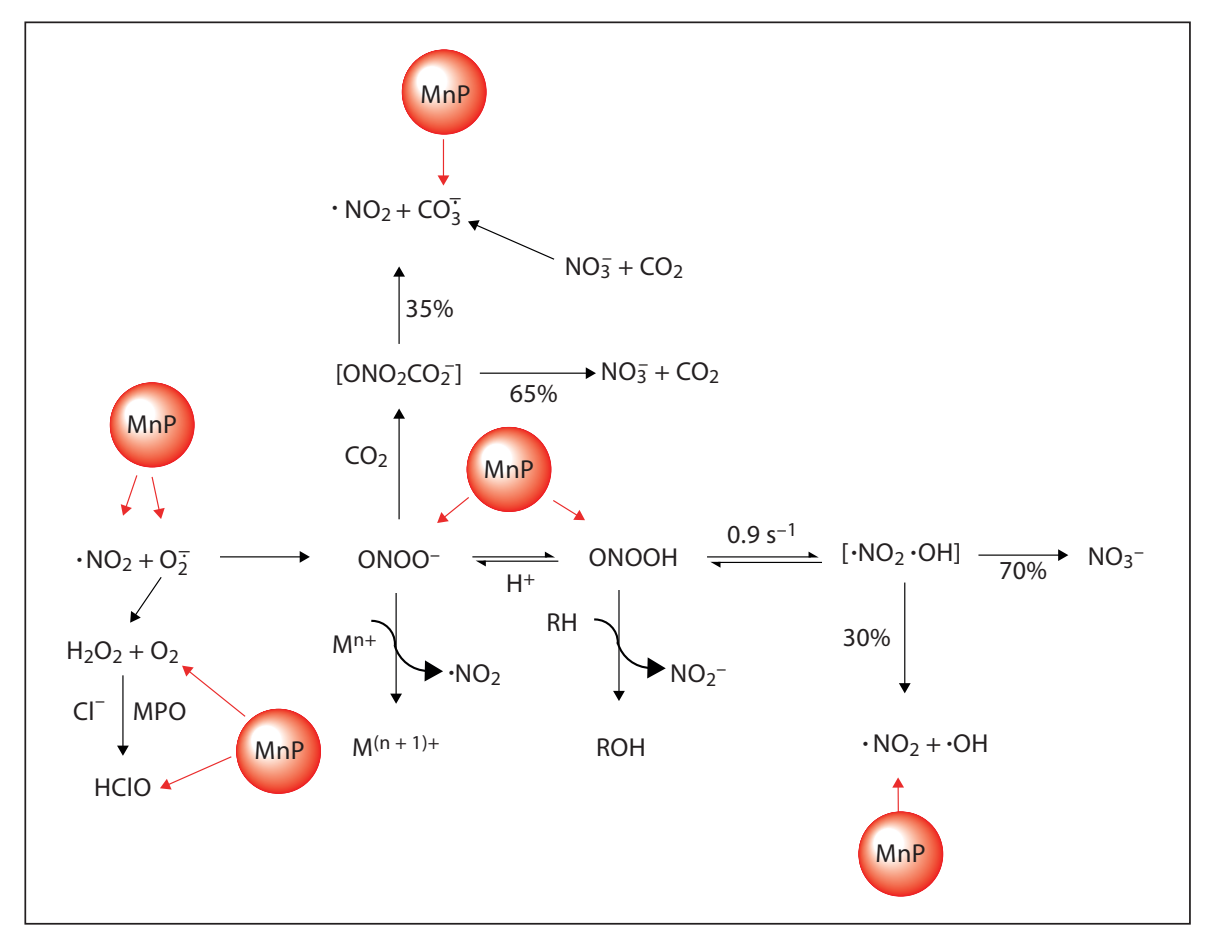

have no charges on the periphery and bear electron-rich metalsites [MnTCHP ${ }^{+}, \mathrm{Mn}$ (III) complexwithbis(dihydroxyphenyl) dipyrromethene derivative, EUK-418 and AEOL11207; fig. 1, 2] are inferior [45, 87-90]. MnTE-2-PyP ${ }^{5+}$ reacts with high affinity, rapidly and stoichiometrically with $\cdot \mathrm{NO}$ [91]. Studies are in progress with the group of Ferrer-Sueta on the reactivity of MnPs towards hypochlorite formed in vivo by the action of myeloperoxidase. Data are reported on the reactivity of several MnPs towards $\mathrm{ClO}^{-}$and $\mathrm{ClO}_{2}^{-}[35,92-94]$. Indirect studies indicate reactivity of $\mathrm{MnTE}-2-\mathrm{PyP}^{5+}$ towards peroxyl and alkoxyl radicals $[77,95,96]$. Studies are in progress to broaden our insight into the reactivity of MnPs towards $\mathrm{H}_{2} \mathrm{O}_{2}$ and other biologically relevant peroxides [97]; Araujo-Chaves et al. [98] reported glutathione peroxidase-like activity of MnTM$4-\mathrm{PyP}^{5+}$, while Gross's group reported fair catalase-like activity of corroles [51]. Potent SOD mimics have metal-centered redox properties compatible with cellular reductants such as ascorbate, glutathione and tetrahydrobiopterin. Due to the high in vivo concentrations of those reductants, MnPs are likely coupled to these molecules while redox cycling with reactive species. By removing reactive species, $\mathrm{MnPs}$ can protect isocitrate dehydrogenase, therefore assuring regeneration of cellular antioxidant defenses $[99,100]$.

As already noted, the reactive species, usually viewed as 'bad guys', are able to oxidize biological molecules, but at nanomolar levels are also essential for cellular signaling. Their levels are tightly controlled by the abundance of cellular endogenous antioxidants: small molecules such as ascorbate, tocopherols, tetrahydrobiopterin and glutathione, and proteins such as the SOD family of enzymes, catalases, peroxidases, peroxiredoxins, etc. Once their concentrations increase and approach micromolar levels, the cell is oxidatively stressed; subsequently it either upregulates antiapoptotic pathways, aiming at cell survival, or activates proinflammatory pathways, eventually leading to cell death or cell transformation and carcinogenesis. We have thus far reported that MnPs are able to prevent activation of major transcription factors that control those processes: hypoxia-inducible factor-1 (HIF-1 $\alpha$ ), a major factor in carcinogenesis; NF$\kappa \mathrm{B}$, a major antiapoptotic factor (though it contains proapoptotic members of its family), and activator protein-1 (AP-1), which controls both cell proliferation and apoptosis (fig. 7) $[6,9$, 10].

Originally, and based on the experimental evidence, the removal of reactive species by MnPs was proposed as means to prevent the activation of HIF- $1 \alpha$, AP-1 and NF- $\kappa$ B (fig. 7) [101105]. However, very early on, in a cell-free system, Piganelli's group suggested that MnTE-2-PyP $\mathrm{P}^{5+}$ likely oxidizes cysteine of the p50 NF- $\kappa B$ subunit in the nucleus, which prevents the DNA binding of NF- $\kappa \mathrm{B}$ and the related transcriptional activity (fig. 7). The efficacy of the imidazolium derivative MnTDE2-ImP $\mathrm{P}^{5+}$ in a stroke model was attributed to a similar mechanism [106]. We have subsequently shown the feasibility of such an event in an aqueous system where MnTE-2-PyP $\mathrm{P}^{5+}$ protondependently oxidized the cysteine residue in glutathione [10]. Moreover, the compound indeed reaches the nucleus and accumulates there at a 3-fold higher level than in the cytosol of bone-marrow-derived macrophages [10]. Such action of MnP likely plays a role in the prevention of excessive inflammation 


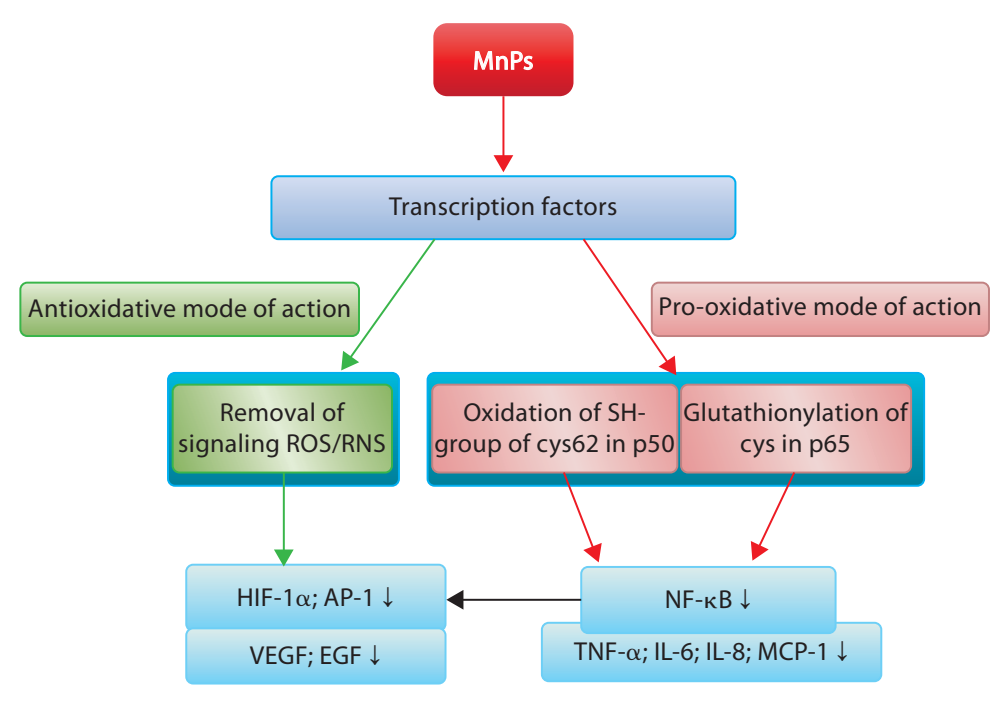

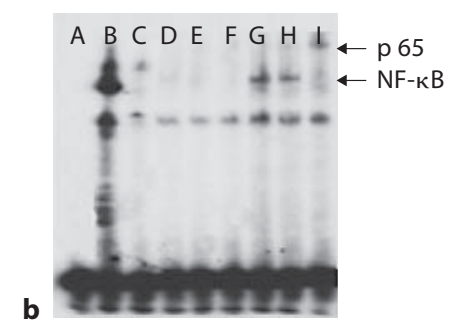

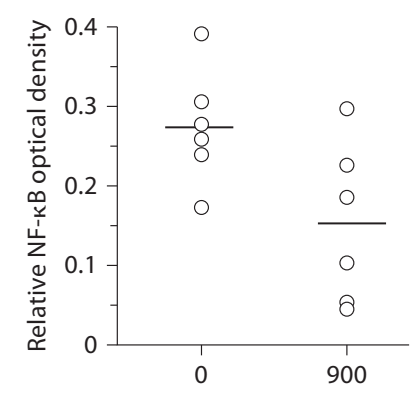

c $\quad \mathrm{Mn}^{\text {IIITDE}}$-2-ImP6+ dose $(\mathrm{ng})$
Fig. 7. The reactivity of $\mathrm{Mn}$ porphyrins towards transcription factors (a), and suppression of postischemic NF- $\kappa \mathrm{B}$ activation by MnTDE-2$\mathrm{ImP}^{5+}$ in a middle cerebral artery occlusion model of stroke (b, c). a One week of intracerebroventricular administration of $\mathrm{Mn}$ porphyrin starting at $90 \mathrm{~min}$ after the onset of reperfusion (after 90-min middle cerebral artery occlusion) allows for a significant decrease in infarct volume and neurological deficit even 8 weeks after ischemia [106]. The efficacy was largely attributed to the suppression of cellular transcriptional activity that would have otherwise perpetuated the primary oxidative event. NF- $\kappa \mathrm{B}$ activation was measured $6 \mathrm{~h}$ after middle cerebral artery occlusion in rats treated intracerebroventricularly with vehicle or $900 \mathrm{ng} \mathrm{MnTDE}-2-\mathrm{ImP}^{5+}$ at $90 \mathrm{~min}$ after onset of reperfusion. ROS = reactive oxygen species; RNS = nitrogen species;
VEGF = vascular endothelial growth factor; EGF = epidermal growth factor; $\mathrm{MCP}=$ monocyte chemoattractant protein. $\mathbf{b}$ Representative electromobility shift analysis. $\mathrm{A}=$ Probe with no sample; $\mathrm{B}=$ positive control $(\mathrm{HeLa}) ; \mathrm{C}=$ positive control with cold probe; $\mathrm{D}=$ contralateral hemisphere with p50 antibody $\left(\mathrm{MnTDE}^{2}-\mathrm{ImP}^{5+}\right)$; $\mathrm{E}=$ contralateral hemisphere with $\mathrm{p} 65$ antibody $\left(\mathrm{MnTDE}-2-\mathrm{ImP}^{5+}\right) ; \mathrm{F}=$ ischemia hemisphere (MnTDE-2-ImP ${ }^{5+}$ ); $\mathrm{G}=$ ischemia hemisphere (vehicle); $\mathrm{H}=$ ischemia hemisphere (vehicle) with p50 antibody; $\mathrm{I}=$ ischemia hemisphere (vehicle) with p65 antibody. A substantially greater supershift was seen for p65 than p50 (here indicated as NF- $\kappa B$ ). c Open circles indicate relative optical density values in individual rat NF- $\mathrm{B}$ bands in the hemisphere ipsilateral to middle cerebral artery occlusion. Horizontal bars indicate group mean values. of islet cells during isolation and significantly delayed or prevented animal death in young nonobese diabetic-severe combined immunodeficient mice [101]; note that the effects observed were antioxidative, but are likely a consequence of the $\mathrm{MnP}$ pro-oxidative action. The fact that MnTE-2- $\mathrm{PyP}^{5+}$ oxidizes and reduces $\mathrm{O}_{2}^{-}$in a dismutation process with similar rate constants (equations 1 and 2) supports such in vivo findings where it indeed acts either as anti- or pro-oxidant. Recently, Tome's group in a study on lymphoma cells showed that, when combined with steroid dexamethasone, MnTE-2-PyP $\mathrm{P}^{5+}$ glutathionylates cysteine of the $\mathrm{p} 65$ subunit of NF- $\mathrm{KB}$ in the presence of $\mathrm{H}_{2} \mathrm{O}_{2}$ (levels of which were increased due to the action of dexamethasone). Such a modification seems to occur in cytosol, and in turn prevents p65 DNA binding in the nucleus and NF- $\kappa \mathrm{B}$ activation. In turn, it deprives cells of their key endogenous antioxidant glutathione and therefore enhances the anticancer/cytotoxic effect of steroids [107]. Whether cationic MnP oxidizes or glutathionylates the protein cysteine, electrostatics plays a role when it approaches the deprotonated an- ionic cysteine. Both sets of experiments caution us to distinguish between the nature of the actions of MnPs and the nature of the effects we observe in vivo.

To investigate the possibility that MnPs act as pro-oxidants in vivo, which results in mild oxidative stress and signals the organism to employ its own endogenous antioxidative defenses, we explored the MnP/ascorbate system [27]. The major reason behind such a strategy is that there are large intracellular micromolar levels of ascorbate whose primary role is to recycle oxidized tocopherol and thus assure its protective role in preventing lipid peroxidation. In a simple aqueous ascorbate/MnP system, MnTE-2-PyP ${ }^{5+}$ catalyzes ascorbate oxidation leading to the enhanced production of peroxide (fig. 8) [27]. Such a system could produce mild oxidative stress and signal to the organism that it needs to upregulate its own defense systems. Such an effect is also reminiscent of the effect of physical exercising: as a mild oxidative event, exercise has been shown to upregulate endogenous antioxidative defenses, including MnSOD [108]. 


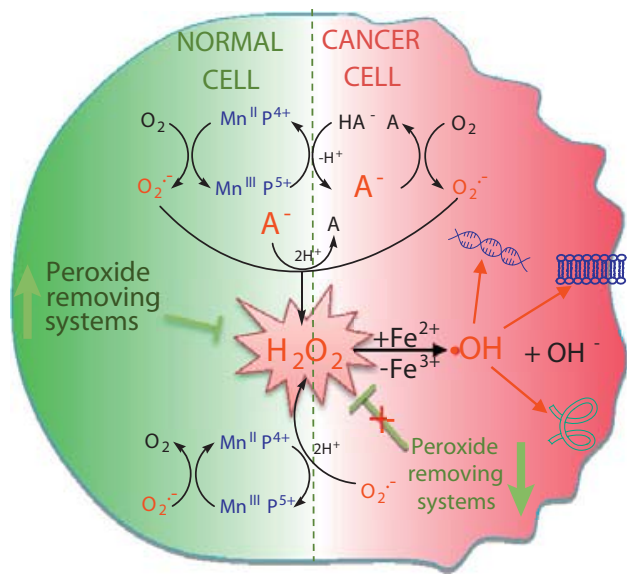

give and accept electrons, and thus to reduce and oxidize substrates. The $\mathrm{k}_{\text {cat }}\left(\mathrm{O}_{\overline{2}}\right)$ is therefore an excellent measure of $\mathrm{MnP}$ therapeutic potential.

\section{Purity and Identity of Mn Porphyrin Preparations}

Researchers need to be aware that the preparations they obtain may not be pure enough or may contain impurities that could cause adverse effects or interfere with the active ingredient. Data have already been provided on such cases related to commercial preparations from Alexis, CalBiochem and Porphyrin Products [7, 109]. Among such cases are those where the insufficient purity of commercial preparations of MnTE-2PyP ${ }^{5+}$ and $\mathrm{MnTBAP}^{3-}$ resulted in failures of those Mn porphyrins to perform in models with oxidative stress background $[38,76,110]$. Thus, prior to their use in biological studies, the compounds should be tested on their activity with basic analytical tools $[76,109]$. The impurities that may be present in preparations of $\mathrm{MnPs}$ relate to incomplete quaternization of pyridyl nitrogens (differently quaternized compounds), incomplete metallation (metal-free ligand) and incomplete removal of free manganese, and may be assessed as described elsewhere $[76,109,111]$.

\section{Assignment of Type of Action to Mn Porphyrins and Related Compounds}

Another problem that continuously appears in publications is incorrect assignment of the function of $\mathrm{Mn}$ porphyrins and other types of antioxidants. Importantly, none of the synthetic or natural compounds explored are specific to a particular reactive species and cellular location. For many compounds, very limited data exist on their reactivity and subcellular distribution. For example, a few years ago we clearly showed that $\mathrm{MnTBAP}^{3-}$ is not an SOD mimic $[76,109]$. However, researchers continue to indicate that they have chosen for their research MnTBAP $^{3-}$ due to its function as a SOD mimic. Its use authors have additionally justified by its mitochondrial targeting [112], even though insufficient data have thus far been provided on the mitochondrial localization of MnTBAP ${ }^{3-}$. Based on the present knowledge that the drug needs to have a cationic charge to enter mitochondria, the accumulation of the negatively charged MnTBAP ${ }^{3-}$ in mitochondria would be disfavored [9]. Neutral porphyrins such as EUK-418, AEOL11207 and $\mathrm{MnTCHP}^{+}$have been claimed to be either SOD mimics (EUK-418 [113] and AEOL11207 [90]) or potent $\mathrm{ONOO}^{-}$scavengers $\left(\mathrm{MnTCHP}^{+}[44]\right.$ and $\mathrm{Mn}$ (III) complex of bis(dihydroxyphenyl)dipyrromethene derivative [45]). The $\mathrm{ONOO}^{-}$-related potency of $\mathrm{MnTCHP}^{+}$and $\mathrm{Mn}$ (III) complex with bis(dihydroxyphenyl)dipyrromethene derivative was evaluated based on the comparison to MnTM-4-PyP ${ }^{4+}\left(\mathrm{k}=4.3 \times 10^{6} \mathrm{M}^{-1} \mathrm{~s}^{-1}\right)$ 
[114] which is an inferior $\mathrm{ONOO}^{-}$scavenger compared to the severalfold more potent $\mathrm{ONOO}^{-}$scavenger, $\mathrm{MnTM}-2-\mathrm{PyP}^{5+}$ $\left(\mathrm{k}=1.85 \times 10^{7} \mathrm{M}^{-1} \mathrm{~s}^{-1}\right)$ [114]. $(\mathrm{OH}) \mathrm{FeTM}-4-\mathrm{PyP}^{4+}$ (commonly indicated in the literature as FeTMPyP), FP15 and INO-4885 are declared as $\mathrm{ONOO}^{-}$scavengers, while based on our data and the data of others, they are likely much stronger catalysts of $\mathrm{O}_{\overline{2}}$ dismutation than scavengers of $\mathrm{ONOO}^{-}$[115-117]. Indeed, $(\mathrm{OH}) \mathrm{FeTM}-4-\mathrm{PyP}^{4+}$ was the first porphyrin-based SOD mimic ever tested by Pasternack and Halliwell [23]. To add to the existing confusion in the literature about metalloporphyrins, a paper by Suofu et al. [118] describes FeT[2,4,6- $\mathrm{Me}_{3}-3,5-$ $\left.\left(\mathrm{SO}_{3}\right)_{2}-\mathrm{P}\right] \mathrm{P}^{7-}$ as 'FeTMPyP', which is a common abbreviation for $\mathrm{Fe}(\mathrm{III}) \quad$ meso-tetrakis(N-methylpyridinium-4-yl)porphyrin. The former is an anionic Fe porphyrin and the latter a cationic compound [118]. The latter is a commercially available Fe porphyrin, and perhaps the one used by the authors. Another manuscript by Thiyagarajan et al. [119] has a confusing statement, listing MnTE-2-PyP ${ }^{5+}, \mathrm{M} 40403$ and M40404 compounds as belonging to the same metalloporphyrin class of SOD mimetics with neuroprotective effects in cerebral ischemia models. Yet, M40403 and M40404 are Mn(II) cyclic polyamines; M40404 is an inactive analog of M40403 [7]. The papers listed above are only few among many which indicate the potential of metalloporphyrins in treating oxidative stress injuries, but introduce errors from therapeutic and mechanistic points of view.

Finally, the justification for use of the wide-spectrum antioxidant tempol in vivo has been based on its SOD activity [120, 121]. However, at physiological $\mathrm{pH}$, it is not an SOD mimic, although it can be oxidized to oxoammonium cation with $\mathrm{ONOO}^{-}$, and oxoammonium cation reacts rapidly with $\mathrm{O}_{\dot{2}}^{\overline{2}}$, closing the catalytic cycle. Thus, tempol may be considered as $\mathrm{ONOO}^{-} / \mathrm{O}_{2}^{-}$oxidoreductase. It does, however, react with $\mathrm{ONOO}^{-}$and with $\mathrm{CO}_{3}^{-}$and $\cdot \mathrm{NO}_{2}^{-}$degradation products of the $\mathrm{ONOO}^{-}$adduct with $\mathrm{CO}_{2}$ [122-125]. Tempol has also been shown to react with other strong oxidants such as protein-derived, peroxyl and thiyl radicals [8].

Such improper assignments obviously lead to incorrect interpretation of data obtained from in vivo studies, and wrongly instruct future researchers what to use in their studies; consequently, incorrect conclusions are being perpetuated.

\section{Cancer}

As the world population ages, the prevalence of cancer increases and is presently one of the major causes of death worldwide. It is thus no wonder that there is a growing interest in the development of anticancer drugs. Cancer is a disease with a staggering complexity that continues to generate new avenues of research. There are more than 200 different tumor types, each with its own subtypes. To further complicate matters, findings from animal models do not translate well to human subjects [126].

Therapeutic Effects of Mn Porphyrins
Most anticancer drugs can be classified according to their mechanism of action, such as DNA-interactive agents, antimetabolites, antitubulin agents, molecular targeting agents, hormones, monoclonal antibodies and other biological agents. MnPs present an entirely novel class of anticancer drugs: they are metal complexes whose redox potency is the basis for their in vivo efficacy; rather than targeting a specific protein, they target the cancer cell redox status which supports cancer cell metabolism and growth. MnPs can: (a) act as single anticancer agents; (b) enhance radiochemotherapy and hyperthermia; (c) offer radioprotection for normal tissue during cancer radiation therapy; (d) diminish consequences of the effect of the 'chemobrain' (the term that describes the brain-damaging effects of chemotherapeutics such as doxorubicin); (e) inhibit chronic morphine tolerance and thus allow pain management; (f) prevent neuropathic pain caused by anticancer chemotherapy, and (g) differentially image tumor versus normal tissue. All of these actions that substantiate the therapeutic potential of Mn porphyrin in cancer have thus far been reported by different laboratories for different cancer types [27, 82, 102, 103, 105, 107, 127-134].

\section{Mn Porphyrins as Single Agents}

Their actions as single agents in breast, prostate, skin and brain animal tumor models were investigated $[63,103,105$, 131-133, 135-138]. Except for skin cancer [105], thus far the antitumor effect has been moderate and is primarily understood as being at the level of tumor vasculature, i.e. by inhibiting HIF- $1 \alpha$ activation and expression of its gene vascular endothelial growth factor (VEGF), which is crucial for tumor growth [63, 103, 131-133, 135-138].

In a $4 \mathrm{~T} 1$ breast cancer mouse model, MnTE-2-PyP ${ }^{5+}$ produced a moderate anticancer effect - tumor growth delay when given daily at $2 \times 7.5 \mathrm{mg} / \mathrm{kg}$ s.c. for the duration of the study. HIF- $1 \alpha$ and VEGF were suppressed, as was hypoxia and consequently microvessel density and endothelial cell proliferation. Oxidative stress was suppressed as measured by decreased levels of nitrotyrosine, DNA oxidation, NADPH oxidase and macrophage infiltration [103].

In an RM-9 mouse prostate model, MnTE-2-PyP ${ }^{5+}$ suppressed tumor growth in its own right only when it was injected immediately after subcutaneous implantation of $5 \times$ $10^{5}$ RM-9 cells [139].

In a mouse skin carcinogenesis study, the antitumor effect of MnTE-2-PyP ${ }^{5+}$ as monotherapy was remarkable. Mouse skin was treated with as low as $5 \mathrm{ng} /$ day for 5 days per week for 14 weeks. Tumor was induced with 7,12-dimethyl-benz-(a)-anthracene and promot-ed with 12-O-tetradecanoylphorbol-13acetate. MnTE-2-PyP ${ }^{5+}$ was applied either $30 \mathrm{~min}$ before or $12 \mathrm{~h}$ after each 12-O-tetradecanoylphorbol-13-acetate treatment. $\mathrm{MnP}$ decreased the number of papillomas from 31 to 5, while MnSOD overexpression decreased the number of papillomas from 19 to $9[105,140]$. The smaller effect of MnSOD overexpression was due to the suppression of both cell apoptosis and pro-

Med Princ Pract 2013;22:103-130 


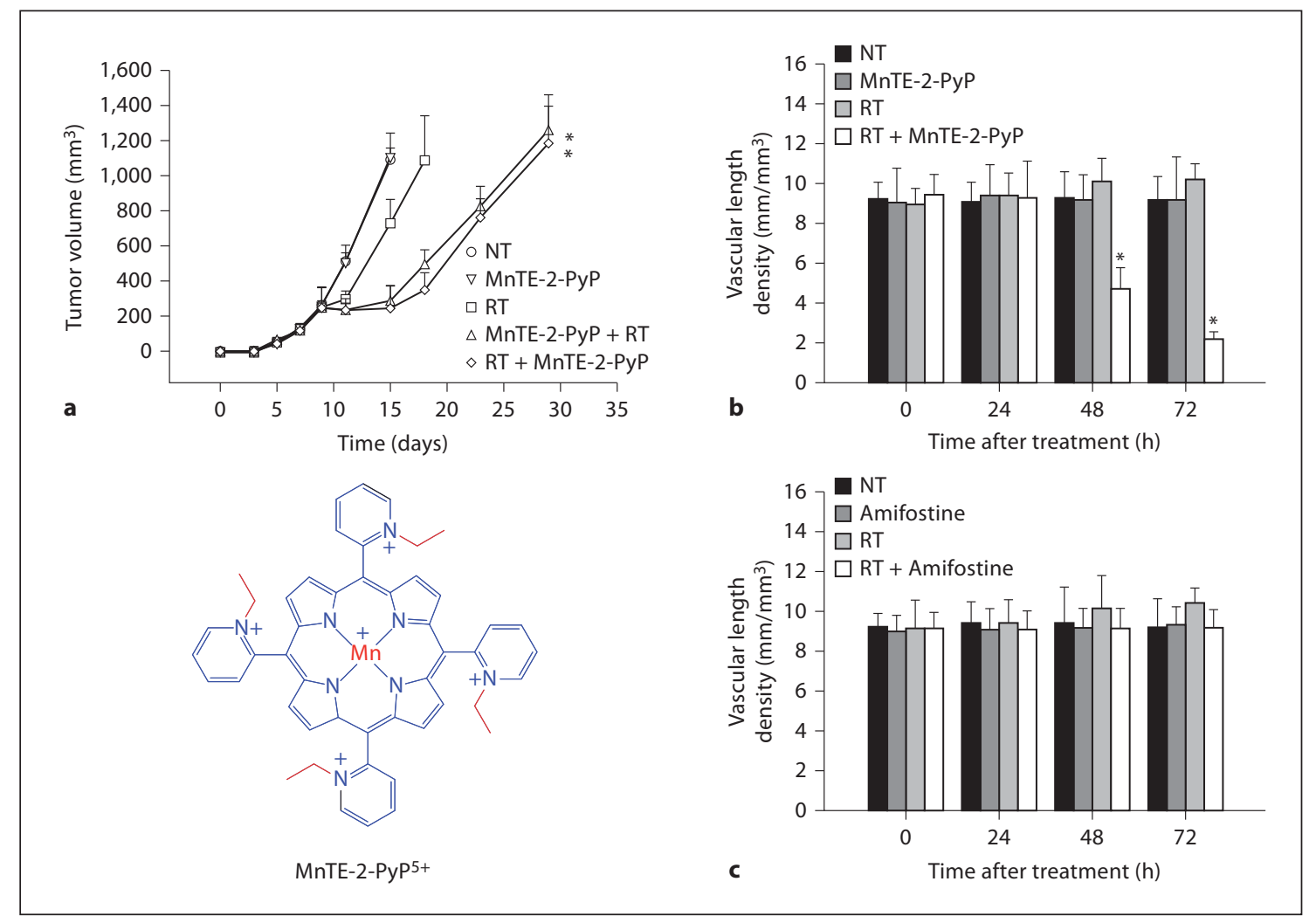

Fig. 9. Radiosensitizing effect of MnTE-2- $\mathrm{PyP}^{5+}$ on tumor growth and on the tumor vasculature in a mouse 4T1 breast cancer study. a Sc xenograft tumor growth delay: $\mathrm{MnTE}-2-\mathrm{PyP}^{5+}$ was given before and after radiation. Two regimes of dosing were employed where $\mathrm{MnP}$ was given either $1 \mathrm{~h}$ before each radiation dose or at 1,13 and $25 \mathrm{~h}$ after the $3 \mathrm{rd}$ dose of radiation. Three doses of radiation were separated by $12 \mathrm{~h}$. Tumors were allowed to reach approximately 200 $\mathrm{mm}^{3}$ in size, and randomized to 1 of 5 treatment groups on postimplantation day 9: (1) phosphate-buffered saline (NT), (2) MnTE-2$\mathrm{PyP}^{5+}$ (6 mg/kg every $12 \mathrm{~h} / 3$ ), (3) radiation (RT; 5 Gy every $12 \mathrm{~h} / 3$ ), (4) MnTE-2-PyP $\mathrm{M}^{5+}+\mathrm{RT}$ (1 MnTE-2-PyP $\mathrm{P}^{5+}$ dose before each fraction of radiation), or (5) RT + MnTE-2-PyP $\mathrm{P}^{5+}\left(3 \mathrm{MnTE}-2-\mathrm{PyP}^{5+}\right.$ doses after the third fraction of radiation). The combined-treatment groups had significant, supra-additive effects on radiation-induced tumor growth delay, irrespective of sequencing. $\mathrm{n}=5$ per group. ${ }^{*} \mathrm{p}=0.01$ versus radiation alone [82]. b, c 4T1 window chamber model: the ra-

liferation; however, $\mathrm{MnP}$ was given in a timely manner (after the peak of apoptosis but before the peak of mitosis) and it thus suppressed proliferation only. In another study, depilated mice were exposed to $5 \mathrm{~kJ} / \mathrm{m}^{2} \mathrm{UVB}$ irradiation [141]. MnTE-2-PyP $\mathrm{P}^{5+}$, given at $5 \mathrm{mg} / \mathrm{kg}$ i.p. for 2 days before radiation protected $\mathrm{mtDNA}$ polymerase (a major constituent of nucleoids, responsible for the replication and repair of the mitochondrial genome). Oxidative damage (as measured by nitrotyrosine formation) was decreased at 1 and $24 \mathrm{~h}$ after radiation [141]. This study suggests that $\mathrm{MnP}$ would protect skin against the UVB-mediated development of skin cancer. diosensitizing effect of MnTE-2-PyP $\mathrm{P}^{5+}$ is at least in part related to the antiangiogenic action of $\mathrm{MnTE}-2-\mathrm{PyP}^{5+}$ as shown by the measurements of vascular density. Amifostin has no effect on vascular density. $4 \mathrm{~T} 1$ window chamber tumors were randomized to treatment with radiation (RT) or sham-irradiation (NT) and phosphate-buffered saline or MnTE-2- $\mathrm{PyP}^{5+}$ (b) or phosphate-buffered saline or amifostine (WR-2721; c). A course of 3 fractions of radiation (5 Gy each, $12 \mathrm{~h}$ apart) was followed immediately by daily administration of MnTE-2-PyP ${ }^{5+}(6 \mathrm{mg} / \mathrm{kg} /$ day) or amifostine $(100 \mathrm{mg} / \mathrm{kg} /$ day $)$ for 3 days. Tumors were imaged immediately after radiation $(0 \mathrm{~h})$ and every day thereafter $(24,48$ and $72 \mathrm{~h}$ ), and these images were used to calculate the tumor vascular length densities. Combined treatment with radiation and $\mathrm{MnTE}-2-\mathrm{PyP}^{5+}$ resulted in significant tumor devascularization between 48 and $72 \mathrm{~h}$ after radiation. $\mathrm{n}=5$ per group. ${ }^{*} \mathrm{p}=0.05$ versus tumor vascular length density at $0 \mathrm{~h}$. Error bars represent standard deviations. Adapted from Moeller et al. [82].

\section{Brain Cancer}

Two lipophilic Mn porphyrins were tested in a mouse brain tumor study on several glioblastoma and medulloblastoma cell lines and exerted an anticancer effect [131]. A significant anticancer effect was found in the presence of radiation, or temozolomide, or when combined both with radiation and temozolomide $[127,128]$. Lam's group found in a cellular study that the combination of $\mathrm{MnTnBuOE}-2-\mathrm{PyP}^{5+}$ with apoptotic gene and gap junction inhibitor confers potency in the treatment of brain tumors [131]. 
Mn Porphyrins as Radiosensitizers

Mn porphyrins have been shown to radiosensitize tumors to radiation therapy $[82,127,128]$. It is known that HIF- $1 \alpha$ is activated as a consequence of increased levels of reactive species formed by radiation [142]. Increased HIF-1 $\alpha$ activation and consequent upregulation of angiogenic proteins (VEGF and basic fibroblast growth factor) outbalances to some extent the cytotoxic effect of radiation [82]. Based on the existing experimental evidence from a 4T1 mouse breast cancer study with subcutaneous xenografts (fig. 9) [102], the radiosensitizing effect of MnTE-2-PyP ${ }^{5+}$ has been attributed to the suppression of HIF- $1 \alpha$ and its VEGF gene activation, which in turn led to suppression of angiogenesis (fig. 9). In a Balb/c nu/nu mouse brain tumor study, both lipophilic compounds MnTnHex-2-PyP ${ }^{5+}$ and $\mathrm{MnTnBuOE}-2-\mathrm{PyP}^{5+}$ produced similar radiosensitizing effects $[127,128]$.

MnTE-2-PyP ${ }^{5+}$ enhanced radiotherapy and showed a potential to enhance the antitumor immune response: a high number of T lymphocytes, natural killer cells in the spleen, B-cell counts in the blood and spleen, and increased IL-2 levels were found in mice receiving $\mathrm{MnP}$ [132]. The group receiving $\mathrm{MnP}$ plus radiation had reduced intratumoral HIF- $1 \alpha$ and a decreased capacity to secrete TNF- $\alpha$, whereas production of IL- 4 was increased [135]. Moreover, MnTE-2-PyP ${ }^{5+}$ decreased the risk of radiation-induced normal tissue toxicity [133]. While the MnPs studied may theoretically protect tumors as well as normal tissue during radiation, such an effect, if present, has been insignificant [135] and has not diminished the cytotoxic effect of tumor radiation. Such negligible radioprotection of tumors by $\mathrm{MnP}$ relative to normal tissue may result from the differences between cancer and normal cells as a consequence of their differential redox status and transcription profile.

\section{Mn Porphyrins as Chemosensitizers}

$M n P+$ Temozolimide. It was further shown, with the brain tumor cell line D-245 MG in a Balb/c nu/nu mouse subcutaneous tumor xenograft study, that two cationic MnPs, MnTnHex-2-PyP ${ }^{5+}$ and MnTnBuOE-2- $\mathrm{PyP}^{5+}$, enhance temozolomide therapeutic efficiency $[127,128]$.

$M n P+$ Corticosteroid and $M n P+$ Cyclophosphamide. In a cellular lymphoma model, Tome's group showed that MnTE$2-\mathrm{PyP}^{5+}$ accelerated dexamethasone-induced apoptosis in mouse thymic lymphoma cells WEHI7.2 and primary follicular lymphoma FL cells [130]. It also potentiated cyclophosphamide toxicity while inhibiting lymphoma cell growth and attenuating doxorubicin toxicity in $\mathrm{H} 9 \mathrm{c} 2$ cardiomyocytes (immortalized clonal cell line derived from BDIX rat embryonic heart tissue) [130]. The effects are related to the inhibition of $\mathrm{NF}-\kappa \mathrm{B}$ activation by $\mathrm{MnP}$ as a consequence of MnP-driven catalysis of glutathionylation of the $\mathrm{p} 65$ subunit of NF- $\kappa \mathrm{B}$ with $\mathrm{H}_{2} \mathrm{O}_{2}$ (produced by corticosteroid; see under 'Mechanism of action of Mn porphyrins') [107]. In an aqueous system, Fe and less so $\mathrm{Mn}$ porphyrins are able to hydroxylate cyclophospha- mide in the presence of ascorbate, acting as cytochrome P450 mimics [26]. Due to the accumulation of MnPs in tumors, the activation of the prodrug cyclophosphamide would occur in situ in the tumor rather than in the liver.

$M n P+A s c o r b a t e$. Levine's group has pointed to the remarkable anticancer potency of ascorbate given as a single agent either via the intraperitoneal or intravenous route, but not orally [143-146]. The action was ascribed to the enhanced production of peroxide catalyzed by endogenous metalloproteins [144]. Ascorbate was also tested in a combination with other redoxable agents such as quinones; the combined treatment with menadione already has a clinical application for the treatment of prostate cancer [147]. In cellular experiments with 5 different cancer cell lines, MnTE-2-PyP ${ }^{5+}$ and MnTnHex-2-PyP $\mathrm{P}^{5+}$ catalyzed ascorbate oxidation leading to the production of cytotoxic peroxide; $30 \mu \mathrm{M} \mathrm{MnP}$ and $3 \mathrm{mM}$ ascorbate were employed [27]. In an E. coli study, in such a scenario, MnPs acting as prorather than antioxidants imparted oxidative stress, which subsequently induced an adaptive response by upregulating endogenous catalases and peroxidases so that the stressed cells grow as well as the nonstressed cells [148]. A similar action may occur even when $\mathrm{MnP}$ is administered as a single agent due to the high millimolar intracellular levels of ascorbate. E. coli data clearly point to the fact that at least one possible action of MnPs under certain in vivo conditions is an induction of mild oxidative stress (similar to physical exercising), which provokes the upregulation of endogenous antioxidative defenses. Subsequently, we observe antioxidative effects. In a preliminary $4 \mathrm{~T} 1$ mouse breast cancer study, conducted with $2 \times 1 \mathrm{mg} / \mathrm{kg} / \mathrm{day}$ of MnTnHex-2-PyP ${ }^{5+}$ (s.c.) and $2 \times 2 \mathrm{~g} / \mathrm{kg}$ ascorbate (i.p.), tumor growth delay was observed (not reaching statistical significance). The effect can be due at least in part to the increased macrophage infiltration and reduced macrovessel density [27]. More work is needed to identify appropriate concentrations of both $\mathrm{MnP}$ and ascorbate in order to conduct an in vivo study with a significant therapeutic outcome. This will further our insight into the type of action of SOD mimics in vivo.

\section{Mn Porphyrins as Enhancers of Hyperthermia}

MnTE-2-PyP ${ }^{5+}$ largely potentiated hyperthermia [129]. Treatment of mice started 10 days after tumor implantation (day 1). Heat was delivered at $41.5^{\circ} \mathrm{C}$ on days 1,5 and 8 . MnTE$2-\mathrm{PyP}^{5+}$ was delivered at $5 \mathrm{mg} / \mathrm{kg}$ twice per day to C57/BL6 mice carrying the B16F10 melanoma cell line, starting on day 1 until mice were sacrificed on day 9. Nearly full suppression of melanoma growth was observed as a result of this combinatorial treatment [129].

\section{Mn Porphyrins as Cancer Imaging Agents}

In a mouse prostate cancer study, Lascola's group [149] showed that contrast changes of $\mathrm{MnTE}-2-\mathrm{PyP}^{5+}$ are up to 6 -fold greater in tumors than surrounding noncancerous tissues, suggesting its potential as a novel diagnostic tool in de- 
tecting prostate malignancy. In MRI experiments at $7 \mathrm{~T}$, the phantom studies revealed approximately 2 -fold higher $\mathrm{T} 1 \mathrm{re}$ laxivity changes with MnPs than observed with commercially available Gd chelates [149].

\section{Radioprotection}

\section{Rectum Radioprotection}

Radiation proctitis is a common adverse event associated with radiotherapy of tumors in the pelvic region. Archambeau [150] has shown that MnTE-2-PyP ${ }^{5+}$ decreases the severity of both acute and chronic proctitis in rats irradiated with 20 - to $30-\mathrm{Gy}$ protons delivered to a $2.5 \mathrm{-cm}$ segment of the rectum. $\mathrm{MnP}$ was given at $5 \mathrm{mg} / \mathrm{kg}$ s.c. either $1 \mathrm{~h}$ before or $1 \mathrm{~h}$ after irradiation with additional drug administered at weekly intervals thereafter [150]. The study indicates that MnPs may be useful as adjunctive agents for radiotherapy of pelvic tumors.

\section{Pulmonary Radioprotection}

In several rat studies both MnTE-2-PyP ${ }^{5+}$ (1-6 mg/kg/day) and $\mathrm{MnTnHex}-2-\mathrm{PyP}^{5+}(0.05-1 \mathrm{mg} / \mathrm{kg} /$ day $)$ protected lungs from radiation when given daily for a 2 -week period before or as late as 8 weeks after irradiation $[73,151,152]$. In a preliminary nonhuman primate study, $\mathrm{MnTnHex}-2-\mathrm{PyP}^{5+}$ protected lungs from radiation at a dose as low as $0.05 \mathrm{mg} / \mathrm{kg} / \mathrm{day}$, given for 3 months starting $2 \mathrm{~h}$ after radiation [153]. The treatment with MnTnHex-2-PyP ${ }^{5+}$ delayed the onset of radiation-induced CT abnormalities and decreased lung weight, inflammation, edema and epithelial hyperplasia [153]. In a proteomic study, treatment with MnTE-2-PyP ${ }^{5+}$ partially prevented the apparent degradation of filamin and talin, reduced the level of cleaved caspases 3 and 9, and promoted Akt phosphorylation as well as $\beta$-catenin expression after a single dose of $28 \mathrm{~Gy}$ irradiation of the rat right hemithorax [154]. The imidazolium analog MnTDE-2-ImP ${ }^{5+}$ was efficacious in a lung radioprotection model also $[63,138]$.

\section{Whole-Body Radioprotection}

Mouse survival was increased by $80 \%$ when MnTM-2$\mathrm{PyP}^{5+}$ was delivered intraperitoneally for 2 weeks at $5 \mathrm{mg} / \mathrm{kg}$ prior to $8-G y$ whole-body radiation $[155,156]$.

\section{Hematopoietic Stem Cell Radioprotection}

Treatment after whole-body radiation (WBR) with MnTE-2$\mathrm{PyP}^{5+}$ significantly inhibited the increase in reactive oxygen species production and DNA damage in hematopoietic stem cells (HSCs) and the reduction in HSC frequency and clonogenic function induced by WBR. It appears also that MnTE-2$\mathrm{PyP}^{5+}$ inhibited the induction of HSC senescence by WBR, which was shown to occur via the p16 senescence pathway: $\mathrm{MnP}$ suppressed the expression of pl6Ink4a (p16) mRNA in HSCs induced by WBR and improved the long-term and multilineage engraftment of irradiated HSCs after transplantation [157]. In another mouse study, Zhou's group showed that reactive species produced by NADPH oxidase play a causal role in the induction of hematopoietic genomic instability by ionizing radiation [158].

\section{Eye Radioprotection}

Protection of photoreceptors and retinal capillaries by $2.5 \mu \mathrm{M}$ MnTE-2-PyP ${ }^{5+}$ administered into the vitreous humor was observed when the rat eye was exposed to 8- and 28-Gy proton radiation [136].

Therapeutic effects of Mn porphyrins on cancer- and radiation-related injuries are briefly summarized in table 2 .

\section{Central Nervous System Diseases}

The therapeutic effects of porphyrins on central nervous system-related disorders/injuries are briefly summarized in table 3 .

Stroke

There is essentially no efficacious therapy available for the treatment of stroke. The efficacy of 3 cationic Mn pyridyl and imidazolyl porphyrins (MnTE-2-PyP ${ }^{5+}$, MnTnHex-2$\left.\mathrm{PyP}^{5+}, \mathrm{MnTDE}-2-\mathrm{ImP}^{5+}\right)$ in several studies of a rodent model of middle cerebral artery occlusion (MCAO) suggests the remarkable potential of these compounds $[85,106,159,160]$. In such models, ischemia/reperfusion was produced via 90-min MCAO. Reoxygenation at reperfusion leads to the increased levels of superoxide and its progeny, and in turn increases oxidative stress. Increased levels of reactive species subsequently upregulate inflammatory pathways via upregulation of NADPH oxidases, NO synthase and cytokines, which perpetuate oxidative stress, which in turn results in irreversible damage and/or cell death. In MCAO studies we have shown that Mn porphyrins are efficacious if given as a single bolus injection $60 \mathrm{~min}$ before ischemia, and either $5 \mathrm{~min}$ or $90 \mathrm{~min}$ or $6 \mathrm{~h}$ (but not at $12 \mathrm{~h}$ ) after MCAO. The compounds were given to rats either intracerebroventricularly, intravenously or subcutaneously. When given intracerebroventricularly at $5 \mathrm{~min}$ or $90 \mathrm{~min}$ after MCAO, MnTE-2-PyP ${ }^{5+}$ decreased infarct size by $70-77 \%$. The infarct size was decreased by $54 \%$ if given $6 \mathrm{~h}$ after MCAO [160]. Neurological effects were measured on day 7 after MCAO and oxidative stress markers $4 \mathrm{~h}$ after MCAO. Protection was observed in both cortex and caudoputamen, with no effect on body temperature. The imidazolium analog MnTDE-2- $\operatorname{ImP}^{5+}$ was also efficacious [160]. For a single injection of Mn porphyrin, the protective effects were primarily related to the initial oxidative damage, but not to the secondary/continuous oxidative stress. No reduction of infarct volume was detected several weeks after MCAO. However, when MnTDE-2-ImP ${ }^{5+}$ was given to rats intracerebroventricularly at $900 \mathrm{ng}$ bolus dose and $56 \mathrm{ng} / \mathrm{h}$ for a week (via intravenous pumps) - starting at $90 \mathrm{~min}$ after 90 -min 
Table 2. Therapeutic effects of Mn porphyrins in cancer- and radiation-related injuries

\begin{tabular}{|c|c|c|c|c|c|}
\hline \multirow[t]{4}{*}{ Cancer } & monotherapy & skin & MnTE-2-PyP ${ }^{5+}$ & mice & 105 \\
\hline & \multirow[t]{3}{*}{$\begin{array}{l}\text { combinatorial } \\
\text { therapy }\end{array}$} & chemotherapy & $\begin{array}{l}\text { MnTE-2-PyP } 5+ \\
\text { MnTnHex-2-PyP } \\
\text { MnTnBuOE-2-PyP }\end{array}$ & $\begin{array}{l}\text { cells } \\
\text { mice } \\
\text { cells }\end{array}$ & $27,130,127,128,131$ \\
\hline & & chemotherapy + radiation & $\begin{array}{l}\text { MnTnHex-2-PyP } \mathrm{P}^{5+} \\
\text { MnTnBuOE-2-PyP }\end{array}$ & \multirow{2}{*}{ mice } & $\begin{array}{l}82,102,127,128 \\
132,133\end{array}$ \\
\hline & & hyperthermia & MnTE-2-PyP ${ }^{5+}$ & & 195 \\
\hline \multirow{6}{*}{\multicolumn{2}{|c|}{ Radiation injury }} & whole-body radioprotection & $\begin{array}{l}\text { MnTE-2-PyP } \\
\text { MnTM-2-PyP }\end{array}$ & $\begin{array}{l}\text { zebrafish } \\
\text { mice }\end{array}$ & $155-158,196$ \\
\hline & & lung radioprotection & MnTnHex-2-Py $\mathrm{P}^{5+}$ & nonhuman primates & 153 \\
\hline & & eye radioprotection & MnTE-2-PyP ${ }^{5+}$ & rats & 136 \\
\hline & & GI tract - rectum & MnTE-2-PyP $\mathrm{P}^{5+}$ & rats & 150 \\
\hline & & brain radioprotection & MnTDE-2-ImP ${ }^{5+}$ & rats & 137 \\
\hline & & cell radioprotection & $\begin{array}{l}\text { EUK-451 } \\
\text { MnTnHex-2-PyP }\end{array}$ & cells & 43,110 \\
\hline
\end{tabular}

Listed are the formulas of Mn porphyrin, the diseases where the beneficial effects were observed, the type of animal tested and the related references. GI = Gastrointestinal.

MCAO, the efficacy was still present at 8 weeks after MCAO [160]. Suppression of NF-кB activation was observed, indicating an effect of $\mathrm{MnP}$ on signaling pathways (fig. 7). Recently, the more lipophilic analog MnTnHex-2- $\mathrm{PyP}^{5+}$ was tested. It was given to rats intravenously at $5 \mathrm{~min}$ or $6 \mathrm{~h}$ after MCAO at 225 $\mu \mathrm{g} / \mathrm{kg}$ bolus dose and continued with $225 \mu \mathrm{g} / \mathrm{kg}$ s.c. twice daily. Neurological function, measured on day 7, was improved and total infarct size (fig. 10) was decreased with either treatment. The NF- $\kappa \mathrm{B}$ activity ( $6 \mathrm{~h}$ after MCAO) and the expression of TNF- $\alpha$ and IL-6 (24 h after MCAO) were attenuated [85]. After bolus injection of $75 \mu \mathrm{g} / \mathrm{kg}$ i.v. followed by 7 days of twice injections of $225 \mu \mathrm{g} / \mathrm{kg}$ s.c., MnTnHex-2-PyP $\mathrm{P}^{5+}$ accumulated in the brain to approximately $30 \mathrm{ng} / \mathrm{mg}$ tissue which level correlates with a remarkable drug efficacy. Given $\mathrm{M}_{\mathrm{r}}=1,189$, the 30 $\mathrm{ng} / \mathrm{mg}$ tissue relates to approximately $25 \mathrm{nM}$ in fig. 10 . At that time point, levels in plasma are only twice as high, about $59 \mathrm{ng} /$ $\mathrm{ml}$ (approx. $50 \mathrm{nM}$ on the plot in fig. 10) [85].

\section{Subarachnoid Hemorrhage}

MnTnHex-2-PyP ${ }^{5+}$ proved efficacious in a mouse subarachnoid hemorrhage model. Mice underwent perforation of an anterior cerebral artery and were treated with MnTnHex-2-
$\mathrm{PyP}^{5+}$ for 4 days at $225 \mu \mathrm{g} / \mathrm{kg}$ i.p. twice daily. Treatment improved their neurological score and increased diameters of internal carotid, middle and anterior cerebral arteries ipsilateral to the anterior cerebral artery perforation [85]. No differences in basilar artery diameter indicated similar perfusion conditions between groups during vessel casting. There was no effect of $\mathrm{MnP}$ on mean arterial pressure.

\section{Cerebral Palsy}

In a rabbit model, MnTE-2-PyP ${ }^{5+}(12 \mathrm{mg} / \mathrm{kg})$ and MnTn$\mathrm{Hex}_{-2}-\mathrm{PyP}^{5+}$ (at 0.12 and $1.2 \mathrm{mg} / \mathrm{kg}$ ) were given to a dam at $30 \mathrm{~min}$ before and $30 \mathrm{~min}$ after $40-\mathrm{min}$ ischemia (fig. 11). The hydrophilic MnTE-2-PyP $\mathrm{P}^{5+}$, although given at up to 100 -fold higher doses, was ineffective, while approximately 4 orders of magnitude more lipophilic compound, MnTnHex-2-PyP ${ }^{5+}$, was effective at both doses in decreasing significantly postnatal motor deficits. However, when the MnP was given after ischemia, and during perfusion only, it did not reach the brain fast enough (its $\mathrm{t}_{\max }$ determined by MRI was $2 \mathrm{~h}$ ), and the beneficial effect was negligible [161]. Under the same conditions, a combination of ascorbate and trolox $(100 \mathrm{mg} / \mathrm{kg}$ trolox - a derivative of vitamin $\mathrm{E}$ and $1,600 \mathrm{mg} / \mathrm{kg}$ ascorbate) was protective. 


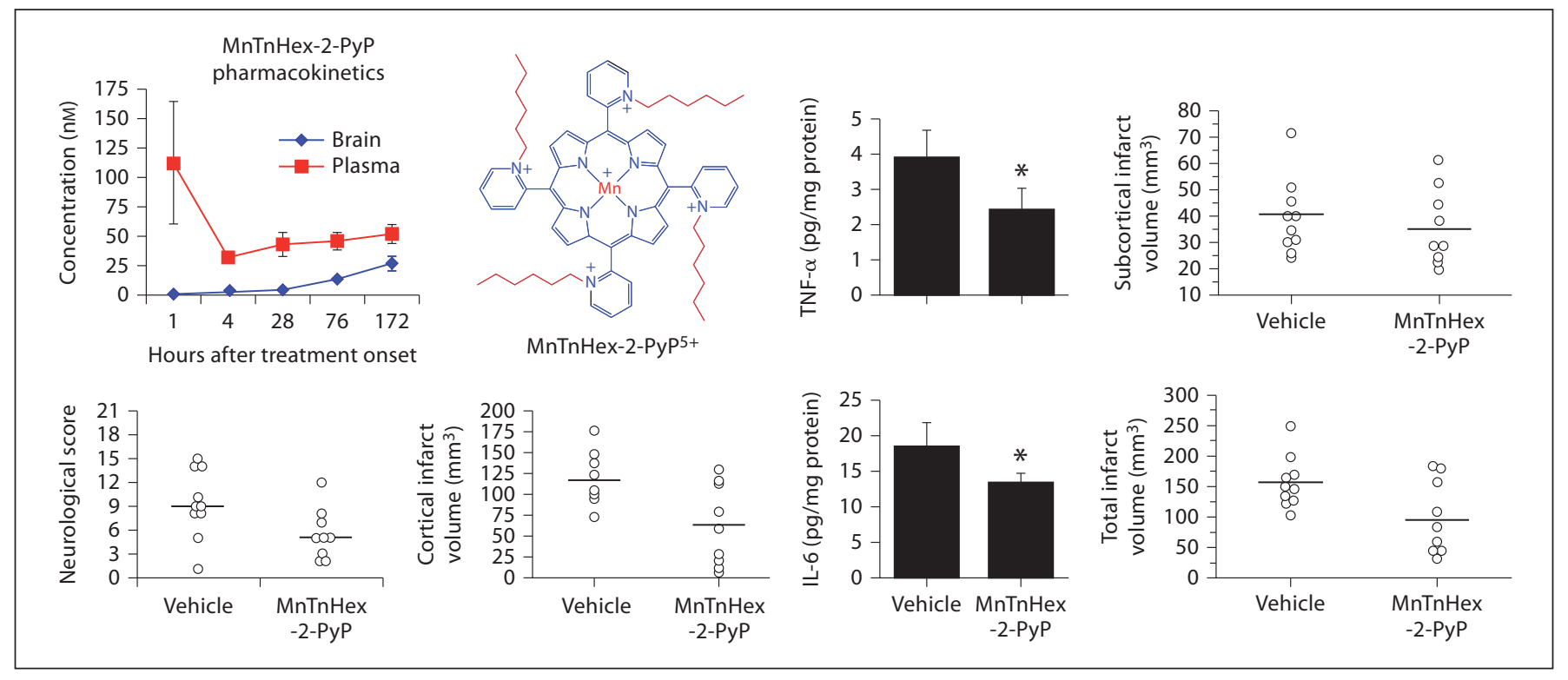

Fig. 10. The effect of MnTnHex-2-PyP ${ }^{5+}$ in a rodent MCAO model of stroke on day 7 after injury. Rats were subjected to 90 min of MCAO. Six hours after reperfusion onset, they were treated with bolus intraarterial $0.3 \mathrm{ml}$ phosphate-buffered saline (vehicle) or $225 \mu \mathrm{g} / \mathrm{kg}$ MnTnHex-2-Py ${ }^{5+}$. The same dose was then given subcutaneously and continued twice daily as subcutaneous injections for 7 days, after which neurological function was assessed. Open circles indicate individual animal values. Horizontal lines indicate group median values. $0=$ No neurological deficit. The neurological score was improved

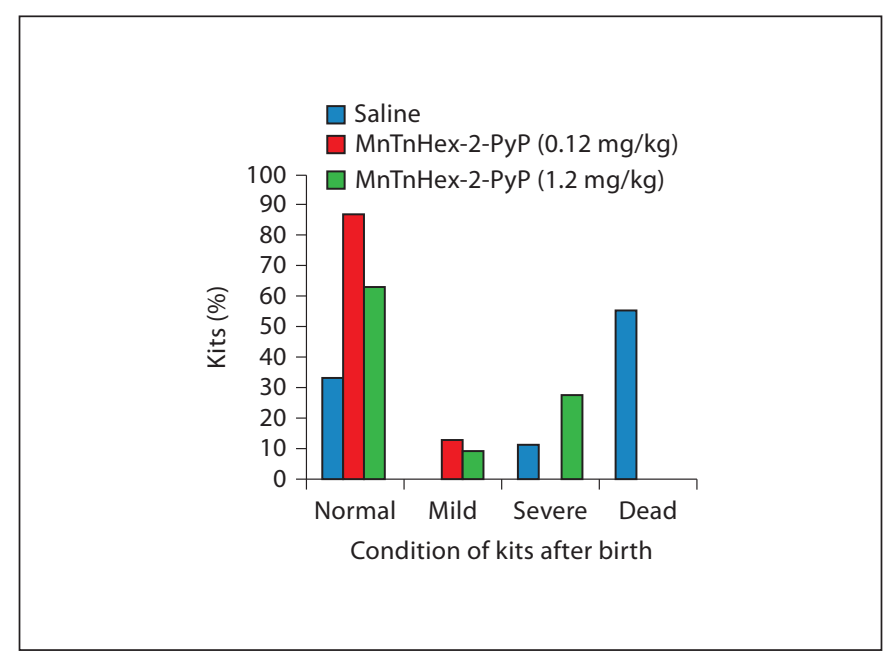

Fig. 11. The rabbit cerebral palsy model. MnTnHex-2-Py $\mathrm{P}^{5+}$ was used at 2 doses, 0.12 and $1.2 \mathrm{mg} / \mathrm{kg}$. The higher dose indicated slight toxicity and suggested that it outbalanced somewhat the benefit of drug. Drug was given intravenously $30 \mathrm{~min}$ before and $30 \mathrm{~min}$ after 40 -min ischemia in two $30-\mathrm{ml}$ volumes (total $60 \mathrm{ml}$ per rabbit dam). The ability of MnTnHex-2-PyP ${ }^{5+}$ to cross several membranes (uterus, placenta, fetus and fetal brain) and enter mitochondria likely contributed to its efficacy. Adapted from Drobyshevsky et al. [161]. in the MnTnHex-2-PyP ${ }^{5+}$ treatment group $(\mathrm{p}=0.04)$. MnTnHex-2$\mathrm{PyP}^{5+}$ decreased infarct volume in the cortex $(\mathrm{p}=0.01)$, which was reflected in a $37 \%$ reduction in total infarct volume $(\mathrm{p}=0.03)$. Infarct size was not changed in the subcortex $(\mathrm{p}=0.58)$. Both TNF- $\alpha$ and IL-6 concentrations were decreased by MnTnHex-2-PyP ${ }^{5+}\left({ }^{*} \mathrm{p}<\right.$ $0.05)$. Pharmacokinetic studies were performed in order to assess the concentration of MnTnHex-2- $\mathrm{PyP}^{5+}$, both in plasma and brain, that corresponds to the beneficial therapeutic outcome. Adapted from Sheng et al. [85].

\section{Spinal Cord Injury}

The generation of reactive oxygen/nitrogen species is an early event following acute mechanical injury; hence the development of antioxidant therapeutic strategies has been considered a promising neuroprotective approach in a combinatorial treatment regimen [162-164]. Sheng et al. [165] have studied the effect of a catalytic antioxidant, MnTDE-2$\mathrm{ImP}^{5+}$, in a mouse spinal cord injury model. The compound offered protection when given intrathecally at a single 2.5 and $5 \mu \mathrm{g} / \mathrm{kg}$ dose at $60 \mathrm{~min}$ after the spinal cord compression [165]. The total damage score and rotarod performance were improved on days 3, 7, 14 and 21 after spinal cord compression. However, the effect did not reach statistical significance when the compound was given intravenously, suggesting that bioavailability is critical in defining efficacy. With single intravenous dosing at 4 and $8 \mathrm{mg} / \mathrm{kg} 15 \mathrm{~min}$ after injury, MnTE-2-PyP $\mathrm{P}^{5+}$ was marginally efficacious and thus shows promise at continuous multiple dosing. Indeed, the most recent data show remarkable efficacy of $\mathrm{MnTE}-2-\mathrm{PyP}^{5+}$ given for a week at $1 \mathrm{mg} / \mathrm{kg}$ s.c. [Floyd et al., unpubl.]. Given the remarkable efficacy of a more lipophilic analog MnTnHex-2$\mathrm{Py}^{5+}$ in a stroke model, its application in spinal cord injury is promising. 
The WW-85 [Fe(III) meso-tetrakis(N-[carboxylatobenzyl] pyridyl)porphyrin] given at $0.43 \mathrm{mg} / \mathrm{kg}$ i.p. at $1 \mathrm{~h}$ after trauma decreased inflammation, nitrotyrosine formation, proinflammatory cytokines (TNF- $\alpha$, IL-1 $\beta$, poly-ADP-ribose polymerase activation, NF- $\mathrm{\kappa}$ B activation) and apoptosis and significantly ameliorated recovery of limb function [166]. Genovese et al. [167] studied the effect of iron porphyrin, FeTSPP ${ }^{3-}$ [Fe(III) meso-tetrakis(4-sulfonatophenyl)porphyrin] in a mouse spinal cord injury model. FeTSPP ${ }^{3-}$ treatment $(10-100 \mathrm{mg} / \mathrm{kg}$, i.p.) decreased the spinal cord inflammation and tissue injury, neutrophil infiltration, nitrotyrosine formation, poly-ADP-ribose polymerase activation, proinflammatory cytokine expression, NF- $\kappa \mathrm{B}$ activation and apoptosis in a dose-dependent manner at 1 and $4 \mathrm{~h}$ after the spinal cord injury. Furthermore, FeTSPP ${ }^{3-}$ ameliorated recovery of limb function (evaluated by motor recovery score) [167].

The metalloporphyrin MnTBAP ${ }^{3-}$ [Mn(III) meso-tetrakis (4-carboxyphenyl)porphyrin] has also been tested in a rat spinal cord injury model by Hachmeister et al. [168]. Intrathecal pretreatment $30 \mathrm{~min}$ before spinal cord injury with 1 $\mathrm{mg} / \mathrm{kg} \mathrm{MnTBAP}{ }^{3-}$ or 4-hour treatment after spinal cord injury with $2.5 \mathrm{mg} / \mathrm{kg}$ MnTBAP $^{3-}$ decreased membrane lipid peroxidation and protein nitration, and increased the number of surviving neurons compared to vehicle controls [168]. In another study, MnTBAP ${ }^{3-}$ was able to partially prevent neuronal loss and apoptosis [169]. When given at 10 and 50 $\mathrm{mg} / \mathrm{kg}$ i.p., it significantly reduced neuronal death in the sections $1-2.5 \mathrm{~mm}$ rostral and $1 \mathrm{~mm}$ caudal from the epicenter compared with that in the vehicle-treated group [169]. The therapeutic impact of neural stem cells was studied by $\mathrm{Yu}$ et al. [170]. During spinal cord injury, the inflammation caused a loss of donor human neural stem cell (hNSC) graft and killed host neurons. The authors studied the protective effect of polylactic coglycolic acid film embedded with MnTBAP $^{3-}$ on the hNSCs [170]. The film was inserted into either $\mathrm{T}_{7-8}$ or $\mathrm{L}_{2-3}$ to cover the ventral side of the implanted porous polylactic coglycolic acid scaffold seeded with hNSCs. The authors showed that $\mathrm{ONOO}^{-}$-triggered protein nitration and the activation of p38 mitogen-activated protein kinase, cytochrome $c$ release, and caspases are involved in the elimination of NSC grafts and killing host neurons. $\mathrm{MnTBAP}^{3-}$ markedly protected hNSCs. Caution needs to be exercised regarding the identity and mechanism of action of $\mathrm{MnTBAP}^{3-}$ (see under 'Purity and identity and assignment of type of action of $\mathrm{Mn}$ porphyrins').

\section{Chronic Morphine Tolerance}

Chronic morphine use eventually ceases to provide an analgesic effect. This is known as chronic morphine tolerance and is ascribed to the oxidative damage of MnSOD and of critical proteins involved in neurotransmission: glutamate transferase and glutamine synthase [171]. The effects of MnPs have been studied in a mouse model of morphine tolerance [172]. At the doses studied, MnTE-2-PyP $\mathrm{P}^{5+}$ and MnTnHex-2-PyP ${ }^{5+}$ did not exert independent analgesic effects; neither drug was efficacious in acutely reversing the established morphine tolerance. However, if given chronically with morphine, both $\mathrm{MnPs}$ inhibited the development of morphine tolerance and expression of inflammatory cytokines in the spinal cord dorsal horn [172]. Morphine tolerance was also associated with the inactivation of the critical endogenous enzyme MnSOD (via protein tyrosine nitration), but not $\mathrm{Cu}, \mathrm{ZnSOD}$ and increased polyADP-ribose polymerase activity and 8-oxo-2'-deoxyguanosine formation in both brain and spinal cord [171]. Mn porphyrins suppressed these responses [172]. MnTnHex-2- $\mathrm{PyP}^{5+}$ was 30 -fold more potent $(0.1 \mathrm{mg} / \mathrm{kg})$ than MnTE-2-PyP ${ }^{5+}(3 \mathrm{mg} /$ $\mathrm{kg}$ ), consistent with its greater lipophilicity.

\section{Neuropathic Pain}

Anticancer drugs such as vincristine, paclitaxel, oxaliplatin, cisplatin and bortezomib exert direct and indirect effects on sensory nerves to induce pain, which results in suffering and limits treatment. Different mechanisms are involved in the development of neuropathic pain and involve inflammation and oxidative stress [173]. Most recently Patti et al. [174] pointed to the N,N-dimethylsphingosine as a key cause of neuropathic pain arising from the sphingomyelin/ceramide pathway. Reactive species have been implicated in the ceramide pathway $[175,176]$. Inhibitors of methyltransferase or ceramidase have been suggested as possible therapeutic strategies. The mediation of the redox-based pathways may be a valid approach also [174-176]. Rats with an experimental painful peripheral neuropathy (the chronic constriction injury of the sciatic nerve model) display heat-evoked hyperalgesia [120]. Chronic constriction injury is a standard model used to screen novel nonnarcotic agents in chronic neuropathic pain. The effect of the nitroxide tempol, a scavenger of a wide range of reactive species [8], on the attenuation of neuropathic pain was reported [120, 177]. Rausaria et al. [44] tested Mn(III) tetracyclohexenylporphyrin ( $\left.\mathrm{MnTCHP}^{+}, \mathrm{SR} 16\right)$ and $\mathrm{MnTE}-2-\mathrm{PyP}^{5+}$ in a neuropathic pain model, where these compounds dosedependently reversed mechanoallodynia.

\section{Amyotrophic Lateral Sclerosis}

Crow's group has successfully tested anionic Fe porphyrin, FeTBAP $^{3-}$ in a G93A amyotrophic lateral sclerosis mouse model [178]. When given at $1 \mathrm{mg} / \mathrm{kg} / \mathrm{day}$, either starting at 40 days of age or at the onset of symptoms (with $2 \mathrm{mg} / \mathrm{kg}$ on the first day), FeTBAP ${ }^{3-}$ extended the survival interval by 1.55 -fold. In a subsequent study, a more potent Mn porphyrin SOD mimic and redox modulator, MnTDE-2-ImP ${ }^{5+}$, was tested at $2.5 \mathrm{mg} /$ $\mathrm{kg}$ delivered from onset of neurological deficit to death; the survival interval was increased 3-fold relative to FeTBAP ${ }^{3-}$.

Equally potent but more lipophilic $\mathrm{MnTnHex}-2-\mathrm{PyP}^{5+}$ (given at $0.1-0.3 \mathrm{mg} / \mathrm{kg}$ i.p., fig. 12 ) was 5 - to 10 -fold more efficacious than MnTDE-2-ImP ${ }^{5+}$ and displayed a similar efficacy 
Fig. 12. The effect of $\mathrm{MnP}$ in the G93A amyotrophic lateral sclerosis mouse model. The effect of $0.3 \mathrm{mg} / \mathrm{kg} /$ day of MnTnHex-2$\mathrm{PyP}^{5+}$ on the survival (a) and motor neuron preservation (b) when delivered intraperitoneally from the onset of disease until death. Adapted from Crow [179].

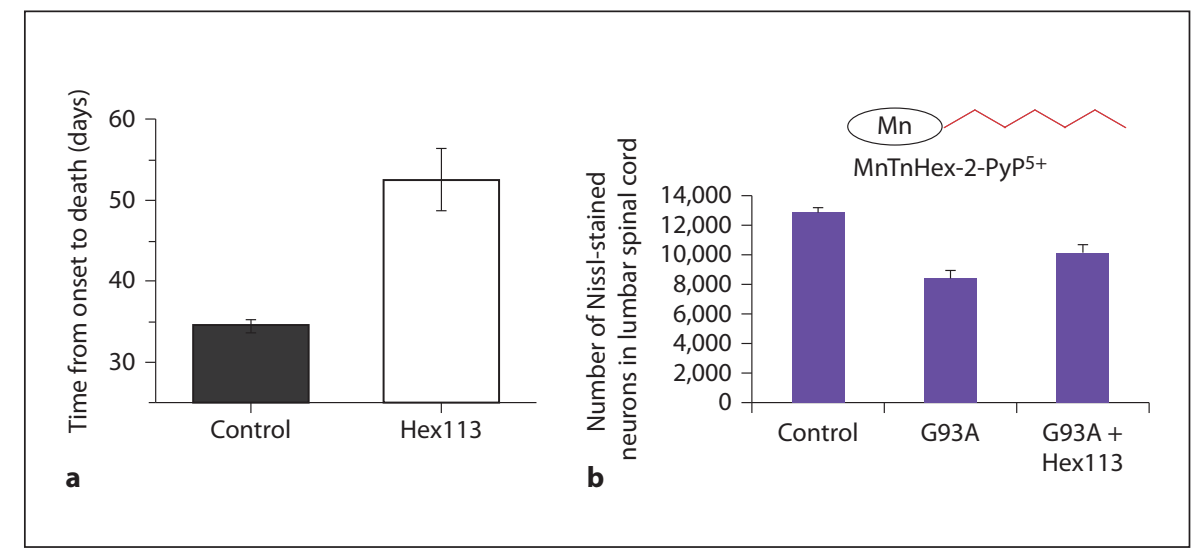

to gadolinium texaphyrin. With the Gd complex, production of reactive species was proposed as a major mode of action [179]. At present, an antioxidant action has been predominantly assigned to MnTnHex-2- $\mathrm{Py}^{5+}$; however, our most recent data suggest that this $\mathrm{MnP}$ may also produce reactive species in vivo (see under 'Mechanism of action').

\section{Parkinson's Disease}

Golden and Patel [180] have successfully employed Mn porphyrins in cellular and animal models of Parkinson's disease.

\section{Epilepsy}

Patel's group studied the role of oxidative stress in epilepsy resulting from mitochondrial dysfunction using cross-bred mutant mice lacking MnSOD and employed the metalloporphyrin antioxidant AEOL11207 (fig. 1). At $5 \mathrm{mg} / \mathrm{kg}$ s.c. given daily (starting at 5 days of age for the duration of the study) AEOL11207-treated Sod2 ${ }^{-/}$mice showed a significant decrease in both the frequency and duration of spontaneous seizures, although seizure severity was not affected. Notably, the average lifespan of AEOL11207-treated Sod2 $2^{-/}$mice was increased compared to vehicle-treated Sod2 $2^{-/-}$mice [181].

\section{Alzheimer's Disease}

St. Clair's group has shown that MnTE-2-PyP $\mathrm{P}^{5+}$ at 0.1 and $1 \mathrm{ng} / \mathrm{ml}$ protected developing neurons against $\beta$-amyloid-induced neuronal death and improved mitochondrial respiration [182]. Neurons were obtained from a homozygous mouse that incorporates the humanized Alzheimer's disease (AD) mutation $\left(A P P^{N L h / N L h} \times P S-1^{P 264 L / P 2641}\right)$, and therefore stimulates natural progression of $\beta$-amyloid pathology observed in AD patients [182].

Oxygen and Glucose Deprivation of Mixed Neuronal/Glial Cortical Cells and Organotypic Hippocampal Slices

In a cellular study, MnTnHex-2-PyP ${ }^{5+}$ and MnTnOct-2$\mathrm{PyP}^{5+}$ were able to protect neurons from oxygen/glucose depri- vation more than hydrophilic compounds; $\mathrm{MnTnOct}-2-\mathrm{Py}^{5+}$ was effective at a $>3$ orders of magnitude lower concentration $(0.01 \mu \mathrm{M})$ than MnTE-2-PyP ${ }^{5+}[183]$.

\section{Diabetes}

MnTE-2-PyP $\mathrm{P}^{5+}$ and $\mathrm{MnTDE}-2-\mathrm{ImP}^{5+}$ are prospective agents in diabetes-related disorders. MnTE-2-PyP $\mathrm{P}^{5+}$ significantly delayed or prevented the death of young nonobese diabetic-severe combined immunodeficient mice when a rapid onset of diabetes was induced with a diabetogenic T-cell clone (BDC-2.5) [184]. Soaking of islet cells in $34 \mu \mathrm{M}$ solution of MnTE-2-PyP ${ }^{5+}$ increased their survival upon isolation: levels of proinflammatory cytokines IL- 6 and IL- 8 and monocyte chemoattractant protein 1 were greatly suppressed and islets gained the capacity to normalize diabetic recipient mice [185]. In streptozotocin-diabetic rats, MnTM-2- $\mathrm{PyP}^{5+}$ suppressed oxidative stress, decreased mortality and extended lifespan. In part such data are explained by the ability of $\mathrm{MnP}$ to protect isocitrate dehydrogenase, a source for NADPH-driven regeneration of endogenous antioxidative defenses $[99,186]$. The data on diabetes are summarized in Batinic-Haberle et al. $[7,8]$.

\section{Toxicity}

While allowing for a wide therapeutic window, Mn porphyrins exert toxicity at higher doses. A limiting acute toxicity is related to blood pressure drop, if administered via the intraperitoneal or intravenous route [187]. Our preliminary data showed that shorter alkyl chain analogs, such as MnTM2-PyP ${ }^{5+}$ and MnTE-2-PyP ${ }^{5+}$, exert a much smaller blood pressure drop than longer alkyl chain analogs. The more lipophilic analogs seem to be more toxic, which have been so far related to increased lipophilicity and thus increased cellular accumulation. Some other effects may possibly be involved. We have done a detailed mouse toxicity study of MnTnHex-2- 
Table 3. Therapeutic effects of porphyrins in central nervous system (CNS)-related disorders/injuries

\begin{tabular}{|c|c|c|c|}
\hline Stroke & $\begin{array}{l}\text { MnTE-2-PyP } \mathrm{P}^{5+} \\
\text { MnTDE-2-ImP } \\
\text { MnTnHex-2-PyP }\end{array}$ & rodents & $85,106,159,160$ \\
\hline Spinal cord injury & $\begin{array}{l}\text { MnTE-2-PyP } \\
\text { MnTDE-2-ImP }^{5+} \\
\text { FeTSPP }^{3-} \\
\text { WW-85 } \\
\text { MnTBAP } \\
\text { M- }\end{array}$ & mice & $6,165-170$ \\
\hline Subarachnoid hemorrhage & MnTnHex-2-PyP $\mathrm{P}^{5+}$ & mice & 85 \\
\hline Cerebral palsy & MnTnHex-2-PyP $\mathrm{P}^{5+}$ & rabbit dams & 161 \\
\hline Amyotrophic lateral sclerosis & $\begin{array}{l}\text { MnTnHex-2-PyP } \\
\text { MnTDE-2-ImP } \\
\text { 5+ }, \text { FeTBAP }^{3-}\end{array}$ & mice & $87,178,179,197$ \\
\hline Epilepsy & AEOL 11207 & mice & 181 \\
\hline Oxygen and glucose deprivation & $\begin{array}{l}\text { MnTE-2-PyP } \mathrm{P}^{5+} \\
\text { MnTDE-2-ImP } \\
\text { MnTnHex-2-PyP } \\
\text { MnTnOct-2-PyP } \\
\text { M+ }\end{array}$ & cells & 183 \\
\hline Staurosporine-induced neurotoxicity & $\begin{array}{l}\text { MnTM-4-PyP }{ }^{5+}, \mathrm{H}_{2} \mathrm{TM}-4-\mathrm{PyP}^{4+}, \mathrm{ZnTM} 4-\mathrm{PyP}^{4+} \\
\text { MnTM-2-PyP }^{5+}, \mathrm{MnTE}^{2}-\mathrm{PyP}^{5+}, \mathrm{MnTBAP}^{3-}, \mathrm{ZnTBAP}^{4-}\end{array}$ & cells & 198 \\
\hline Neuropathic pain & $\mathrm{MnTCHP}^{+}$(SR16), MnTE-2-PyP $\mathrm{P}^{5+}$ & mice & 44,211 \\
\hline Chronic morphine tolerance & $\begin{array}{l}\text { MnTnHex-2-PyP } \mathrm{P}^{5+} \\
\text { MnTE-2-PyP }\end{array}$ & mice & 172 \\
\hline
\end{tabular}

Listed are the diseases where beneficial effects were observed, the Mn porphyrin name, the animal tested and the related references.

$\mathrm{PyP}^{5+}$. Observations, weight measurements and morphopathological studies were performed on the following organs: salivary glands, skin, skeletal muscles, larynx, lymph nodes; lungs, heart, trachea, esophagus, bone marrow, bones; liver, spleen; pancreas, small intestine, stomach; colon, cecum, small intestine, kidneys, urinary bladder, adrenal, uterus, colon, oviduct, ovary; brain; eye and adnexae. MnP was delivered for a month twice daily subcutaneously at a total daily dose of $0.2-5 \mathrm{mg} / \mathrm{kg}$. The drug caused skin (mild inflammation) and brain (acute degeneration of hippocampal neurons) toxicity at 1, 3 and $5 \mathrm{mg} / \mathrm{kg} / \mathrm{day}$. A coloration of liver Kupfer cells was also observed. No toxicity was observed when the $\mathrm{MnP}$ was given at 0.2 and $0.5 \mathrm{mg} / \mathrm{kg} /$ day doses. Preliminary data showed that when the mice were left without the drug for another month after a month of $0.2-5 \mathrm{mg} / \mathrm{kg} / \mathrm{day}$ injections, these toxic effects disappeared.

\section{Conclusions and Future Directions}

Cationic, water-soluble Mn porphyrins are potential therapeutics for the treatment of different diseases that have oxidative stress in common as a mechanism of injury. Herein we summarized their effects in cancer (in particular in combination with radiation and chemotherapy) and in central nervous system injuries, because these are conditions where drugs are needed. Both cancer and stroke are prevalent pathological conditions and will become even more prevalent as the world population ages. The efficacy of those compounds, reported from several independent groups, is obvious and substantial and is in part related to their ability to accumulate in critical cellular compartments (mitochondria and nucleus), cross the bloodbrain barrier, effectively scavenge reactive species, and couple with cellular reductants and cellular signaling proteins. Many factors involved in the actions of $\mathrm{Mn}$ porphyrins in vivo complicate the understanding of the mechanistic aspects of therapeutic effects: (1) numerous reactive species involved; (2) sig- 
naling proteins whose redox-active amino acids, such as cysteine, couple with MnPs; (3) reductants involved in the redox coupling with MnPs such as ascorbate, glutathione, tetrahydrobiopterin and uric acid; (4) multiple oxidation states of MnPs involved, and (5) different subcellular compartmentalization. Thus, more work is needed to fully comprehend the nature of the beneficial effects of Mn porphyrins which we routinely observe. For that purpose additional analogs have been synthesized, including Fe porphyrins. Also, future work will concentrate on the development of less toxic analogs. The good manufacturing practice campaign is in progress to obtain investigational new drug approval from the Food and Drug Administration and initialize clinical trials for several MnPs.

\section{Acknowledgements}

The authors acknowledge the financial help from Duke University's CTSA grant 1 UL 1 RR024128-01 from NCRR/NIH (to A.T., I.B.H., I.S., T.W., H.S., D.S.W., M.L., A.A.), W.H. Coulter Translational Partners Grant Program (to I.B.H., I.S., A.T.), NIH U19AI067798 (Z.V., I.B.H. and A.T.) and NIH/NCI Duke Comprehensive Cancer Center Core Grant (5-P30-CA14236-29; to I.S.), and IBH general research funds (to A.T.). I.B.H., D.S.W. and I.S. are consultants with BioMimetix Pharmaceuticals Inc.

\section{Appendix}

Charges of porphyrins are omitted in the figures for simplicity; $\mathrm{ONOO}^{-}+\mathrm{ONOOH}=$ peroxynitrite; given its $\mathrm{pK}_{\mathrm{a}}=6.6$ at $\mathrm{pH}$ 7.8 , peroxynitrite exists predominantly as $\mathrm{ONOO}^{-} ; \mathrm{O}_{2}^{\overline{2}}=$ superoxide; $\cdot \mathrm{NO}=$ nitric oxide; $\mathrm{CO}_{\overline{3}}^{\overline{3}}=$ carbonate radical; $\mathrm{MnP}=\mathrm{Mn}$ porphyrin; $5,10,15,20=$ meso position on porphyrin ring (fig. 1 ). When cationic porphyrins bear a $5+$ charge, they have $\mathrm{Mn}$ in the
+3 oxidation state $\left(\mathrm{Mn}^{\mathrm{III}} \mathrm{P}^{5+}\right)$, and with a $4+$ total charge $\mathrm{Mn}$ is in $+2\left(\mathrm{Mn}^{\mathrm{II}} \mathrm{P}^{4+}\right)$ or +4 oxidation states $\left(\mathrm{O}=\mathrm{Mn}^{\mathrm{IV}} \mathrm{P}^{4+}\right)$; MnTAlkyl-2$\mathrm{PyP}^{5+}=\mathrm{Mn}(\mathrm{III})$ meso-tetrakis(N-alkylpyridinium-2-yl)porphyrin, the alkyl being methyl (M, AEOL10112), ethyl (E, AEOL10113, FBC007), n-hexyl (nHex), n-heptyl (nHep), n-octyl (nOct); MnTDE-2-ImP ${ }^{5+}=\mathrm{Mn}(\mathrm{III})$ meso-tetrakis(N,N'-diethylimidazolium-2-yl)porphyrin, AEOL10150; $\mathrm{Mn}^{\mathrm{II}} \mathrm{Br}_{8} \mathrm{TM}-4-\mathrm{PyP}^{4+}=\mathrm{Mn}$ (II) $\beta$-octabromo-meso-tetrakis(N-methylpyridinium-4-yl)porphyrin; $\mathrm{MnBr}_{8} \mathrm{TM}-3$ - $\mathrm{PyP}^{4+}=\mathrm{Mn}(\mathrm{II}) \quad \beta$-octabromo-meso-tetrakis (N-methylpyridinium-3-yl)porphyrin; $\mathrm{Mn}^{\mathrm{III}} \mathrm{TCPP}^{3-}=\mathrm{Mn}(\mathrm{III})$ meso-tetrakis(4-carboxyphenyl)porphyrin (also $\mathrm{Mn}^{\mathrm{III}} \mathrm{TBAP}^{3-}$, also abbreviated as MnTBAP); MnTTEG-2-PyP ${ }^{5+}=\mathrm{Mn}$ (III) meso-tetrakis[N-(1-[2-(2[-2-methoxy]ethoxy)ethoxy]ethyl)pyridinium-2-yl]porphyrin; AEOL11207 = Mn(III) 5,15-bis(methylcarboxylato)-10,20-bis(trifluoromethyl)porphyrin; FeTSPP ${ }^{3-}=$ $\mathrm{Fe}$ (III) meso-tetrakis(4-sulfonatophenyl)porphyrin; $\mathrm{FeT}(2,4,6$ $\left.\mathrm{Me}_{3}-3,5-\left(\mathrm{SO}_{3}\right)_{2}-\mathrm{P}\right) \mathrm{P}^{7-}=\mathrm{Fe}(\mathrm{III})$ meso-tetrakis (2,4,6-trimethyl3,5-disulfonatophenyl)porphyrin; FeTTEG-2-PyP ${ }^{5+}=\mathrm{Fe}(\mathrm{III}) \mathrm{me}-$ so-tetrakis[N-(1-[2-(2[-2-methoxy]ethoxy)ethoxy]ethyl)pyridinium-2-yl] porphyrin, FP15; WW-85 = Fe(III) meso-tetrakis $(\mathrm{N}$-carboxylatobenzylpyridyl)porphyrin; INO-4885 = Fe(III) meso-tetrakis[N-(4-carboxylatobenzyl)pyridinium-2-yl]porphyrin; $[\mathrm{MnBVDME}]_{2}=\mathrm{Mn}(\mathrm{II})$ biliverdin IX dimethylester; MnTrM-2-corrole $\mathrm{e}^{3+}=\mathrm{Mn}$ (III) meso-tris(N-methylpyridinium-2-yl) corrole; $\mathrm{MnTrF}_{5} \mathrm{P}-\beta\left(\mathrm{SO}_{3}\right)_{2}$-corrole $^{2-}=\mathrm{Mn}(\mathrm{III})$ meso-tris (pentafluorophenyl)- $\beta$-bis(sulfonato)corrole; salen $=\mathrm{N}, \mathrm{N}$ '-bis(salicylideneamino)ethane; tempo $=2,2,6,6$,-tetramethylpiperidine-1-oxyl; tempol $=4$-OH-2,2,6,6,-tetramethylpiperidine-1oxyl; $\mathrm{P}_{\mathrm{OW}}=$ coefficient which describes the partition between $\mathrm{n}$ octanol and water; $\mathrm{R}_{\mathrm{f}}=$ thin-layer chromatographic retention factor that presents the ratio between the solvent and compound path in 1:1:8 = sat $\mathrm{KNO}_{3}(\mathrm{aq}): \mathrm{H}_{2} \mathrm{O}$ :acetonitrile; $\mathrm{E}_{\frac{1}{2}}=$ half-wave reduction potential; $\mathrm{NHE}=$ normal hydrogen electrode; $\mathrm{SOD}=$ superoxide dismutase; HIF- $1 \alpha=$ hypoxia-inducible factor-1, $\alpha$-subunit; $\mathrm{NF}-\kappa \mathrm{B}=$ nuclear factor $\kappa \mathrm{B}$; AP-1 = activator protein-1; $\mathrm{MCAO}=$ middle cerebral artery occlusion. $\mathrm{VEGF}=$ vascular endothelial growth factor; i.v. = intravenous; i.p. = intraperitoneal; s.c. $=$ subcutaneous.

\section{References}

$>1$ Gutierrez-Merino C, Lopez-Sanchez C, Lagoa R, Samhan-Arias AK, Bueno C, Garcia-Martinez V: Neuroprotective actions of flavonoids. Curr Med Chem 2011;18:11951212.

-2 Ndhlala AR, Moyo M, Van Staden J: Natural antioxidants: fascinating or mythical biomolecules? Molecules 2010;15:6905-6930.

$>3$ Augustyniak A, Bartosz G, Cipak A, Duburs G, Horakova L, Luczaj W, Majekova M, Odysseos AD, Rackova L, Skrzydlewska E, Stefek M, Strosova M, Tirzitis G, Venskutonis PR, Viskupicova J, Vraka PS, Zarkovic N: Natural and synthetic antioxidants: an updated overview. Free Radic Res 2010;44: 1216-1262.
4 Kizhakekuttu TJ, Widlansky ME: Natural antioxidants and hypertension: promise and challenges. Cardiovasc Ther 2010;28:e20-32.

5 Zhao B: Natural antioxidants protect neurons in Alzheimer's disease and Parkinson's disease. Neurochem Res 2009;34:630-638.

-6 Batinic-Haberle I, Rajic Z, Tovmasyan A, Reboucas JS, Ye X, Leong KW, Dewhirst MW, Vujaskovic Z, Benov L, Spasojevic I: Diverse functions of cationic Mn(III) N-substituted pyridylporphyrins, recognized as SOD mimics. Free Radic Biol Med 2011;51:10351053.

7 Batinic-Haberle I, Reboucas JS, Benov L, Spasojevic I: Chemistry, biology and medical effects of water soluble metalloporphyrins; in Kadish KM, Smith KM, Guillard R (eds): Handbook of Porphyrin Science. Singapore, World Scientific, 2011, vol 11, pp 291-393.
8 Batinic-Haberle I, Reboucas JS, Spasojevic I: Superoxide dismutase mimics: chemistry, pharmacology, and therapeutic potential. Antioxid Redox Signal 2010;13:877-918.

$\checkmark 9$ Miriyala S, Spasojevic I, Tovmasyan A, Salvemini D, Vujaskovic Z, St Clair D, Batinic-Haberle I: Manganese superoxide dismutase, MnSOD and its mimics. Biochim Biophys Acta 2012;1822:794-814.

10 Batinic-Haberle I, Spasojevic I, Tse HM, Tovmasyan A, Rajic Z, St Clair DK, Vujaskovic Z, Dewhirst MW, Piganelli JD: Design of Mn porphyrins for treating oxidative stress injuries and their redox-based regulation of cellular transcriptional activities. Amino Acids 2012;42:95-113. 
-11 Colon J, Herrera L, Smith J, Patil S, Komanski C, Kupelian P, Seal S, Jenkins DW, Baker $\mathrm{CH}$ : Protection from radiation-induced pneumonitis using cerium oxide nanoparticles. Nanomedicine 2009;5:225-231.

12 Goldstein S, Czapski G, Heller A: Osmium tetroxide, used in the treatment of arthritic joints, is a fast mimic of superoxide dismutase. Free Radic Biol Med 2005;38:839-845.

-13 Kim J, Takahashi M, Shimizu T, Shirasawa T, Kajita M, Kanayama A, Miyamoto Y: Effects of a potent antioxidant, platinum nanoparticle, on the lifespan of Caenorhabditis elegans. Mech Ageing Dev 2008;129:322-331.

-14 James AM, Cocheme HM, Smith RA, Murphy MP: Interactions of mitochondria-targeted and untargeted ubiquinones with the mitochondrial respiratory chain and reactive oxygen species. Implications for the use of exogenous ubiquinones as therapies and experimental tools. J Biol Chem 2005;280:21295-21312.

15 Murphy MP: Targeting lipophilic cations to mitochondria. Biochim Biophys Acta 2008; 1777:1028-1031.

-16 Smith RA, Murphy MP: Animal and human studies with the mitochondria-targeted antioxidant MitoQ. Ann NY Acad Sci 2010;1201: 96-103.

$\checkmark 17$ Shaffer SG, O’Neill DH, Thibeault DW: Administration of bovine superoxide dismutase fails to prevent chronic pulmonary sequelae of neonatal oxygen exposure in the rat. J Pediatr 1987;110:942-946.

18 Archibald FS, Fridovich I: Manganese, superoxide dismutase, and oxygen tolerance in some lactic acid bacteria. J Bacteriol 1981; 146:928-936.

19 Al-Maghrebi M, Fridovich I, Benov L: Manganese supplementation relieves the phenotypic deficits seen in superoxide-dismutasenull Escherichia coli. Arch Biochem Biophys 2002;402:104-109.

-20 Munroe W, Kingsley C, Durazo A, Gralla EB, Imlay JA, Srinivasan C, Valentine JS: Only one of a wide assortment of manganese-containing SOD mimicking compounds rescues the slow aerobic growth phenotypes of both Escherichia coli and Saccharomyces cerevisiae strains lacking superoxide dismutase enzymes. J Inorg Biochem 2007;101:1875-1882.

-21 Batinic-Haberle I, Benov L, Spasojevic I, Fridovich I: The ortho effect makes manganese(III) meso-tetrakis(N-methylpyridinium-2-yl)porphyrin a powerful and potentially useful superoxide dismutase mimic. J Biol Chem 1998;273:24521-24528.

22 Tovmasyan A, Weitner T, Sheng H, Lu M, Rajic Z, Warner DS, Spasojevic I, Reboucas JS, Benov L, Batinic-Haberle I: Differential coordination demands in Fe vs Mn watersoluble cationic metalloporphyrins translates into remarkably different aqueous redox chemistry and biology. Inorg Chem, in revision.
23 Pasternack RF, Halliwell B: Superoxide dismutase activities of an iron porphyrin and other iron complexes. J Am Chem Soc 1979; 101:1026-1031.

24 Rajic Z, Tovmasyan A, Spasojevic I, Sheng H, Lu M, Li AM, Gralla EB, Warner DS, Benov L, Batinic-Haberle I: A new SOD mimic, $\mathrm{Mn}$ (III) ortho N-butoxyethylpyridylporphyrin, combines superb potency and lipophilicity with low toxicity. Free Radic Biol Med 2012;52:1828-1834.

25 Batinic-Haberle I, Benov L, Spasojevic I, Hambright P, Crumbliss AL, Fridovich I: The relationship between redox potentials, proton dissociation constants of pyrrolic nitrogens, and in vitro and in vivo superoxide dismutase activities of manganese(III) and iron(III) cationic and anionic porphyrins. Inorg Chem 1999;38:4011-4022.

-26 Spasojevic I, Colvin OM, Warshany KR, Batinic-Haberle I: New approach to the activation of anti-cancer pro-drugs by metalloporphyrin-based cytochrome P450 mimics in all-aqueous biologically relevant system. J Inorg Biochem 2006;100:1897-1902.

27 Ye X, Fels D, Tovmasyan A, Aird KM, Dedeugd C, Allensworth JL, Kos I, Park W, Spasojevic I, Devi GR, Dewhirst MW, Leong KW, Batinic-Haberle I: Cytotoxic effects of $\mathrm{Mn}$ (III) $\mathrm{N}$-alkylpyridylporphyrins in the presence of cellular reductant, ascorbate. Free Radic Res 2011;45:1289-1306.

28 Halliwell B, Gutteridge JMC: Free Radicals in Biology and Medicine. New York, Oxford University Press, 2007.

29 O'Shea SK, Wang W, Wade RS, Castro CE: Selective oxygen transfers with iron(III) porphyrin nitrite. J Org Chem 1996;61:6388-6395.

30 Oszajca M, Franke A, Brindell M, Stochel G, van Eldik R: Mechanistic studies on the reactions of cyanide with a water-soluble Fe(III) porphyrin and their effect on the binding of NO. Inorg Chem 2011;50:3413-3424.

31 Laverman LE, Ford PC: Mechanistic studies of nitric oxide reactions with water soluble iron(II), cobalt(II), and iron(III) porphyrin complexes in aqueous solutions: implications for biological activity. J Am Chem Soc 2001;123:11614-11622.

32 Faulkner KM, Liochev SI, Fridovich I: Stable $\mathrm{Mn}$ (III) porphyrins mimic superoxide dismutase in vitro and substitute for it in vivo. J Biol Chem 1994;269:23471-23476.

33 Liu W, Groves JT: Manganese porphyrins catalyze selective $\mathrm{C}-\mathrm{H}$ bond halogenations. J Am Chem Soc 2010;132:12847-12849.

34 Radovits T, Beller CJ, Groves JT, Merkely B, Karck M, Szabo C, Szabo G: Effects of FP15, a peroxynitrite decomposition catalyst on cardiac and pulmonary function after cardiopulmonary bypass. Eur J Cardiothorac Surg 2012;41:391-396.

-35 Umile TP, Groves JT: Catalytic generation of chlorine dioxide from chlorite using a watersoluble manganese porphyrin. Angew Chem Int Ed Engl 2011;50:695-698.
36 Ferrer-Sueta G, Manta B, Botti H, Radi R, Trujillo M, Denicola A: Factors affecting protein thiol reactivity and specificity in peroxide reduction. Chem Res Toxicol 2011;24: 434-450.

37 Bartesaghi S, Wenzel J, Trujillo M, Lopez M, Joseph J, Kalyanaraman B, Radi R: Lipid peroxyl radicals mediate tyrosine dimerization and nitration in membranes. Chem Res Toxicol 2010;23:821-835.

-38 Batinic-Haberle I, Cuzzocrea S, Reboucas JS, Ferrer-Sueta G, Mazzon E, Di Paola R, Radi R, Spasojevic I, Benov L, Salvemini D: Pure MnTBAP selectively scavenges peroxynitrite over superoxide: comparison of pure and commercial MnTBAP samples to MnTE-2$\mathrm{PyP}$ in two models of oxidative stress injury, an SOD-specific Escherichia coli model and carrageenan-induced pleurisy. Free Radic Biol Med 2009;46:192-201.

-39 Moreno DM, Marti MA, De Biase PM, Estrin DA, Demicheli V, Radi R, Boechi L: Exploring the molecular basis of human manganese superoxide dismutase inactivation mediated by tyrosine 34 nitration. Arch Biochem Biophys 2011;507:304-309.

- 40 Szabo C, Ischiropoulos H, Radi R: Peroxynitrite: biochemistry, pathophysiology and development of therapeutics. Nat Rev Drug Discov 2007;6:662-680.

-41 Mahmood J, Jelveh S, Calveley V, Zaidi A, Doctrow SR, Hill RP: Mitigation of radiation-induced lung injury by genistein and EUK-207. Int J Radiat Biol 2011;87:889-901.

- 42 Melov S, Doctrow SR, Schneider JA, Haberson J, Patel M, Coskun PE, Huffman K, Wallace DC, Malfroy B: Lifespan extension and rescue of spongiform encephalopathy in superoxide dismutase 2 nullizygous mice treated with superoxide dismutase-catalase mimetics. J Neurosci 2001;21:8348-8353.

43 Vorotnikova E, Rosenthal RA, Tries M, Doctrow SR, Braunhut SJ: Novel synthetic SOD/ catalase mimetics can mitigate capillary endothelial cell apoptosis caused by ionizing radiation. Radiat Res 2010;173:748-759.

44 Rausaria S, Ghaffari MM, Kamadulski A, Rodgers K, Bryant L, Chen Z, Doyle T, Shaw MJ, Salvemini D, Neumann WL: Retooling manganese(III) porphyrin-based peroxynitrite decomposition catalysts for selectivity and oral activity: a potential new strategy for treating chronic pain. J Med Chem 2011;54: 8658-8669.

45 Rausaria S, Kamadulski A, Rath NP, Bryant L, Chen Z, Salvemini D, Neumann WL: Manganese(III) complexes of bis(hydroxyphenyl)dipyrromethenes are potent orally active peroxynitrite scavengers. J Am Chem Soc 2011;133:4200-4203.

46 Eckshtain M, Zilbermann I, Mahammed A, Saltsman A, Okun Z, Maimon E, Cohen H, Meyerstein D, Gross Z: Superoxide dismutase activity of corrole metal complexes. Dalton Trans 2009;38:7879-7882. 
-47 Eckshtain M, Zilbermann I, Mahammed A, Saltsman I, Okun Z, Maimon E, Cohen H, Meyerstein D, Gross Z: Superoxide dismutase activity of corrole metal complexes. Dalton Trans 2009:7879-7882.

-48 Kanamori A, Catrinescu MM, Mahammed A, Gross Z, Levin LA: Neuroprotection against superoxide anion radical by metallocorroles in cellular and murine models of optic neuropathy. J Neurochem 2010;114: 488-498.

-49 Kupershmidt L, Okun Z, Amit T, Mandel S, Saltsman I, Mahammed A, Bar-Am O, Gross Z, Youdim MB: Metallocorroles as cytoprotective agents against oxidative and nitrative stress in cellular models of neurodegeneration. J Neurochem 2010;113:363-373.

50 Mahammed A, Gross Z: Iron and manganese corroles are potent catalysts for the decomposition of peroxynitrite. Angew Chem Int Ed Engl 2006;45:6544-6547.

51 Mahammed A, Gross Z: Highly efficient catalase activity of metallocorroles. Chem Commun (Camb) 2010;46:7040-7042.

52 Preihs C, Magda D, Sessler JL: Crown ether functionalized texaphyrin monomers and dimers. J Porphyr Phthalocyanines 2011;15: 539-546.

-53 Sessler JL, Miller RA: Texaphyrins: new drugs with diverse clinical applications in radiation and photodynamic therapy. Biochem Pharmacol 2000;59:733-739.

-54 Young SW, Qing F, Harriman A, Sessler JL, Dow WC, Mody TD, Hemmi GW, Hao Y, Miller RA: Gadolinium(III) texaphyrin: a tumor selective radiation sensitizer that is detectable by MRI. Proc Natl Acad Sci USA 1996;93:6610-6615.

-55 Reboucas JS, De Freitas-Silva G, Spasojevic I, Idemori YM, Benov L, Batinic-Haberle I: Impact of electrostatics in redox modulation of oxidative stress by $\mathrm{Mn}$ porphyrins: protection of SOD-deficient Escherichia coli via alternative mechanism where $\mathrm{Mn}$ porphyrin acts as an Mn carrier. Free Radic Biol Med 2008;45:201-210.

-56 Spasojevic I, Batinic-Haberle I, Reboucas JS, Idemori YM, Fridovich I: Electrostatic contribution in the catalysis of $\mathrm{O}_{2}{ }^{*}$ - dismutation by superoxide dismutase mimics. $\mathrm{Mn}^{\mathrm{III}} \mathrm{TE}$ $2-\mathrm{PyP}^{5+}$ versus $\mathrm{Mn}^{\mathrm{III}} \mathrm{Br}_{8} \mathrm{~T}-2-\mathrm{PyP}^{+}$. J Biol Chem 2003;278:6831-6837.

-57 Reboucas JS, Spasojevic I, Tjahjono DH, Richaud A, Mendez F, Benov L, BatinicHaberle I: Redox modulation of oxidative stress by Mn porphyrin-based therapeutics: the effect of charge distribution. Dalton Trans 2008:1233-1242.

58 Desideri A, Falconi M, Parisi V, Morante S, Rotilio G: Is the activity-linked electrostatic gradient of bovine $\mathrm{Cu}, \mathrm{Zn}$ superoxide dismutases conserved in homologous enzymes irrespective of the number and distribution of charges? Free Radic Biol Med 1988;5:313317.
Getzoff ED, Tainer JA, Weiner PK, Kollman PA, Richardson JS, Richardson DC: Electrostatic recognition between superoxide and copper, zinc superoxide dismutase. Nature 1983;306:287-290.

60 Zhou HX, Wong KY, Vijayakumar M: Design of fast enzymes by optimizing interaction potential in active site. Proc Natl Acad Sci USA 1997;94:12372-12377.

61 McGovern T, Day BJ, White CW, Powell WS, Martin JG: AEOL10150: a novel therapeutic for rescue treatment after toxic gas lung injury. Free Radic Biol Med 2011;50:602-608.

62 O’Neill HC, Orlicky DJ, Hendry-Hofer TB, Loader JE, Day BJ, White CW: Role of reactive oxygen and nitrogen species in olfactory epithelial injury by the sulfur mustard analogue 2-chloroethyl ethyl sulfide. Am J Respir Cell Mol Biol 2011;45:323-331.

63 Rabbani ZN, Salahuddin FK, Yarmolenko P, Batinic-Haberle I, Thrasher BA, GauterFleckenstein B, Dewhirst MW, Anscher MS, Vujaskovic Z: Low molecular weight catalytic metalloporphyrin antioxidant AEOL 10150 protects lungs from fractionated radiation. Free Radic Res 2007;41:1273-1282.

-64 O’Neill HC, White CW, Veress LA, HendryHofer TB, Loader JE, Min E, Huang J, Rancourt RC, Day BJ: Treatment with the catalytic metalloporphyrin AEOL 10150 reduces inflammation and oxidative stress due to inhalation of the sulfur mustard analog 2-chloroethyl ethyl sulfide. Free Radic Biol Med 2010;48:1188-1196.

65 Batinic-Haberle I, Liochev SI, Spasojevic I, Fridovich I: A potent superoxide dismutase mimic: manganese beta-octabromo-meso-tetrakis-(N-methylpyridinium-4-yl) porphyrin. Arch Biochem Biophys 1997;343: 225-233.

66 De Freitas-Silva G, Reboucas JS, Spasojevic I, Benov L, Idemori YM, Batinic-Haberle I: SOD-like activity of $\mathrm{Mn}$ (II) beta-octabromo-meso-tetrakis(N-methylpyridinium-3yl)porphyrin equals that of the enzyme itself. Arch Biochem Biophys 2008;477:105-112.

67 Kachadourian R, Batinić-Haberle I, Fridovich I: Syntheses and superoxide dismuting activities of partially $(1-4) \beta$-chlorinated derivatives of manganese(III) meso-tetrakis (N-ethylpyridinium-2-yl)porphyrin. Inorg Chem 1999;38:391-396.

68 Kos I, Reboucas JS, De Freitas-Silva G, Salvemini D, Vujaskovic Z, Dewhirst MW, Spasojevic I, Batinic-Haberle I: Lipophilicity of potent porphyrin-based antioxidants: comparison of ortho and meta isomers of $\mathrm{Mn}(\mathrm{III}) \mathrm{N}$-alkylpyridylporphyrins. Free Radic Biol Med 2009;47:72-78.

69 Kos I, Benov L, Spasojevic I, Reboucas JS, Batinic-Haberle I: High lipophilicity of meta $\mathrm{Mn}(\mathrm{III}) \mathrm{N}$-alkylpyridylporphyrin-based superoxide dismutase mimics compensates for their lower antioxidant potency and makes them as effective as ortho analogues in protecting superoxide dismutase-deficient Escherichia coli. J Med Chem 2009;52:7868-7872.
0 Spasojevic I, Chen Y, Noel TJ, Fan P, Zhang L, Reboucas JS, St Clair DK, Batinic-Haberle I: Pharmacokinetics of the potent redoxmodulating manganese porphyrin, MnTE$2-\mathrm{PyP}(5+)$, in plasma and major organs of B6C3F1 mice. Free Radic Biol Med 2008;45: 943-949.

71 Spasojevic I, Chen Y, Noel TJ, Yu Y, Cole MP, Zhang L, Zhao Y, St Clair DK, BatinicHaberle I: Mn porphyrin-based superoxide dismutase (SOD) mimic, MnIIITE-2-PyP5+, targets mouse heart mitochondria. Free Radic Biol Med 2007;42:1193-1200.

72 Spasojevic I, Li AM, Tovmasyan A, Rajic Z, Salvemini D, St. Clair D, Valentine JS, Vujaskovic Z, Gralla EB, Batinic-Haberle I: Accumulation of porphyrin-based SOD mimics in mitochondria is proportional to their lipophilicity. Free Radic Biol Med 2010; 49:S199.

73 Gauter-Fleckenstein B, Fleckenstein K, Owzar K, Jiang C, Batinic-Haberle I, Vujaskovic $\mathrm{Z}$ : Comparison of two Mn porphyrin-based mimics of superoxide dismutase in pulmonary radioprotection. Free Radic Biol Med 2008;44:982-989.

74 Tovmasyan AG, Rajic Z, Spasojevic I, Reboucas JS, Chen X, Salvemini D, Sheng H, Warner DS, Benov L, Batinic-Haberle I: Methoxy-derivatization of alkyl chains increases the in vivo efficacy of cationic Mn porphyrins. Synthesis, characterization, SOD-like activity, and SOD-deficient E. coli study of meta $\mathrm{Mn}$ (III) N-methoxyalkylpyridylporphyrins. Dalton Trans 2011;40:41114121.

75 Batinic-Haberle I, Spasojevic I, Stevens RD, Hambright P, Neta P, Okado-Matsumoto A, Fridovich I: New class of potent catalysts of $\mathrm{O}_{2}$ dismutation. $\mathrm{Mn}$ (III) ortho-methoxyethylpyridyl- and di-ortho-methoxyethylimidazolylporphyrins. Dalton Trans 2004;11: 1696-1702.

76 Reboucas JS, Spasojevic I, Batinic-Haberle I: Pure manganese(III) 5,10,15,20-tetrakis(4benzoic acid)porphyrin (MnTBAP) is not a superoxide dismutase mimic in aqueous systems: a case of structure-activity relationship as a watchdog mechanism in experimental therapeutics and biology. J Biol Inorg Chem 2008;13:289-302.

-77 Ferrer-Sueta G, Vitturi D, Batinic-Haberle I, Fridovich I, Goldstein S, Czapski G, Radi R: Reactions of manganese porphyrins with peroxynitrite and carbonate radical anion. J Biol Chem 2003;278:27432-27438.

78 Batinic-Haberle I, Spasojevic I, Stevens RD, Bondurant B, Okado-Matsumoto A, Fridovich I, Vujaskovic Z, Dewhirst MW: New PEG-ylated Mn(III) porphyrins approaching catalytic activity of SOD enzyme. Dalton Trans 2006;4:617-624.

79 Carlioz A, Touati D: Isolation of superoxide dismutase mutants in Escherichia coli: is superoxide dismutase necessary for aerobic life? EMBO J 1986;5:623-630 
80 Fridovich I: Fundamental aspects of reactive oxygen species, or what's the matter with oxygen? Ann NY Acad Sci 1999;893:13-18.

-81 Okado-Matsumoto A, Batinic-Haberle I, Fridovich I: Complementation of SOD-deficient Escherichia coli by manganese porphyrin mimics of superoxide dismutase activity. Free Radic Biol Med 2004;37:401-410.

\$82 Moeller BJ, Batinic-Haberle I, Spasojevic I, Rabbani ZN, Anscher MS, Vujaskovic Z, Dewhirst MW: A manganese porphyrin superoxide dismutase mimetic enhances tumor radioresponsiveness. Int $J$ Radiat Oncol Biol Phys 2005;63:545-552.

83 Gralla EB, Valentine JS: Null mutants of Saccharomyces cerevisiae $\mathrm{Cu}, \mathrm{Zn}$ superoxide dismutase: characterization and spontaneous mutation rates. J Bacteriol 1991;173:59185920.

84 Spasojevic I, Miryala S, Tovmasyan A, Salvemini D, Vujaskovic Z, Batinic-Haberle I, St. Clair D: Lipophilicity of Mn(III) N-alkylpyridylporphyrins dominates their accumulation within mitochondria and therefore in vivo efficacy. A mouse study. Free Radic Biol Med 2011;51:S98.

- 85 Sheng H, Spasojevic I, Tse HM, Jung JY, Hong J, Zhang Z, Piganelli JD, BatinicHaberle I, Warner DS: Neuroprotective efficacy from a lipophilic redox-modulating Mn(III) N-hexylpyridylporphyrin, MnTnHex-2-PyP: rodent models of ischemic stroke and subarachnoid hemorrhage. J Pharmacol Exp Ther 2011;338:906-916.

86 Weitner T, Kos I, Sheng H, Tovmasyan A, Fan P, Salvemini D, Warner DS, Vujaskovic Z, Batinic-Haberle I, Spasojevic I: Comprehensive pharmacokinetic studies of hydrophilic MnTE-2-PyP ${ }^{5+}$ vs lipophilic MnTnHex-2$\mathrm{PyP}^{5+}$ biocatalysts: oral vs intraperitoneal availability. Free Radic Biol Med, in revision.

87 Crow JP: Catalytic antioxidants to treat amyotropic lateral sclerosis. Expert Opin Investig Drugs 2006;15:1383-1393.

88 Shimanovich R, Groves JT: Mechanisms of peroxynitrite decomposition catalyzed by FeTMPS, a bioactive sulfonated iron porphyrin. Arch Biochem Biophys 2001;387:307-317.

89 Drel VR, Pacher P, Vareniuk I, Pavlov IA, Ilnytska O, Lyzogubov VV, Bell SR, Groves JT, Obrosova IG: Evaluation of the peroxynitrite decomposition catalyst $\mathrm{Fe}(\mathrm{III})$ tetra-mesitylporphyrin octasulfonate on peripheral neuropathy in a mouse model of type 1 diabetes. Int J Mol Med 2007;20:783-792.

-90 Liang LP, Huang J, Fulton R, Day BJ, Patel M: An orally active catalytic metalloporphyrin protects against 1-methyl-4-phenyl-1,2,3,6tetrahydropyridine neurotoxicity in vivo. J Neurosci 2007;27:4326-4333.

-91 Spasojevic I, Batinic-Haberle I, Fridovich I: Nitrosylation of manganese(II) tetrakis(Nethylpyridinium-2-yl)porphyrin: a simple and sensitive spectrophotometric assay for nitric oxide. Nitric Oxide 2000;4:526-533.
$\$ 2$ Carnieri N, Harriman A, Porter G: Photochemistry of manganese porphyrins. 6 . Oxidation-reduction equilibria of manganese(III) porphyrins in aqueous solution. J Chem Soc Dalton Trans 1982:931-938.

$\checkmark 93$ Hicks SD, Petersen JL, Bougher CJ, AbuOmar MM: Chlorite dismutation to chlorine dioxide catalyzed by a water-soluble manganese porphyrin. Angew Chem Int Ed Engl 2011;50:699-702.

\$4 Umile TP, Wang D, Groves JT: Dissection of the mechanism of manganese porphyrincatalyzed chlorine dioxide generation. Inorg Chem 2011;50:10353-10362.

95 Hidalgo C, Donoso P: Crosstalk between calcium and redox signaling: from molecular mechanisms to health implications. Antioxid Redox Signal 2008;10:12751312.

96 Rubbo H, Radi R: Protein and lipid nitration: role in redox signaling and injury. Biochim Biophys Acta 2008;1780:1318-1324.

-97 Fernandes AS, Gaspar J, Cabral MF, Rueff J, Castro M, Batinic-Haberle I, Costa J, Oliveira NG: Protective role of ortho-substituted Mn(III) N-alkylpyridylporphyrins against the oxidative injury induced by tertbutylhydroperoxide. Free Radic Res 2010; 44:430-440.

$\$ 98$ Araujo-Chaves JC, Yokomizo CH, Kawai C, Mugnol KC, Prieto T, Nascimento OR, Nantes IL: Towards the mechanisms involved in the antioxidant action of MnIII [meso-tetrakis(4-N-methyl pyridinium) porphyrin] in mitochondria. J Bioenerg Biomembr 2011;43:663-671.

-99 Batinic-Haberle I, Benov LT: An SOD mimic protects NADP+-dependent isocitrate dehydrogenase against oxidative inactivation. Free Radic Res 2008;42:618-624.

100 Jin G, Reitman ZJ, Spasojevic I, BatinicHaberle I, Yang J, Schmidt-Kittler O, Bigner $\mathrm{DD}$, Yan H: 2-Hydroxyglutarate production, but not dominant negative function, is conferred by glioma-derived NADP-dependent isocitrate dehydrogenase mutations. PLoS One 2011;6:e16812.

101 Bottino R, Balamurugan AN, Tse H, Thirunavukkarasu C, Ge X, Profozich J, Milton M, Ziegenfuss A, Trucco M, Piganelli JD: Response of human islets to isolation stress and the effect of antioxidant treatment. Diabetes 2004;53:2559-2568.

102 Moeller BJ, Cao Y, Li CY, Dewhirst MW: Radiation activates HIF-1 to regulate vascular radiosensitivity in tumors: role of reoxygenation, free radicals, and stress granules. Cancer Cell 2004;5:429-441.

103 Rabbani ZN, Spasojevic I, Zhang X, Moeller BJ, Haberle S, Vasquez-Vivar J, Dewhirst MW, Vujaskovic Z, Batinic-Haberle I: Antiangiogenic action of redox-modulating $\mathrm{Mn}(\mathrm{III})$ meso-tetrakis(N-ethylpyridinium2-yl)porphyrin, MnTE-2-PyP(5+), via suppression of oxidative stress in a mouse model of breast tumor. Free Radic Biol Med 2009;47:992-1004.
04 Tse HM, Milton MJ, Piganelli JD: Mechanistic analysis of the immunomodulatory effects of a catalytic antioxidant on antigenpresenting cells: implication for their use in targeting oxidation-reduction reactions in innate immunity. Free Radic Biol Med 2004;36:233-247.

105 Zhao Y, Chaiswing L, Oberley TD, BatinicHaberle I, St Clair W, Epstein CJ, St Clair D: A mechanism-based antioxidant approach for the reduction of skin carcinogenesis. Cancer Res 2005;65:1401-1405.

106 Sheng H, Yang W, Fukuda S, Tse HM, Paschen W, Johnson K, Batinic-Haberle I, Crapo JD, Pearlstein RD, Piganelli J, Warner DS: Long-term neuroprotection from a potent redox-modulating metalloporphyrin in the rat. Free Radic Biol Med 2009;47: 917-923.

107 Jaramillo MC, Briehl MM, Crapo J, BatinicHaberle I, Tome ME: Manganese porphyrin, MnTE-2-PyP5 +, acts as a pro-oxidant to potentiate glucocorticoid-induced apoptosis in lymphoma cell. Free Radic Biol Med 2012;52:1272-1284.

108 Goodman M, Bostick RM, Kucuk O, Jones DP: Clinical trials of antioxidants as cancer prevention agents: past, present, and future. Free Radic Biol Med 2011;51:1068-1084.

109 Reboucas JS, Spasojevic I, Batinic-Haberle I: Quality of potent Mn porphyrin-based SOD mimics and peroxynitrite scavengers for pre-clinical mechanistic/therapeutic purposes. J Pharm Biomed Anal 2008;48: 1046-1049.

110 Pollard JM, Reboucas JS, Durazo A, Kos I, Fike F, Panni M, Gralla EB, Valentine JS, Batinic-Haberle I, Gatti RA: Radioprotective effects of manganese-containing superoxide dismutase mimics on ataxia-telangiectasia cells. Free Radic Biol Med 2009; 47:250-260.

111 Reboucas JS, Kos I, Vujaskovic Z, BatinicHaberle I: Determination of residual manganese in Mn porphyrin-based superoxide dismutase (SOD) and peroxynitrite reductase mimics. J Pharm Biomed Anal 2009; 50:1088-1091.

112 Li Y, Wende AR, Nunthakungwan O, Huang Y, Hu E, Jin H, Boudina S, Abel ED, Jalili T: Cytosolic, but not mitochondrial, oxidative stress is a likely contributor to cardiac hypertrophy resulting from cardiac specific GLUT4 deletion in mice. FEBS J 2012;279:599-611.

113 Rosenthal RA, Huffman KD, Fisette LW, Damphousse CA, Callaway WB, Malfroy B, Doctrow SR: Orally available Mn porphyrins with superoxide dismutase and catalase activities. J Biol Inorg Chem 2009;14: 979-991.

114 Ferrer-Sueta G, Batinic-Haberle I, Spasojevic I, Fridovich I, Radi R: Catalytic scavenging of peroxynitrite by isomeric Mn(III) $\mathrm{N}$-methylpyridylporphyrins in the presence of reductants. Chem Res Toxicol 1999; $12: 442-449$. 
115 Lee J, Hunt JA, Groves JT: Mechanisms of iron porphyrin reactions with peroxynitrite. J Am Chem Soc 1998;120:7493-7501.

- 116 Szabo C, Mabley JG, Moeller SM, Shimanovich R, Pacher P, Virag L, Soriano FG, Van Duzer JH, Williams W, Salzman AL, Groves JT: I. Pathogenetic role of peroxynitrite in the development of diabetes and diabetic vascular complications: studies with FP15, a novel potent peroxynitrite decomposition catalyst. Mol Med 2002;8:571-580.

- 117 Muscoli C, Cuzzocrea S, Ndengele MM, Mollace V, Porreca F, Fabrizi F, Esposito E, Masini E, Matuschak GM, Salvemini D: Therapeutic manipulation of peroxynitrite attenuates the development of opiate-induced antinociceptive tolerance in mice. J Clin Invest 2007;117:3530-3539.

- 118 Suofu Y, Clark J, Broderick J, Wagner KR, Tomsick T, Sa Y, Lu A: Peroxynitrite decomposition catalyst prevents matrix metalloproteinase activation and neurovascular injury after prolonged cerebral ischemia in rats. J Neurochem 2010;115:1266-1276.

-119 Thiyagarajan M, Kaul CL, Sharma SS: Neuroprotective efficacy and therapeutic time window of peroxynitrite decomposition catalysts in focal cerebral ischemia in rats. Br J Pharmacol 2004;142:899-911.

120 Tal M: A novel antioxidant alleviates heat hyperalgesia in rats with an experimental painful peripheral neuropathy. Neuroreport 1996;7:1382-1384.

- 121 Kim BS, Cha HN, Kim YW, Kim JY, Dan JM, Park SY: Inhibition of lipid infusion-induced skeletal muscle insulin resistance by cotreatment with tempol and glutathione in mice. J Pharmacol Sci 2009;110:370-380.

-122 Goldstein S, Merenyi G, Russo A, Samuni A: The role of oxoammonium cation in the SOD-mimic activity of cyclic nitroxides. J Am Chem Soc 2003;125:789-795.

-123 Goldstein S, Samuni A, Hideg K, Merenyi G: Structure-activity relationship of cyclic nitroxides as SOD mimics and scavengers of nitrogen dioxide and carbonate radicals. J Phys Chem A 2006;110:3679-3685.

124 Goldstein S, Samuni A, Merenyi G: Reactions of nitric oxide, peroxynitrite, and carbonate radicals with nitroxides and their corresponding oxoammonium cations. Chem Res Toxicol 2004;17:250-257.

125 Goldstein S, Samuni A, Merenyi G: Kinetics of the reaction between nitroxide and thiyl radicals: nitroxides as antioxidants in the presence of thiols. J Phys Chem A 2008; 112:8600-8605.

126 Cao Y: Antiangiogenic cancer therapy: why do mouse and human patients respond in a different way to the same drug? Int J Dev Biol 2011;55:557-562.

127 Batinic-Haberle I, Keir ST, Rajic Z, Tovmasyan A, Bigner DD: Lipophilic Mn porphyrins in the treatment of brain tumors.: Free Radic Biol Med 2011;51:S119.
128 Batinic-Haberle I, Keir ST, Rajic Z, Tovmasyan A, Spasojevic I, Dewhirst MW, Bigner DD: Glioma growth suppression via modulation of cellular redox status by a lipophilic Mn porphyrin. Mid-Winter SPORE Meet, San Francisco, 2011, pp 31-32.

129 Jackson IL, Gaunter-Fleckenstein BM, Batinic-Haberle I, Poulton S, Zhao Y, Dewhirst MW, Vujaskovic Z: Hyperthermia enhances the anti-angiogenic effect of metalloporphyrin mimetic of superoxide dismutase. 24th Annu Meet Eur Soc Hyperthermic Oncol, Prague, 2007.

130 Jaramillo MC, Frye JB, Crapo JD, Briehl MM, Tome ME: Increased manganese superoxide dismutase expression or treatment with manganese porphyrin potentiates dexamethasone-induced apoptosis in lymphoma cells. Cancer Res 2009;69:5450-5457.

131 Ho Y, Tovmasyan A, Batinic-Haberle I, Lam PYP: The combination of a new SOD mimic with apoptotic gene and gap junction inhibitor confers potency in the treatment of brain tumors. ISCGT Annual Meeting, Singapore, 4-6 October, 2012.

132 Makinde AY, Luo-Owen X, Rizvi A, Crapo JD, Pearlstein RD, Slater JM, Gridley DS: Effect of a metalloporphyrin antioxidant (MnTE-2-PyP) on the response of a mouse prostate cancer model to radiation. Anticancer Res 2009;29:107-118.

133 Makinde AY, Rizvi A, Crapo JD, Pearlstein RD, Slater JM, Gridley DS: A metalloporphyrin antioxidant alters cytokine responses after irradiation in a prostate tumor model. Radiat Res 2010;173:441-452.

134 Lascola C, Batinic-Haberle I, Venkataraman S, Amrhein TJ, Mouraviev V, Wang H: Mn-porphyrins SOD mimetics as novel MR imaging probes. 6th Int Conf Porphyrins Phthalocyanines, New Mexico, 2010, p 156.

135 Gridley DS, Makinde AY, Luo X, Rizvi A, Crapo JD, Dewhirst MW, Moeller BJ, Pearlstein RD, Slater JM: Radiation and a metalloporphyrin radioprotectant in a mouse prostate tumor model. Anticancer Res 2007;27:3101-3109.

136 Mao XW, Crapo JD, Mekonnen T, Lindsey N, Martinez P, Gridley DS, Slater JM: Radioprotective effect of a metalloporphyrin compound in rat eye model. Curr Eye Res 2009;34:62-72.

-137 Pearlstein RD, Higuchi Y, Moldovan M, Johnson K, Fukuda S, Gridley DS, Crapo JD, Warner DS, Slater JM: Metalloporphyrin antioxidants ameliorate normal tissue radiation damage in rat brain. Int J Radiat Biol 2010;86:145-163.

138 Rabbani ZN, Batinic-Haberle I, Anscher MS, Huang J, Day BJ, Alexander E, Dewhirst MW, Vujaskovic Z: Long-term administration of a small molecular weight catalytic metalloporphyrin antioxidant, AEOL 10150, protects lungs from radiation-induced injury. Int J Radiat Oncol Biol Phys 2007;67:573-580.
139 Mehrotra S, Pecaut MJ, Freeman TL, Crapo JD, Rizvi A, Luo-Owen X, Slater JM, Gridley DS: Analysis of a metalloporphyrin antioxidant mimetic (MnTE-2-PyP) as a radiomitigator: prostate tumor and immune status. Technol Cancer Res Treat DOI: 10.7785/tcrt.2012.500260.

140 Zhao Y, Xue Y, Oberley TD, Kiningham KK, Lin SM, Yen HC, Majima H, Hines J, St Clair D: Overexpression of manganese superoxide dismutase suppresses tumor formation by modulation of activator protein-1 signaling in a multistage skin carcinogenesis model. Cancer Res 2001;61: 6082-6088.

141 Bakthavatchalu V, Dey S, Xu Y, Noel T, Jungsuwadee P, Holley AK, Dhar SK, Batinic-Haberle I, St Clair DK: Manganese superoxide dismutase is a mitochondrial fidelity protein that protects polgamma against UV-induced inactivation. Oncogene 2012;31:2129-2139.

142 Dewhirst MW, Cao Y, Moeller B: Cycling hypoxia and free radicals regulate angiogenesis and radiotherapy response. Nat Rev Cancer 2008;8:425-437.

143 Chen Q, Espey MG, Sun AY, Lee JH, Krishna MC, Shacter E, Choyke PL, Pooput C, Kirk KL, Buettner GR, Levine M: Ascorbate in pharmacologic concentrations selectively generates ascorbate radical and hydrogen peroxide in extracellular fluid in vivo. Proc Natl Acad Sci USA 2007;104:8749-8754.

144 Chen Q, Espey MG, Sun AY, Pooput C, Kirk KL, Krishna MC, Khosh DB, Drisko J, Levine M: Pharmacologic doses of ascorbate act as a prooxidant and decrease growth of aggressive tumor xenografts in mice. Proc Natl Acad Sci USA 2008; 105 : 11105-11109.

145 Levine M, Espey MG, Chen Q: Losing and finding a way at $\mathrm{C}$ : new promise for pharmacologic ascorbate in cancer treatment. Free Radic Biol Med 2009;47:27-29.

146 Padayatty SJ, Levine M: Reevaluation of ascorbate in cancer treatment: emerging evidence, open minds and serendipity. J Am Coll Nutr 2000;19:423-425.

147 Tareen B, Summers JL, Jamison JM, Neal DR, McGuire K, Gerson L, Diokno A: A 12 week, open label, phase I/IIa study using apatone for the treatment of prostate cancer patients who have failed standard therapy. Int J Med Sci 2008;5:62-67.

148 Batinic-Haberle I, Rajic Z, Benov L: A combination of two antioxidants (an SOD mimic and ascorbate) produces a pro-oxidative effect forcing Escherichia coli to adapt via induction of oxyR regulon. Anticancer Agents Med Chem 2011;11:329-340.

149 Mouraviev V, Venkatraman T, Tovmasyan A, Kimura M, Tsivian M, Mouravieva V, Polascik T, Wang H, Amrhein TJ, BatinicHaberle I, Lascola C: Mn porphryins as novel molecular MRI contrast agents. J Endourol DOI:10.1089/end.2012.0171. 
150 Archambeau JO: Manganese(III)-porphyrin superoxide dismutase mimic ameliorates acute proctitis and late radiation toxicity following focal irradiation of the rat rectum. Submitted.

151 Vujaskovic Z, Batinic-Haberle I, Rabbani ZN, Feng QF, Kang SK, Spasojevic I, Samulski TV, Fridovich I, Dewhirst MW, Anscher MS: A small molecular weight catalytic metalloporphyrin antioxidant with superoxide dismutase (SOD) mimetic properties protects lungs from radiation-induced injury. Free Radic Biol Med 2002;33:857-863.

152 Gauter-Fleckenstein B, Fleckenstein K, Owzar K, Jiang C, Reboucas JS, Batinic-Haberle I, Vujaskovic Z: Early and late administration of MnTE-2-PyP5+ in mitigation and treatment of radiation-induced lung damage. Free Radic Biol Med 2010;48:1034-1043.

153 Cline M, Dugan G, Perry D, Batinic-Haberle I, Vujaskovic Z: MnTnHex-2-PyP ${ }^{5+}$ provides protection in nonhuman primate lungs after whole-thorax exposure to ionizing irradiation. 56th Radiat Res Soc Meet, Hawaii, 2010, p 54.

154 Yakovlev VA, Rabender CS, Sankala H, Gauter-Fleckenstein B, Fleckenstein K, Batinic-Haberle I, Jackson I, Vujaskovic Z, Anscher MS, Mikkelsen RB, Graves PR: Proteomic analysis of radiation-induced changes in rat lung: modulation by the superoxide dismutase mimetic MnTE-2PyP(5+). Int J Radiat Oncol Biol Phys 2010; 78:547-554.

155 Lee JH, Lee YM, Park JW: Regulation of ionizing radiation-induced apoptosis by a manganese porphyrin complex. Biochem Biophys Res Commun 2005;334:298-305.

-156 Lee JH, Park JW: A manganese porphyrin complex is a novel radiation protector. Free Radic Biol Med 2004;37:272-283.

157 Li H, Wang Y, Pazhanisamy SK, Shao L, Batinic-Haberle I, Meng A, Zhou D: Mn(III) meso-tetrakis-(N-ethylpyridinium-2-yl) porphyrin mitigates total body irradiationinduced long-term bone marrow suppression. Free Radic Biol Med 2011;51:30-37.

158 Pazhanisamy SK, Li H, Wang Y, BatinicHaberle I, Zhou D: NADPH oxidase inhibition attenuates total body irradiation-induced haematopoietic genomic instability. Mutagenesis 2011;26:431-435.

159 Mackensen GB, Patel M, Sheng H, Calvi CL, Batinic-Haberle I, Day BJ, Liang LP, Fridovich I, Crapo JD, Pearlstein RD, Warner DS: Neuroprotection from delayed postischemic administration of a metalloporphyrin catalytic antioxidant. J Neurosci 2001;21:4582-4592.

160 Sheng H, Enghild JJ, Bowler R, Patel M, Batinic-Haberle I, Calvi CL, Day BJ, Pearlstein RD, Crapo JD, Warner DS: Effects of metalloporphyrin catalytic antioxidants in experimental brain ischemia. Free Radic Biol Med 2002;33:947-961.
161 Drobyshevsky A, Luo K, Derrick M, Yu L, Du H, Prasad PV, Vasquez-Vivar J, BatinicHaberle I, Tan S: Motor deficits are triggered by reperfusion-reoxygenation injury as diagnosed by MRI and by a mechanism involving oxidants. J Neurosci 2012;32: 5500-5509.

162 Bains M, Hall ED: Antioxidant therapies in traumatic brain and spinal cord injury. Biochim Biophys Acta 2012;1822:675-684.

163 Kubota K, Saiwai H, Kumamaru H, Maeda T, Ohkawa Y, Aratani Y, Nagano T, Iwamoto Y, Okada S: Myeloperoxidase exacerbates secondary injury by generating highly reactive oxygen species and mediating neutrophil recruitment in experimental spinal cord injury. Spine (Phila Pa 1976) 2012;37: 1363-1369.

164 Jia Z, Zhu H, Li J, Wang X, Misra H, Li Y: Oxidative stress in spinal cord injury and antioxidant-based intervention. Spinal Cord 2012;50:264-274.

165 Sheng H, Spasojevic I, Warner DS, BatinicHaberle I: Mouse spinal cord compression injury is ameliorated by intrathecal cationic manganese(III) porphyrin catalytic antioxidant therapy. Neurosci Lett 2004;366: 220-225.

166 Genovese T, Mazzon E, Esposito E, Di Paola R, Murthy K, Neville L, Bramanti P, Cuzzocrea S: Effects of a metalloporphyrinic peroxynitrite decomposition catalyst, WW-85, in a mouse model of spinal cord injury. Free Radic Res 2009;43:631-645.

167 Genovese T, Mazzon E, Esposito E, Muia C, Di Paola R, Bramanti P, Cuzzocrea S: Beneficial effects of FeTSPP, a peroxynitrite decomposition catalyst, in a mouse model of spinal cord injury. Free Radic Biol Med 2007;43:763-780.

168 Hachmeister JE, Valluru L, Bao F, Liu D: $\mathrm{Mn}$ (III) tetrakis(4-benzoic acid) porphyrin administered into the intrathecal space reduces oxidative damage and neuron death after spinal cord injury: a comparison with methylprednisolone. J Neurotrauma 2006; 23:1766-1778.

169 Ling X, Liu D: Temporal and spatial profiles of cell loss after spinal cord injury: reduction by a metalloporphyrin. J Neurosci Res 2007;85:2175-2185

170 Yu D, Neeley WL, Pritchard CD, Slotkin JR, Woodard EJ, Langer R, Teng YD: Blockade of peroxynitrite-induced neural stem cell death in the acutely injured spinal cord by drug-releasing polymer. Stem Cells 2009; 27:1212-1222.

171 Doyle T, Bryant L, Batinic-Haberle I, Little J, Cuzzocrea S, Masini E, Spasojevic I, Salvemini D: Supraspinal inactivation of mitochondrial superoxide dismutase is a source of peroxynitrite in the development of morphine antinociceptive tolerance. Neuroscience 2009;164:702-710.
172 Batinic-Haberle I, Ndengele MM, Cuzzocrea S, Reboucas JS, Spasojevic I, Salvemini D: Lipophilicity is a critical parameter that dominates the efficacy of metalloporphyrins in blocking the development of morphine antinociceptive tolerance through peroxynitrite-mediated pathways. Free Radic Biol Med 2009;46:212-219.

173 Jaggi AS, Singh N: Mechanisms in cancerchemotherapeutic drugs-induced peripheral neuropathy. Toxicology 2012;291:1-9.

174 Patti GJ, Yanes O, Shriver LP, Courade JP, Tautenhahn R, Manchester M, Siuzdak G: Metabolomics implicates altered sphingolipids in chronic pain of neuropathic origin. Nat Chem Biol 2012;8:232-234.

175 Corda S, Laplace C, Vicaut E, Duranteau J: Rapid reactive oxygen species production by mitochondria in endothelial cells exposed to tumor necrosis factor-alpha is mediated by ceramide. Am J Respir Cell Mol Biol 2001;24:762-768.

176 Masini E, Giannini L, Nistri S, Cinci L, Mastroianni R, Xu W, Comhair SA, Li D, Cuzzocrea S, Matuschak GM, Salvemini D: Ceramide: a key signaling molecule in a Guinea pig model of allergic asthmatic response and airway inflammation. J Pharmacol Exp Ther 2008;324:548-557.

177 Kim HY, Wang JG, Lu Y, Chung JM, Chung $\mathrm{K}$ : Superoxide signaling in pain is independent of nitric oxide signaling. Neuroreport 2009;20:1424-1428.

178 Wu AS, Kiaei M, Aguirre N, Crow JP, Calingasan NY, Browne SE, Beal MF: Iron porphyrin treatment extends survival in a transgenic animal model of amyotrophic lateral sclerosis. J Neurochem 2003;85:142150.

179 Crow JP: Administration of Mn porphyrin and Mn texaphyrin at symptom onset extends survival of ALS mice; in Doctrow SR, McMurry TJ, Sessler SJ (eds): Medicinal Inorganic Chemistry. Washington, American Chemical Society, 2005.

180 Golden TR, Patel M: Catalytic antioxidants and neurodegeneration. Antioxid Redox Signal 2009; 11:555-570.

181 Liang LP, Waldbaum S, Rowley S, Huang TT, Day BJ, Patel M: Mitochondrial oxidative stress and epilepsy in SOD2 deficient mice: attenuation by a lipophilic metalloporphyrin. Neurobiol Dis 2012;45:1068-1076.

182 Sompol P, Ittarat W, Tangpong J, Chen Y, Doubinskaia I, Batinic-Haberle I, Abdul HM, Butterfield DA, St Clair DK: A neuronal model of Alzheimer's disease: an insight into the mechanisms of oxidative stressmediated mitochondrial injury. Neuroscience $2008 ; 153: 120-130$.

183 Wise-Faberowski L, Warner DS, Spasojevic I, Batinic-Haberle I: Effect of lipophilicity of $\mathrm{Mn}$ (III) ortho N-alkylpyridyl- and diortho $\mathrm{N}, \mathrm{N}^{\prime}$-diethylimidazolylporphyrins in two in-vitro models of oxygen and glucose deprivation-induced neuronal death. Free Radic Res 2009;43:329-339. 
184 Piganelli JD, Flores SC, Cruz C, Koepp J, Batinic-Haberle I, Crapo J, Day B, Kachadourian R, Young R, Bradley B, Haskins K: A metalloporphyrin-based superoxide dismutase mimic inhibits adoptive transfer of autoimmune diabetes by a diabetogenic T-cell clone. Diabetes 2002; 51:347-355.

- 185 Bottino R, Balamurugan AN, Bertera S, Pietropaolo M, Trucco M, Piganelli JD: Preservation of human islet cell functional mass by anti-oxidative action of a novel SOD mimic compound. Diabetes 2002;51: 2561-2567.

186 Benov L, Batinic-Haberle I: A manganese porphyrin suppresses oxidative stress and extends the life span of streptozotocin-diabetic rats. Free Radic Res 2005;39:81-88.

187 Ross AD, Sheng H, Warner DS, Piantadosi CA, Batinic-Haberle I, Day BJ, Crapo JD: Hemodynamic effects of metalloporphyrin catalytic antioxidants: structure-activity relationships and species specificity. Free Radic Biol Med 2002;33:1657-1669.

188 Kasugai N, Murase T, Ohse T, Nagaoka S, Kawakami H, Kubota S: Selective cell death by water-soluble Fe-porphyrins with superoxide dismutase (SOD) activity. J Inorg Biochem 2002;91:349-355.

189 Jiao XY, Gao E, Yuan Y, Wang Y, Lau WB, Koch W, Ma XL, Tao L: INO-4885 $\left[5,10,15,20\right.$-tetra[N-(benzyl-4' ${ }^{\prime}$-carboxylate)-2-pyridinium]-21H,23H-porphine iron(III) chloride], a peroxynitrite decomposition catalyst, protects the heart against reperfusion injury in mice. J Pharmacol Exp Ther 2009;328:777-784.

190 Spasojevic I, Batinic-Haberle I, Stevens RD, Hambright P, Thorpe AN, Grodkowski J, Neta P, Fridovich I: Manganese(III) biliverdin IX dimethyl ester: a powerful catalytic scavenger of superoxide employing the $\mathrm{Mn}(\mathrm{III}) / \mathrm{Mn}(\mathrm{IV})$ redox couple. Inorg Chem 2001;40:726-739.

-191 Kunchandy E, Rao MNA: Oxygen radical scavenging activity of curcumin. Int J Pharm 1990;58:237-240.

192 Dikalov S, Losik T, Arbiser JL: Honokiol is a potent scavenger of superoxide and peroxyl radicals. Biochem Pharmacol 2008;76: 589-596.
193 Batinic-Haberle I, Reboucas JS, Spasojevic I: Response to Rosenthal et al. Antioxid Redox Signal 2011;14:1174-1176.

194 Engelmann FM, Rocha SV, Toma HE, Araki K, Baptista MS: Determination of n-octanol/water partition and membrane binding of cationic porphyrins. Int J Pharm 2007;329:12-18.

195 Jackson IL, Batinic-Haberle I, Sonveaux P, Dewhirst MW, Vujaskovic Z: ROS production and angiogenic regulation by macrophages in response to heat therapy. Int $\mathrm{J} \mathrm{Hy-}$ perthermia 2006;22:263-273.

196 Daroczi B, Kari G, Zengin AY, Chinnaiyan P, Batinic-Haberle I, Rodeck U, Dicker AP: Radioprotective effects of two superoxide dismutase (SOD) mimetics and the nanoparticle DF-1 in a vertebrate zebrafish model. 48th ASTRO, Annual Meeting of the American Society for Radiation Oncology, 2006.

197 Crow JP, Calingasan NY, Chen J, Hill JL, Beal MF: Manganese porphyrin given at symptom onset markedly extends survival of ALS mice. Ann Neurol 2005;58:258-265.

198 Tauskela JS, Brunette E: Neuroprotection against staurosporine by metalloporphyrins independent of antioxidant capability. Neurosci Lett 2009;466:41-46.

199 Radovits T, Seres L, Gero D, Lin LN, Beller CJ, Chen SH, Zotkina J, Berger I, Groves JT, Szabo C, Szabo G: The peroxynitrite decomposition catalyst FP15 improves ageing-associated cardiac and vascular dysfunction. Mech Ageing Dev 2007;128:173181.

200 Rosenthal RA, Fish B, Hill RP, Huffman KD, Lazarova Z, Mahmood J, Medhora M, Molthen R, Moulder JE, Sonis ST, Tofilon PJ, Doctrow SR: Salen Mn complexes mitigate radiation injury in normal tissues. Anticancer Agents Med Chem 2011;11:359372.

201 Arambula JF, Sessler JL, Siddik ZH: Overcoming biochemical pharmacologic mechanisms of platinum resistance with a texaphyrin-platinum conjugate. Bioorg Med Chem Lett 2011;21:1701-1705.
202 Aston K, Rath N, Naik A, Slomczynska U, Schall OF, Riley DP: Computer-aided design (CAD) of $\mathrm{Mn}$ (II) complexes: superoxide dismutase mimetics with catalytic activity exceeding the native enzyme. Inorg Chem 2001;40:1779-1789.

203 Aykin-Burns N, Ahmad IM, Zhu Y, Oberley LW, Spitz DR: Increased levels of superoxide and $\mathrm{H}_{2} \mathrm{O}_{2}$ mediate the differential susceptibility of cancer cells versus normal cells to glucose deprivation. Biochem J 2009;418:29-37.

204 Devi GS, Prasad MH, Saraswathi I, Raghu D, Rao DN, Reddy PP: Free radicals antioxidant enzymes and lipid peroxidation in different types of leukemias. Clin Chim Acta 2000;293:53-62.

205 Hileman EO, Liu J, Albitar M, Keating MJ, Huang P: Intrinsic oxidative stress in cancer cells: a biochemical basis for therapeutic selectivity. Cancer Chemother Pharmacol 2004;53:209-219.

206 Kondo S, Toyokuni S, Iwasa Y, Tanaka T, Onodera H, Hiai H, Imamura M: Persistent oxidative stress in human colorectal carcinoma, but not in adenoma. Free Radic Biol Med 1999;27:401-410.

207 Pelicano H, Carney D, Huang P: ROS stress in cancer cells and therapeutic implications. Drug Resist Updat 2004;7:97-110.

208 Szatrowski TP, Nathan CF: Production of large amounts of hydrogen peroxide by human tumor cells. Cancer Res 1991;51:794798.

209 Toyokuni S: Oxidative stress and cancer: the role of redox regulation. Biotherapy 1998;11:147-154.

210 Arambula JF, Preihs C, Borthwick D, Magda D, Sessler JL: Texaphyrins: tumor localizing redox active expanded porphyrins. Anticancer Agents Med Chem 2011;11: 222-232.

211 Doyle T, Chen Z, Muscoli C, Bryant L, Esposito E, Cuzzocrea S, Dagostino C, Ryerse J, Rausaria S, Kamadulski A, Neumann WL, Salvemini D: Targeting the overproduction of peroxynitrite for the prevention and reversal of paclitaxel-induced neuropathic pain. J Neurosci 2012;32:6149-6160. 